University of Windsor

Scholarship at UWindsor

\title{
Psychological Skills Used by Sport Psychology Consultants to Improve Their Consulting
}

\author{
Shawn Filion \\ University of Windsor
}

Follow this and additional works at: https://scholar.uwindsor.ca/etd

\section{Recommended Citation}

Filion, Shawn, "Psychological Skills Used by Sport Psychology Consultants to Improve Their Consulting" (2018). Electronic Theses and Dissertations. 7454.

https://scholar.uwindsor.ca/etd/7454

This online database contains the full-text of PhD dissertations and Masters' theses of University of Windsor students from 1954 forward. These documents are made available for personal study and research purposes only, in accordance with the Canadian Copyright Act and the Creative Commons license-CC BY-NC-ND (Attribution, Non-Commercial, No Derivative Works). Under this license, works must always be attributed to the copyright holder (original author), cannot be used for any commercial purposes, and may not be altered. Any other use would require the permission of the copyright holder. Students may inquire about withdrawing their dissertation and/or thesis from this database. For additional inquiries, please contact the repository administrator via email (scholarship@uwindsor.ca) or by telephone at 519-253-3000ext. 3208. 


\title{
PSYCHOLOGICAL SKILLS USED BY SPORT PSYCHOLOGY CONSULTANTS TO IMPROVE THEIR CONSULTING
}

by

Shawn Filion

\begin{abstract}
A Thesis
Submitted to the Faculty of Graduate Studies through the Faculty of Human Kinetics in Partial Fulfillment of the Requirements for the Degree of Master of Human Kinetics at the University of Windsor
\end{abstract}

Windsor, Ontario, Canada

(C) 2018 Shawn Filion 
Psychological Skills Used by Sport Psychology Consultants to Improve Their Consulting by

Shawn Filion

APPROVED BY:

J. Casey
Department of Psychology

T. Loughead

Department of Kinesiology

K. Chandler, Advisor

Department of Kinesiology

April $26^{\text {th }}, 2018$ 


\section{DECLARATION OF ORIGINALITY}

I hereby certify that I am the sole author of this thesis and that no part of this thesis has been published or submitted for publication.

I certify that, to the best of my knowledge, my thesis does not infringe upon anyone's copyright nor violate any proprietary rights and that any ideas, techniques, quotations, or any other material from the work of other people included in my thesis, published or otherwise, are fully acknowledged in accordance with the standard referencing practices. Furthermore, to the extent that I have included copyrighted material that surpasses the bounds of fair dealing within the meaning of the Canada Copyright Act, I certify that I have obtained a written permission from the copyright owner(s) to include such material(s) in my thesis and have included copies of such copyright clearances to my appendix.

I declare that this is a true copy of my thesis, including any final revisions, as approved by my thesis committee and the Graduate Studies office, and that this thesis has not been submitted for a higher degree to any other University or Institution. 


\begin{abstract}
The purpose of this study was to qualitatively examine self-practice by identifying the psychological skills that sport psychology consultants (SPCs) used to improve their consulting as well as where, when, why, and how they used those skills. The participants were eight Canadian-based SPCs ( 3 male, 5 female) that had between 4 and 23 years of consulting experience $(M=10.5, S D=6.74)$. The SPCs reported using deep breathing, goal setting, self-reflection, time management, imagery, mindfulness, self-talk, and bioneurofeedback with themselves. They practiced these psychological skills at different times (e.g., when needed, before a session), in a variety of ways (e.g., spontaneously, deliberately, applying specific techniques), and for various purposes (e.g., refine their service delivery, achieve a work-life balance). As such, SPCs should be encouraged to "practice what they preach", given the range of potential benefits associated with the use of psychological skills (e.g., foster the consultant-client relationship, understand the psychological skill, enhance psychological constructs).
\end{abstract}




\section{ACKNOWLEDGEMENTS}

I would like to take this opportunity to recognize and thank everyone that helped me successfully complete my thesis. Firstly, I would like to thank my advisor, Dr. Krista Chandler, for guiding me through this whole process and sending me edits in a timely fashion. I would also like to extend my gratitude to Dr. Todd Loughead for providing me with constructive feedback and helping me refine my interviewing skills as well as my interview guide. Moreover, I would like to thank Dr. Joseph Casey for having an open mind and asking me thoughtful questions during my proposal and defense. I would also like to give a special thanks to the members of the Sport Psychology and Physical Activity Research Collaborative for sharing their experiences and encouraging me along the way. Finally, I would like to thank my family and friends for giving me the support I needed to achieve my goals. 
TABLE OF CONTENTS

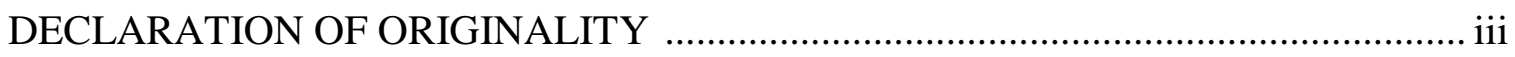

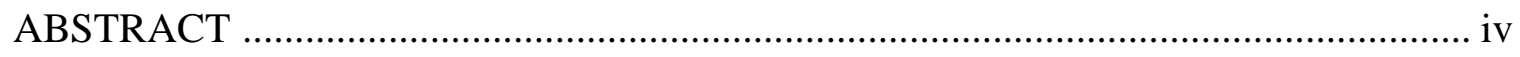

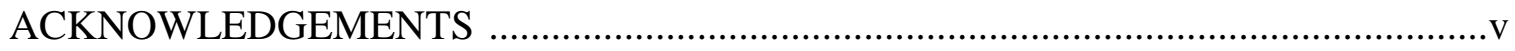

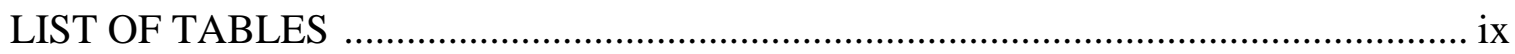

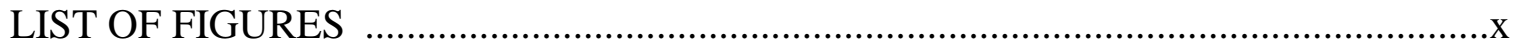

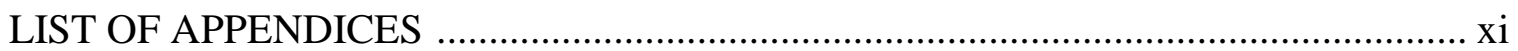

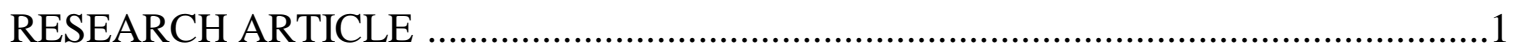

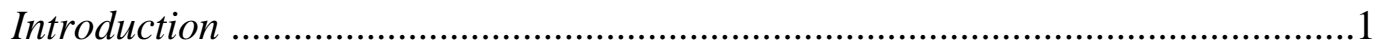

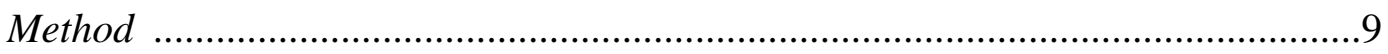

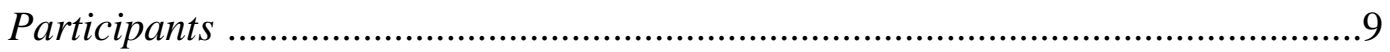

Procedure and Data Collection ..............................................................

Interview Guide ................................................................................

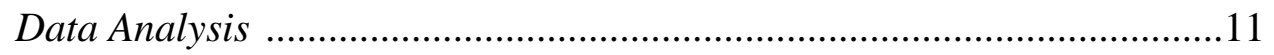

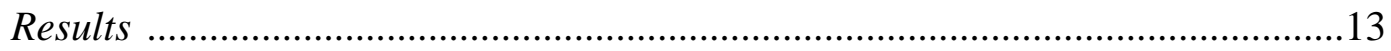

Deep Breathing ……………………………………........................13

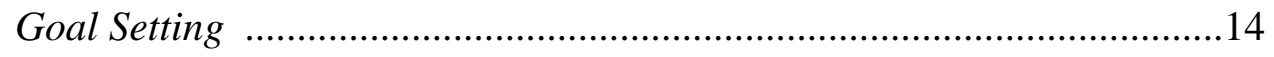

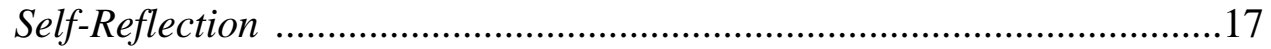

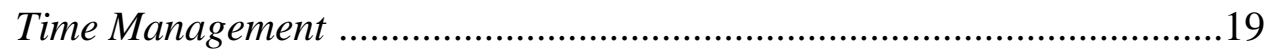

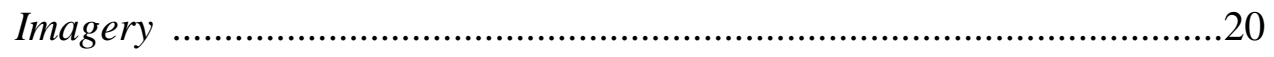

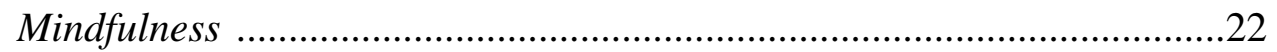

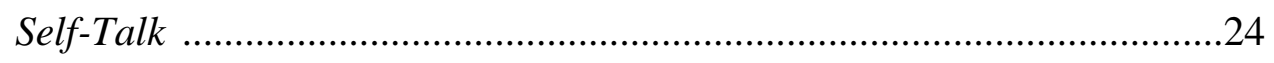

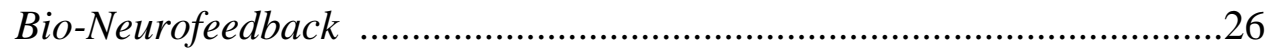


Discussion

References

Table

Figures

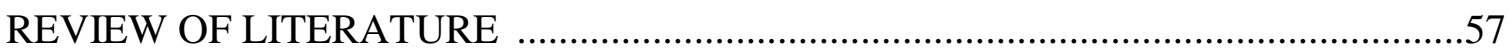

Introduction

Applied Sport Psychology ...........................................................57

Psychological Skills Provided by Sport Psychology Consultants

Arousal regulation

Attentional control

Communication

Goal setting

Imagery

Self-talk

Team building

Time management/organization

Sport Psychology Service Delivery Heuristic

Managing the Self as an Intervention Instrument

Coping tools

Intra- an inter-personal self-management strategies

Psychological Skills Used by Other Performers

Sport

Medicine 


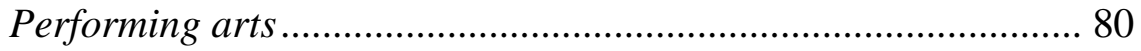

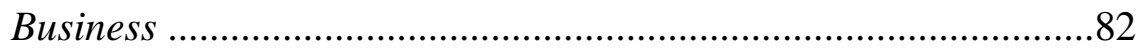

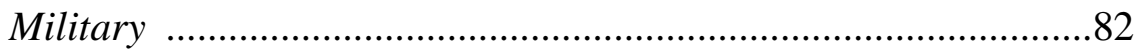

Research with Sport Psychology Consultants .....................................83

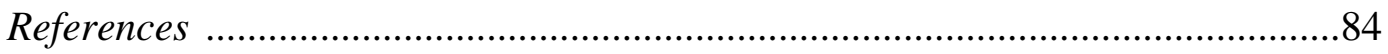

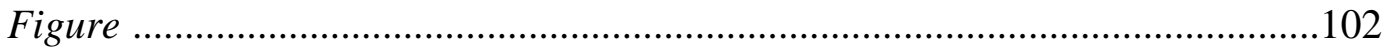

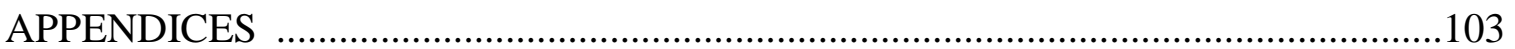

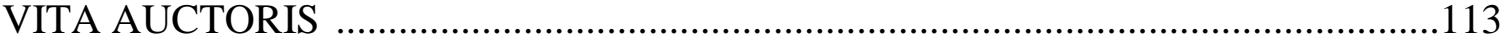




\section{LIST OF TABLES}

TABLE 1 Participant Characteristics and Consulting Details 


\section{LIST OF FIGURES}

Figure 1 Revised Sport Psychology Service Delivery Heuristic ...........................46

Figure 2 Framework of SPCs' Use of Deep Breathing ......................................47

Figure $3 a \quad$ Framework of SPCs' Use of Goal Setting for Business Development ......47

Figure $3 b \quad$ Framework of SPCs' Use of Goal Setting for Professional Development .48

Figure 3c Framework of SPCs' Use of Goal Setting for Client Development .........49

Figure $4 a \quad$ Framework of SPCs' Use of Self-Reflection for Checking-In .................50

Figure $4 b \quad$ Framework of SPCs' Use of Self-Reflection for Debriefing .....................50

Figure $5 \quad$ Framework of SPCs' Use of Time Management ....................................51

Figure $6 a \quad$ Framework of SPCs' Use of Imagery for Individual Consultations ..........51

Figure $6 b \quad$ Framework of SPCs' Use of Imagery for Team Workshops ....................52

Figure 7a Framework of SPCs' Use of Mindful Awareness and Acceptance ...........53

Figure $7 b \quad$ Framework of SPCs' Use of Mindful Intention ....................................53

Figure 7c Framework of SPCs' Use of Mindful Meditation ...................................54

Figure $8 a \quad$ Framework of SPCs' Use of Self-Talk for Focus ...................................55

Figure $8 b \quad$ Framework of SPCs' Use of Self-Talk for Motivation .............................55

Figure $8 c \quad$ Framework of SPCs' Use of Self-Talk for Relaxation …........................56

Figure $9 \quad$ Framework of SPCs' Use of Bio-Neurofeedback .................................56

Figure 10 Revised Sport Psychology Service Delivery Heuristic ..........................102 


\section{LIST OF APPENDICES}

APPENDIX A $\quad$ Email to Participants …............................................................... 103

APPENDIX B $\quad$ Letter of Information and Consent ….......................................104

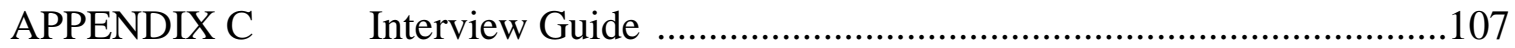




\section{RESEARCH ARTICLE}

\section{Introduction}

Applied sport psychology can be defined as "the application of psychological principles of human performance in helping athletes consistently perform in the upper range of their capabilities and more thoroughly enjoy the sport performance process" (Portenga, Aoyagi, \& Cohen, 2017, p. 52). Often times, these psychological principles are delivered by a sport psychology consultant (SPC), who can either be a licensed psychologist trained in clinical and counseling psychology or a performance enhancement consultant with a background in sport and exercise sciences (AASP, n.d.). Sessions conducted by SPCs either take the form of individual consultations that are short, practical (Giges \& Petitpas, 2000), and occur in a variety of settings (e.g., office, locker room, competition venue; Andersen, 2000; McCann, 2008) or team workshops. The combination of psychological skills taught to athletes, such as self-talk, imagery, goal setting, and relaxation (e.g., Hatzigeorgiadis, Zourbanos, Galanis, \& Theodorakis, 2011; Sheard \& Golby, 2006) is referred to as a psychological skills training program.

Recently, some researchers have argued that a psychological skill should refer to a technique that can be practiced or an indicator of the level of ability, as opposed to a psychological quality (Arthur, Fitzwater, Roberts, Hardy, \& Arthur, 2017). For example, imagery and arousal regulation would be considered psychological skills, while selfconfidence would be considered a psychological quality. The goal of any psychological skills training program is to help athletes systematically and consistently practice psychological skills for enhancing performance, increasing enjoyment, or achieving greater sport and physical activity self-satisfaction (Weinberg \& Gould, 2015). A 
psychological skills training program will often include a combination of the following psychological skills: arousal regulation (e.g., progressive relaxation, meditation, breathing, pep talks, pre-competitive workouts), attentional control (e.g., attention simulation training, performance routines, attentional cues), communication (e.g., assertiveness training, active listening, showing empathy), goal setting, imagery, selftalk, team building, and time management (e.g., making lists and schedules, developing a preference for organization; AASP, n.d.). Before implementing any psychological skills training program, SPCs should practice on themselves the psychological skills they wish to teach their clients (Simons \& Andersen, 1995) to improve the technical and interpersonal skills necessary to be an effective practitioner.

Through interviews with coaches and athletes, researchers have examined the characteristics and behaviours of effective practitioners. According to both coaches and athletes, SPCs should be trustworthy, have good listening skills and suitable sport knowledge, and get to know the athletes (Anderson, Miles, Robinson, \& Mahoney, 2004; Sharp \& Hodge, 2013). A perspective unique to athletes is that SPCs should also be personable, provide psychological skills training programs and other activities (e.g., address issues outside of sport), deliver information well, and provide feedback (Anderson et al., 2004). Although it is often assumed that SPCs only implement psychological skills training programs with clients, based on the aforementioned findings, there are clearly more factors to consider to be effective.

To provide a systematic and strategic approach to the delivery of psychological services, Poczwardowski, Sherman, and Henschen (1998) developed the sport psychology service delivery heuristic, which was later revised by Poczwardowski and 
Sherman (2011). The revised sport psychology service delivery heuristic is composed of 18 factors (see Figure 1) designed to help SPCs effectively plan, implement, and evaluate their psychological services (Poczwardowski \& Sherman, 2011). SPCs can use this model to identify which factors they need to develop to maximize their effectiveness.

Given the number of factors to consider in the revised heuristic, it is not surprising that SPCs view the delivery of psychological services as a "performance" (Poczwardowski \& Sherman, 2011; Woodcock, Richards, \& Mugford, 2008). However, to perform to the best of their abilities, SPCs need to take care of themselves by carefully monitoring their nutrition, rest, physical fitness, mental health, relationships, work-life balance, self-care, and life skills (Moyle, 2015). If SPCs fail to manage themselves properly, then every aspect of the consulting process could be negatively impacted. For instance, SPCs who are continually stressed due to a lack of time to exercise and eat well, may not be effective in their ability to focus and show empathy during an individual consultation. This lack of focus and empathy could prevent them from uncovering the "real issue" hindering a client's performance, effectively teaching psychological skills, and maintaining a positive relationship with a client. Fortunately, managing the self as an intervention instrument, which refers to the coping and intra- and inter-personal selfmanagement strategies used by SPCs, can help SPCs deal with these types of physical and psychological limitations (Poczwardowski et al., 1998) and ensure that the consulting process is not negatively impacted. Because managing the self as an intervention instrument is one of the most important factors that SPCs need to develop and because of the central role that it plays in the consulting process, it will be the focus of the current study. 
Given SPCs are regularly faced with a variety of stressors (e.g., workload and long hours, role ambiguity, lack of social support, job insecurities, inadequate communication channels; Fletcher, Rumbold, Tester, \& Coombes, 2011), it is crucial for them to manage the self in order to maintain their general well-being (Cropley et al., 2016). It has been noted that SPCs should cultivate self-confidence (Stambulova \& Johnson, 2010), live a healthy and active lifestyle (Arnold \& Sarkar, 2015; Partington \& Orlick, 1991), and maintain a proper balance between work, play, and relationships (Partington \& Orlick, 1991) to successfully help their clients. Apart from using coping strategies, SPCs should also find ways to broaden their professional knowledge base and enhance their counseling skills (Poczwardowski et al., 1998).

SPCs can potentially improve their performance and serve as a role model to their clients, if they "practice what they preach" and use psychological skills on themselves (Poczwardowski et al., 1998). SPCs should model the refocusing and self-control skills they teach to their clients (Partington \& Orlick, 1991) and personally experiment with all types of psychological skills (Straub \& Hinman, 1992). More specifically, SPCs can stay mentally fresh by practicing psychological skills such as relaxation techniques, cognitive behavioural therapy techniques, and mindfulness (Elsborg, Diment, \& Elbe, 2015).

Practicing psychological skills is one of the most effective ways for SPCs to manage themselves because it can help them deal with personal and professional challenges (Pack, Hemmings, \& Arvinen-Barrow, 2014). For instance, a SPC can use imagery to cope with life stressors or rehearse the key talking points of a presentation to a group of athletes on goal setting. Given there is little evidence, other than anecdotal, on 
the use of psychological skills by SPCs, valuable insight may be gained from other types of performers.

Elite athletes use imagery, self-talk, and relaxation techniques to maximize their performance during competitions (Gould, Finch, \& Jackson, 1993; Park, 2000). Moreover, they prioritize tasks and take time for themselves (Gould et al., 1993), set goals (Burke \& Orlick, 2003; Freitas, Dias, \& Fonseca, 2013a), and regularly evaluate their performance for future improvement (Barbour \& Orlick, 1999). Similar to elite athletes, elite-level coaches use self-talk, imagery, relaxation, and goal-setting strategies in different locations (training and competition), during different time frames (before, during, and after training or competition), and for various purposes (Freitas, Dias, \& Fonseca, 2013b; Thelwell, Weston, Greenlees, \& Hutchings, 2008).

Surgeons (Anton, Montero, Howley, Brown, \& Stefanidis, 2015; Ibrahim, Richardson, \& Nestel, 2015), professional musicians (Agnew, 1922), dancers (Nordin \& Cumming, 2005), actors (Murphy \& Orlick, 2006) as well as military pilots and astronauts (Hohmann \& Orlick, 2014; Sprung, 1995) use imagery to improve their performance. Performing artists relax by engaging in self-talk (Steptoe, 1989), isolating themselves, practicing breathing exercises (Murphy \& Orlick, 2006; Pirie, 1998), finding their own "inner mental room", and listening to relaxation recordings (Fagéus, 1999). Further, business executives use different listening techniques such as reflective listening, focusing on the message, and paraphrasing the message, to improve the communication they have with their employees (Weinberg \& McDermott, 2002). Lastly, military pilots engage in self-talk to enhance their personal confidence and refocus when they get 
distracted, control distractions by compartmentalizing them, and partake in personal debriefs, after every flight, to learn from their mistakes (Hohmann \& Orlick, 2014).

Taken together, a considerable amount of research demonstrates the range and combination of psychological skills used by performers (e.g., athletes, coaches, surgeons, actors, musicians, astronauts). Given SPCs are also performers (Woodcock et al., 2008), they too would benefit from the personal use of psychological skills. Although some researchers have studied the general lessons that neophyte and experienced SPCs have learned, which often included elements pertaining to managing the self as an intervention instrument (e.g., McDougall, Nesti, \& Richardson, 2015; Tod, Marchant, \& Andersen, 2007), only one study has specifically examined the psychological skills used by SPCs.

Pack et al. (2014) conducted semi-structured interviews with 12 UK-based SPCs to determine if SPCs use self-practice, how they use it, and for what reasons. Selfpractice refers to applying psychological skills (e.g., goal setting, cognitive behavioural techniques) on oneself (Bennett-Levy et al., 2001). SPCs reported using self-practice as a way of managing the self, legitimising their interventions, and gaining a deeper understanding of the psychological skills they teach. More specifically, some of the SPCs adapted different psychological skills to suit their needs (e.g., setting goals in different parts of their lives), and used psychological skills to cope with personal and professional demands (e.g., engaging in self-talk to reduce their anxiety, doing something to relax to remain empathic) as well as improve their sport performance (e.g., using self-talk and imagery while running). However, several participants noted that it can be hard to incorporate self-practice into their lives because of their busy schedule. 
Although Pack et al. (2014) confirmed that SPCs do engage in self-practice, it is not clear which psychological skills they use as well as where, when, why, and how they use them. Munroe, Giacobbi, Hall, and Weinberg (2000) argued that developing a conceptual framework based on the four Ws (what, where, when, why) can be used as an educational tool to teach athletes psychological skills (e.g., imagery) and create more specific and effective interventions. Therefore, SPCs may benefit from the development of a conceptual framework based on the four Ws to learn different psychological skills aimed at improving their consulting.

Based on Bennett-Levy's (2006) three-systems model of therapist skills development, which is composed of the declarative system (factual knowledge), procedural system (how and when to do something), and reflective system (reflecting on experiences), self-practice can be a useful learning strategy to develop and refine procedural knowledge and skills (e.g., technical, interpersonal perceptual, and interpersonal relational skills), and thus improve a SPC's consulting. Although Pack et al. (2014) found that SPCs use psychological skills to enhance their technical skills (e.g., improve their ability to teach psychological skills to their clients by engaging in selfpractice), it would be important to determine if they also use them to directly improve their interpersonal perceptual and relational skills as well as cultivate important psychological constructs (e.g., confidence, creativity). For example, SPCs could develop empathy, a non-judgmental attitude, and a better connection with themselves and their clients, if they practice mindfulness (Andersen, 2012; Zizzi \& Andersen, 2010). Given athletes and coaches pay particular attention to the consultant-client relationship when evaluating the effectiveness of SPCs (Fortin-Guichard, Boudreault, Gagnon, \& Trottier, 
2017), finding a practical and cost-effective way for SPCs to enhance their interpersonal skills and foster important psychological constructs would be extremely beneficial.

Only SPCs from the United Kingdom were interviewed by Pack et al. (2014). Obtaining the point of view of SPCs from other countries, such as Canada, can expand the knowledge on and highlight the similarities and/or differences that may exist in this area of research. For example, UK-based SPCs may have varied experiences compared to Canadian-based SPCs given the route to certification is different. That is, SPCs certified through the British Association of Sport and Exercise Sciences (BASES) are required to fulfill two to six years of supervised experience (Cotterill, 2011), whereas SPCs certified through the Canadian Sport Psychology Association (CSPA) are required to accumulate 400 hours of supervised practice (CSPA, n.d.). Moreover, BASES supervised experience guidelines emphasize the use of reflective practice by neophyte SPCs (Faull \& Cropley, 2009), whereas CSPA does not provide any guidelines with respect to reflective practice. Taken together, there is a need to examine the psychological skills that Canadian-based SPCs use to improve their consulting.

The aims of self-practice in sport psychology are to facilitate the management of the consultant-client relationship, enhance self-insight as well as personal, interpersonal, and counseling skills, reduce the potential negative impact that the SPC can have on the process, identify the subtle processes behind the psychological skills being taught, and understand how psychological skills can help clients (Pack et al., 2014). To this end, the general purpose of the current study was to qualitatively examine self-practice, and more specifically the psychological skills used by SPCs to improve their consulting. Using semi-structured interviews, the four Ws approach (Munroe et al., 2000) was used to guide 
the discussion with SPCs and help identify what psychological skills are used by SPCs as well as where, when, why, and how they used them.

\section{Method}

\section{Participants}

The sample comprised eight (3 male, 5 female) Canadian-based SPCs ranging from 29 to 47 years of age $(M=37.38, S D=6.86)$. These SPCs had between 4 and 23 years of consulting experience $(M=10.5, S D=6.74)$ and were full-time $(n=1)$ or parttime $(n=7)$ performance enhancement consultants (i.e., they have a background in sport and exercise sciences) with either a PhD $(n=5)$ or a master's degree $(n=3)$. All SPCs got paid for most of their services and worked with athletes from a variety of sports (e.g., hockey, track and field, swimming, curling, skiing; see Table 1).

\section{Procedure and Data Collection}

Ethical approval for the study was obtained from the University of Windsor.

Criterion-based sampling, which involves identifying a set of criteria for selecting cases, sites, or places (Sparkes \& Smith, 2014), was used to identify SPCs that could provide rich data. Based on this criterion sampling approach, those eligible to participate were male or female licensed psychologists or performance enhancement consultants with at least two years of consulting experience that were professional members of CSPA and who had obtained their highest degree at a Canadian university, and who used psychological skills on themselves to improve their consulting. Using the researcher's network of contacts, a potential participant was identified and sent an email outlining the nature of the study and inviting them to participate (see Appendices A and B).

Afterwards, snowball sampling, which is a process whereby the researcher asks 
participants to identify other individuals who satisfy the study's inclusion criteria (Sparkes \& Smith, 2014), was used to recruit other SPCs.

Individual, open-ended, semi-structured interviews were conducted with the participants. This type of interview allows the researcher and the participants to have a conversation on a predetermined topic of interest that is within a specific subject area (Rubin \& Rubin, 2012). According to Sparkes and Smith (2014), compared to structured interviews, semi-structured interviews provide the participants with a greater opportunity to express their thoughts and feelings and elaborate on the different meanings they attach to their experiences. As a result, the researcher is able to gain a more profound understanding of the participants' perceptions. All interviews were conducted via telephone. Telephone interviews are cost-effective, flexible, allow the researcher to access and obtain data from different locations (Hanna, 2012), and can produce rich and detailed data (Holt, 2010). To guarantee anonymity, the participants were notified that their names were going to be replaced with a code (SPC1 to SPC8) in the transcripts.

\section{Interview Guide}

The interview guide (see Appendix C) was based on Smith and Sparkes' (2016) guidelines, previous studies that used elements of the four Ws approach to examine the psychological skills employed by different performers (e.g., Freitas et al., 2013a; Freitas et al., 2013b; Thelwell et al., 2008), and Bennett-Levy's (2006) three-systems model of therapist skills development. It comprised three sections. In the first section, the participants were asked to give their verbal consent for the audio-recording of the interview and provided with a brief description of the study as well as a definition of a psychological skill. Moreover, they were asked to describe how they became a SPC, what 
their typical week looked like during their "peak season", and the range of services they provided to their clients. In the second section, the participants were asked specific questions pertaining to what psychological skills they used to improve their consulting as well as where, when, how, and why they used them. In the third section, the interviewer (lead author) summarized the main findings that emerged from the interview and provided the participants with the opportunity to elaborate on previous responses and ask any questions about the interview or the study in general. Every interview was audio recorded, transcribed verbatim, and imported into the QSR NVivo 11 program, a computer software designed to store and categorize qualitative data. To refine the interviewer's skills and verify the appropriateness of the interview guide, two pilot interviews were conducted, prior to the start of the study, with certified SPCs (1 male, 1 female).

\section{Data Analysis}

The current study used a social constructivist approach to interpret the participants' experiences. Social constructivist researchers rely as much as possible on the subjective meanings that participants attach to their experiences and acknowledge that their interpretations of the results are shaped by their own personal, cultural, and historical experiences (Creswell, 2007). In the present study, the researcher was interested in understanding the experiences of SPCs who used psychological skills to improve their own consulting. The data were analyzed using a thematic analysis based on Braun and Clarke's (2006) guidelines. This straightforward and flexible method of analysis is designed to highlight similarities and differences as well as summarize important features found in the data set (Sparkes \& Smith, 2014). In the first phase, the 
researcher familiarized himself with the database by reading the transcripts multiple times and taking notes. In the second phase, initial codes were produced in a systematic fashion. Boyatzis (1998) defined a code as the most rudimentary segment of raw data. In the third phase, initial codes were organized into broader themes using an abductive approach (i.e., analysing the data both inductively and deductively; Sparkes \& Smith, 2014) and to help with this process, a thematic map was created. More specifically, the higher-order themes were generated deductively based on the four Ws approach, while the sub-themes were inductively produced. In the fourth phase, the themes were reviewed, with the use of the thematic map, to verify if they fit well in relation to the coded extracts and the whole data set. In the fifth phase, each theme was clearly defined and named. In the sixth and final phase, relevant and compelling data extracts were selected and included in the report to provide evidence for the existence of each theme. Theoretical saturation was reached when the categorization of new data fit adequately existing themes (Miles \& Huberman, 1990).

Sincerity, which refers to the concepts of authenticity and genuineness, was achieved through self-reflexivity (Tracy, 2010). More specifically, the researcher kept a reflexive research journal (Etherington, 2004) to examine his assumptions, choice of topic, research questions, methods, analytical strategies, writing style, roles, relationship with participants, and the impact he had on every stage of the research process (Sparkes $\&$ Smith, 2014). Furthermore, credibility, which refers to the trustworthiness and plausibility of the research findings, was achieved through thick description (i.e., provide enough detail in the report to help the reader draw his own conclusion) and multipleanalyst triangulation (Tracy, 2010). Denzin (1978) noted that if two or more researchers 
come to the same conclusion, then the conclusion is more credible. Therefore, an investigator, with qualitative research experience and who was not part of the data collection process, reviewed the researcher's interpretations of the data.

\section{Results}

The SPCs reported details regarding what psychological skills they used as well as how, when, and why they used them. Thematic analysis revealed that all SPCs used a variety of psychological skills to improve their consulting, including deep breathing ( $n=$ 7), goal setting $(n=7)$, self-reflection ( $n=6)$, time management $(n=6)$, imagery $(n=5)$, mindfulness $(n=5)$, self-talk $(n=4)$, and bio-neurofeedback $(n=1)$. The following section will focus on the breadth of psychological skills used by SPCs rather than the frequency of the coded extracts.

\section{Deep Breathing}

How. SPCs described using deep breathing techniques (e.g., focusing on their breath) and in conjunction with technology (i.e., breath pacer) as well as other skills (e.g., self-talk; see Figure 2). The following quotation from one SPC depicts the technique of deep breathing:

I would focus on breathing from my belly and not from my chest and then I usually breathe in through my nose and try to get a whole full-belly of air and then breathe through my mouth and usually count in to four for the inhale and then pause for two seconds and then breathe out for four. (SCP4)

Moreover, one SPC performed deep breathing exercises in conjunction with selfreflection: "I'm often doing the breathing as I'm doing the reflection piece." (SPC6) 
When. SPCs discussed practicing deep breathing before a session, as well as before and during their client's competition, when needed, and while commuting (i.e., driving to work). For instance, SPCs took a few deep breaths before starting a team workshop:

[The athletes] are coming in and I have my presentation up, even though it's my fourth year with them, there's still a little bit of this, okay I'm about to speak to these incredible athletes who are not an easy audience. And so, I can watch on my wristwatch as my heart rate is increasing and then I'll actually call it out to one of the guys sitting in the front row, so this is what my heart rate is doing right now and then I'll actively reflect on that, take a few breaths to get it under control. (SPC7)

Why. SPCs indicated engaging in deep breathing exercises to understand the skill, foster the consultant-client relationship, and enhance psychological constructs (e.g., regulate emotions, increase focus). With respect to this latter point, SPCs used deep breathing to decrease their stress levels: "I definitely want to make sure that I'm calm, cool, and collected in most situations I'm in. And so, I use the breathing specifically to do that." (SPC1)

\section{Goal Setting}

\section{Business development.}

How. SPCs reported various business goal setting techniques such as setting different types of goals (e.g., outcome goals) as well as short-term and long-term goals, used the S.M.A.R.T. guidelines (i.e., specific, measurable, attainable, realistic, and timely) to refine them, and took time to review their goals (see Figure 3a): 
[I] utilize goal setting especially around designing a private practice, you have to have your short-term and your long-term goals and you have to have your performance and process goals. So, utilizing the S.M.A.R.T. principles to facilitate those and regularly checking-in on them to make sure that you're meeting your marks, your targets. (SPC3)

When. SPCs mentioned setting business goals daily, weekly, and when needed. For instance, one SPC noted: "at the end of each week, depending on how you look at the weeks, I sit down and look at what ... I have a template for what I want to accomplish in that week." (SPC2)

Why. SPCs discussed using goal setting to grow their business. For example, one SPC set goals to enhance her business knowledge and skills as well as increase her clientele:

How am I going to develop my client base, how am I going to help clients, do I want to take more courses because I want to achieve certain things and it's not necessarily formal education courses, but maybe some online or reading. (SPC2)

\section{Professional development.}

How. SPCs described using goal setting techniques (e.g., different types of goals, short-term and long-term goals) and in conjunction with other skills (see Figure 3b). Specifically, SPCs based their goals on the research literature: "I'm looking at the current trends, what's new in the research right now that's been working, kind of some best practices that I can implement." (SPC8) Furthermore, one SPC's goals were based on her clients' performance issues: "To be honest most of my professional goals are directly related to gaps I see in the performance solution I can provide ... based on what's being 
presented to me from my client groups." (SPC1) Finally, SPCs practiced goal setting in conjunction with self-reflection:

I think when you're doing the reflection process of like this is what went well, this is what didn't go well, and this is what I can do to improve, so maybe like a goal that I would set in terms of I need to learn more about this. So, I'm going to set the goal of reading this book. (SPC4)

When. SPCs reported setting goals daily, weekly, and after a session. For instance, one SPC set goals after team workshops: "I always like to set goals after [team workshops] and try to learn something positive from them." (SPC4)

Why. SPCs discussed using goal setting to foster the consultant-client relationship, understand the skill, enhance their knowledge and skills, help clients achieve their goals, and enhance psychological constructs (i.e., decrease stress and increase focus). More specifically, one SPC set goals to build a better relationship with her clients: "if I can just better myself for them, I feel like they can feed off of that, right. It kind of comes out in that rapport that you build with them." (SPC8) In addition, SPCs set goals to enhance skills:

If I want to be a gold-medal performer what kinds of skills do I need to build and what kinds of things do I need to be regularly performing at to help my clients. So, it's about looking at where are the gaps in my skill-base and how do I fill those gaps to make sure that I've got as many resources for the client's needs as possible. (SPC1) 


\section{Client development.}

How. SPCs indicated using goal setting techniques (i.e., setting different types of goals and taking time to review them) and in conjunction with other skills (i.e., selfreflection) when setting goals for client development (see Figure 3c).

When. SPCs reported setting goals before a session, after a competition, at the beginning and end of a season as well as while commuting. For example, one SPC set goals at the start and end of her clients' competitive season:

When I would do it would be when I would start with a team or athlete ... When I would start and then re-evaluate at the end of whether it's a year or their competitive season and then reset again. Keeping in mind that you're always reviewing it as you go, but as far as big goals and actually setting them would be at the start and then at the end of their competitive season. (SPC5)

Why. SPCs indicated engaging in goal setting to foster the consultant-client relationship, help clients achieve their goals, and enhance psychological constructs (i.e., be mentally prepared and increase focus).

\section{Self-reflection}

\section{Checking-in.}

How. SPCs described using checking-in techniques, spontaneous self-reflection, and in conjunction with other skills (i.e., deep breathing; see Figure 4a). In particular, one SPC used checking-in techniques by self-reflecting on her pre-conceived assumptions and goals for the session:

That self-reflection piece, I will do a check-in on what my goals are or what my objectives are and what [my clients] might be coming in with, so that's aligned. 
Yeah so, I think it's kind of just a checking-in and making sure that I'm not going in there with pre-conceived assumptions of what the session should look like or will be like. (SPC6)

When. SPCs reported engaging in self-reflection before a session (e.g., prior to an individual consultation or team workshop) and while commuting to work.

Why. SPCs described practicing self-reflection to foster the consultant-client relationship, identify potential solutions, and enhance psychological constructs (i.e., be mentally prepared, be open minded, and increase confidence). For example, one SPC fostered her relationship with the client by utilizing self-reflection: "just making sure that I can park all of that and be there for the athlete." (SPC6)

\section{Debrief.}

How. SPCs recounted using debrief techniques as well as deliberate selfreflection (see Figure 4b). Specifically, SPCs self-reflected on their strengths, weaknesses, and areas of improvement:

What I would try to do and how I like to reflect is focus on what did I do wrong ... what are the positives that came out of that session or that workshop. And then what can I improve on. Try to identify a couple of things that can be improved the next time and then how can I improve that. (SPC4)

When. SPCs indicated using self-reflection after a session and competition as well as when needed. With respect to the former, one SPC self-reflected after every session and major competition: "I always do self-reflect after every individual and every group presentation and major event." (SPC5) 
Why. SPCs discussed engaging in self-reflection to foster the consultant-client relationship, understand the skill, refine their service delivery, and enhance psychological constructs (e.g., decrease stress). More specifically, SPCs self-reflected to refine the delivery of their team workshops:

I don't think I would be improving if I wasn't doing [self-reflection]. I would just be teaching the same skills that I taught five years ago or trying to do a workshop in the exact same way that I did the first time that I did it, which doesn't produce a lot of results. I think that the reflection piece has probably been one of the most important things because it helps you to just improve the delivery of what you're doing. (SPC4)

\section{Time Management}

How. SPCs described using time management techniques (e.g., use planning tools, such as a calendar or planning journal; see Figure 5).

When. One SPC recounted using time management strategies while commuting (i.e., on an airplane).

Why. SPCs indicated managing their time to achieve a work-life balance, understand the skill, help achieve their goals, increase efficiency, and enhance psychological constructs (e.g., decrease stress, feel prepared, increase confidence). With respect to the work-life balance, one SPC noted:

I think it's also really important for just balance. You can see that I really have worked hard in the last five years to create a lifestyle that integrates a bit of balance. When I'm doing my meditation, when I'm doing my gratitude journaling, like when I'm doing my own self [...] and I have a family, I have 
friends and then I have a child. So, I try to live my life fully and authentically.

Partially as a role model to my client groups. You can be a high performer doing all of these things, it just has to be "periodized" really well. (SPC1)

\section{Imagery}

\section{Individual consultations.}

How. SPCs reported using imagery techniques and spontaneous imagery for their individual consults with clients (see Figure 6a). More specifically, one SPC practiced imagery techniques by imaging how she wanted to feel and behave during an individual consultation: "starting with new athletes, I'm going to visualize myself coming across as very confident, professional, delivering like a positive service for the athlete, showing empathy, active listening, that rapport building." (SPC8)

When. SPCs discussed using imagery before and after a session, while commuting, and when needed. For example, one SPC imaged before an individual consultation and sometimes after, depending on the outcome: "but a lot of times it's before having a session with an athlete or even after if something didn't feel right, didn't go the way I thought it would.” (SPC2)

Why. SPCs mentioned practicing imagery to foster the consultant-client relationship, refine their service delivery, and enhance psychological constructs (i.e., be mentally prepared, decrease stress, increase motivation). For instance, one SPC refined her service delivery by using imagery to learn from her mistakes: "using imagery to see how I would have played it out differently or how I would play it out differently in the future.” (SPC2) 


\section{Team workshops.}

How. SPC described using imagery techniques (e.g., imaging sights and sounds, imaging from a first-person perspective), spontaneous imagery, and deliberate imagery (e.g., imaging for three to five minutes when planning a team workshop) in concert with team workshops (see Figure 6b). In particular, SPCs used imagery techniques by imaging how they wanted to feel during a team workshop: "I'm giving a presentation then I'm obviously picturing myself giving that presentation and being confident in delivering that presentation and answering those questions.” (SPC8)

When. SPCs indicated using imagery before a session, while commuting, while planning, and when needed. For example, SPCs utilized imagery when planning team workshops:

I think it was also maybe part of the planning process as well $[\ldots]$ a rehearsal in advance of like this is how this is going to go. So, when planning the workshop, I'm thinking about it from like a step-by-step process of this is how I want the workshop to go, but at the same time I'm kind of visualizing what it's going to look like in the room" (SPC4)

Why. SPCs noted practicing imagery to foster the consultant-client relationship, prepare, and enhance psychological constructs (e.g., be mentally prepared, be more flexible). For instance, SPCs used imagery to enhance various psychological constructs: One, it helps my confidence and it helps decrease my anxiety. Being nervous to speak in front of a large group of people or just a couple people that are unfamiliar to me can evoke some anxiety in myself. So, by doing this, this is kind of like a pre-competition routine. I like to do it for myself, it's something that I 
need to do. If I don't do it then I feel like I'm not properly prepared. So, for me it's definitely an anxiety reducer and a confidence booster. (SPC8)

\section{Mindfulness}

\section{Awareness and Acceptance.}

How. SPCs reported practicing mindfulness by using awareness techniques, acceptance techniques, and in conjunction with other skills (i.e., deep breathing and self-talk; see Figure 7a). One SPC recounted using awareness techniques to be more mindful:

I use this $\mathrm{ABC}$ process of awareness, breath, choose, for those times where I notice that my head is in an unproductive place. So that awareness and then I take a couple of breaths to come back to the present and then choose to focus on something that's happening now, something that matters now. (SPC7)

The same SPC also accepted the things that were not under his control:

I really think about some of the things that might stress me or bother me and reflect on whether or not they're controllable entities or not and if they're controllable then I can game plan for how to deal with them. If they're not controllable, I process from accepting them, so I actively accept them as part of my experience. (SPC7)

When. One SPC mentioned using awareness and acceptance before a session and when needed.

Why. SPCs reported practicing this approach to understand the skill and enhance psychological constructs (i.e., decrease stress and increase focus). 


\section{Intention.}

How. When practicing mindfulness, SPCs mentioned using intention techniques and in conjunction with other skills (i.e., deep breathing; see Figure 7b). For example, one SPC defined his identity as a SPC, put his intentions into actionable terms, and regularly reminded himself of his intentions:

I really define what I want my identity to be as a sport psychology consultant with the team. And for instance, I may set, I want to be positive, I want to be prepared and I want to be passionate [...]. So, intentions for this trip and then I'll write them down, I'll define what I mean by those things, I'll put them into actionable terms, and I set that as an intention. I remind myself of that intention every day. (SPC7)

When. One SPC described setting intentions while commuting: "I may set those intentions, so you can sort of see me sitting on an airplane, got my tray down, I got my coffee and I'm writing these, what are my intentions." (SPC7)

Why. SPCs indicated setting intentions to understand the skill and enhance psychological constructs (e.g., increase confidence, increase focus). For instance, one SPC set intentions to increase her motivation: "it can just be one or two words and just by looking at it, you know it just elicits an emotion, it may elicit an impactful kind of motivating factor.” (SPC8)

\section{Meditation.}

How. SPCs noted using spontaneous meditation, deliberate meditation (e.g., meditating 10 to 20 minutes in the morning), meditation techniques (i.e., breathing, sensory, reflective, and body-scan meditations), and in conjunction with technology (see 
Figure 7c). With respect to the latter, SPCs meditated with the help of apps: "so I have a couple of apps that I may use or when I'm feeling kind of lazy and don't want to do it on my own.” (SPC7)

When. SPCs talked about meditating daily, weekly, and when needed (e.g., when they felt stressed).

Why. SPCs discussed practicing meditation to achieve a work-life balance, foster the consultant-client relationship, understand the skill, and enhance psychological constructs. More specifically, SPCs meditated to be more present with their clients:

The value is that I can recognize where my mind is going and then I can accept that and then I can come back to the present moment and be present with the athlete. And I think that's more important for me in a consulting session that I'm present with the athlete than if I'm coming up with the best strategy. I think presence is really important. (SPC4)

Furthermore, SPCs practiced meditation to feel more confident in their abilities to teach it to their clients: "there's a confidence and conviction that comes from being a successful practitioner of those skills. Like I'm much better a teaching mindfulness, having my own mindfulness meditation practice, right. Like there's just more behind it." (SPC7)

\section{Self-talk}

Focus

How. SPCs reported using self-talk techniques to focus (see Figure 8a). SPCs would notice that their mind was wandering and then used attentional cues to bring their focus back to the present moment: "It's just being able to direct my attention if it is 
wandering to the task at hand [...] and I have to say I do that quite a bit, like we have to remind ourselves to refocus a lot." (SPC3)

When. SPCs recounted engaging in self-talk before and during a session, during a practice, before and during a competition, and when needed. For example, one SPC used self-talk while observing practices and competitions: "if I'm observing a competition or if I'm observing practice sessions, to make sure that I'm staying focused on the task at hand and not drifting off." (SPC2)

Why. SPCs described practicing self-talk to understand the skill, increase efficiency, and enhance psychological constructs (e.g., increase focus).

\section{Motivation}

How. SPCs noted using self-talk techniques and in conjunction with other skills

(i.e., deep breathing) for motivation (see Figure 8b). For instance, SPCs used motivational cues to remind themselves that they had the necessary knowledge and skills to be effective:

In terms of self-talk, it would be like okay, this is my first time with a national team, I would use self-talk to remind myself that I do have the skills, I have the expertise, I just need to present it and you know it's something new to them. And to just remind myself to be confident in my skills and what I'm actually presenting. (SPC5)

When. SPCs discussed using self-talk before a session (e.g., before giving a presentation to a new group of athletes).

Why. SPCs indicated practicing self-talk to understand the skill and enhance psychological constructs (e.g., decrease stress, increase confidence). As an example, one 
SPC engaged in self-talk to increase her energy and motivational levels when working with young clients:

I use it sometimes even to get yourself pumped up, get energized, especially if you're working with a younger group, you got to show your energy and motivation for it and excitement. Because younger groups will feed off that as well, you know getting yourself into the moment, so talking yourself into the moment. (SPC3)

\section{Relaxation.}

How. SPCs mentioned using self-talk techniques in conjunction with other skills (e.g., deep breathing and mindfulness) for relaxation (see Figure 8c). For instance, one SPC noted: "I may sometimes talk a little too fast or notice that my physiology is kind of off. And so, I'll talk myself back down like, you got to chill, you got to relax ... you got to come down, just slow down, slow down you're losing them." (SPC2)

When. SPCs talked about engaging in self-talk before and during a session, before and during a competition, and when needed.

Why. SPCs discussed using self-talk to understand the skill, be the calming presence for clients, and enhance psychological constructs (i.e., decrease stress). More specifically, one SPC utilized self-talk to feel more confident in teaching it to his clients: "It's kind of nice when you can apply it to yourself and know that it works, and you know feel confident in it when you teach it to athletes." (SPC4)

\section{Bio-neurofeedback}

Why. One SPC recounted employing a bio-neurofeedback machine to understand the skill and enhance psychological constructs (see Figure 9). For example, she noted: 
When I do the [bio-neurofeedback] I think for me it's just more of an understanding of the tool, understanding its potential, playing around with it. If I made a mistake with my breath, did I breathe like this or I didn't ... you know I'll come in and pretend, I'll simulate, ah what would I do if I was this type of an athlete. You know I think of one of my athlete and I just go, how did they use it and what would that number look like and what would I say to them to try and relax into it or take it on or do it seriously. (SPC1)

\section{Discussion}

The purpose of the current study was to qualitatively examine self-practice by identifying what psychological skills SPCs used to improve their consulting as well as where, when, how, and why they used those skills. SPCs reported using deep breathing, goal setting, self-reflection, time management, imagery, mindfulness, self-talk, and bioneurofeedback. They practiced these psychological skills at different times (e.g., daily, weekly, when needed, before a session), in a variety of ways (e.g., spontaneously, deliberately, applying specific techniques), and for various purposes (e.g., foster the consultant-client relationship, refine their service delivery, enhance psychological constructs).

In accordance with the definition of a psychological skill provided in the introduction, SPCs in the present study discussed techniques that could be practiced (e.g., goal setting, mindfulness) as well as indicators of the level of ability (e.g., arousal regulation, attentional control). However, to ensure that the findings would be clear, consistent, and practical, the sub-themes in this section were only organized around techniques that could be practiced. With respect to what psychological skills they used, 
SPCs in the current study practiced the same types of skills as other SPCs (e.g., Elsborg et al., 2015; Pack et al., 2014) and performers (Anton et al., 2015; Freitas et al., 2013a). Unique to the present study, however, was the use of bio-neurofeedback by one SPC. Researchers have noted that athletes are becoming increasingly interested in using bioneurofeedback because of its growing sophistication and ability to quantify psychological progress (Pusenjak, Grad, Tusak, Leskovsek, \& Schwarzlin, 2015). As a result, SPCs are beginning to utilize bio-neurofeedback to satisfy their clients' needs. In light of this finding, SPCs should stay informed on the latest psychological skills being used by performers and practice them to determine if they could be beneficial to their clients.

When asked about when and where SPCs used psychological skills, only the "when" emerged as a theme. This may be due to the fact that SPCs do not see the "where" as a crucial component to the practice of their psychological skills. With respect to when, SPCs often described using psychological skills while commuting. This is not surprising given that other SPCs have indicated spending a considerable amount of time on the road, due to the nature of their work (Cecil, 2015; Symes, 2014). Therefore, SPCs should be encouraged to use the time they spend commuting to practice psychological skills in order to prepare themselves mentally before a session as well as debrief after a session. For instance, an SPC driving to a team workshop could think about the goals for that session and then self-reflect on what went well and what could be improved, on the way back home. Contrary to Pack et al.'s (2014) findings, SPCs in the present study did not mention utilizing psychological skills while playing sports or exercising. The reason for this could be that the questions in the interview guide were only focused on the SPCs' consulting practice and not their everyday lives. Nevertheless, this would be the ideal 
time for SPCs to practice different psychological skills and identify the subtle processes behind them. For example, a SPC lifting weights in the gym with a personal trainer could use self-talk to determine if assigned or freely chosen self-talk appears to be more effective in that setting.

Regarding how they used psychological skills, SPCs discussed both the deliberate and spontaneous practice of skills. This is surprising given the research supports the view that psychological skills need to be practiced systematically and consistently to enhance performance (Weinberg \& Gould, 2015). Thus, SPCs should practice their psychological skills in a deliberate fashion (e.g., meditate for 10 minutes every morning) in order to experience their full benefits and further improve their performance. Moreover, SPCs indicated using psychological skills in conjunction with other psychological skills. This makes intuitive sense given that psychological skills can be more effective when practiced in combination (Thelwell \& Greenlees, 2001). Therefore, SPCs should select a few psychological skills that they can use in combination to achieve a desired outcome. For instance, a SPC can use deep breathing, self-talk, and imagery to relax before an individual consultation with a new client. Lastly, SPCs discussed using psychological skills in concert with technology. Cotterill and Symes (2014) noted that new technologies, such as applications on smart phones and tablets, can enable SPCs to deliver more effective services to their clients by enhancing the sharing of information. For example, a SPC could ask a client, who is starting to learn imagery, to listen to a guided imagery recording on YouTube before going to bed. However, the inverse is also true. SPCs could use technology to refine their own psychological skills and learn new 
ones. For instance, a SPC could utilize the Headspace app to gain a better understanding of different types of meditation (e.g., breathing meditation, body scan meditation).

When exploring why they used psychological skills, SPCs described practicing them for many reasons, one of them being to foster the consultant-client relationship. This is not surprising given that the quality of the consultant-client relationship is the most significant predictor of treatment adherence and positive consulting outcomes (Petitpas, Giges, \& Danish, 1999). The importance of building quality relationships with clients has been echoed by numerous SPCs in qualitative studies (e.g., Arnold \& Sarkar; McCormick \& Meijen, 2015; Poczwardowski \& Sherman, 2011) as well as personal reflections (e.g., Cotterill, 2012; Neff, 1990). Petitpas et al. (1999) made a list of suggestions to help SPCs foster the consultant-client relationship which include: being a client, videotaping and live supervision models, verbatim, training logs, the traineesupervisor relationship, and process versus content supervision. Based on the results of the current study, practicing psychological skills should be considered as a new and viable strategy to foster the consultant-client relationship. For instance, SPCs could achieve this by imaging themselves having compassion for their clients or meditating to increase their focus and be more present with their clients.

SPCs reported using psychological skills to enhance different psychological constructs, such as decreasing stress. Researchers have consistently found that neophyte SPCs experience a great deal of anxiety when delivering their services (Lindsay, Breckon, Thomas, \& Maynard, 2007; Tod, Andersen, \& Marchant, 2011). More experienced SPCs are also faced with a variety of stressors (e.g., workload and hours, role ambiguity, lack of social support; Fletcher et al., 2011). Thus, SPCs should select 
one or multiple psychological skills that they could use when they feel stressed. For example, a SPC could use deep breathing or self-reflection to relax after a difficult and emotionally charged session.

SPCs in the present study noted practicing psychological skills to achieve a worklife balance. Most notably, they used various time management strategies (e.g., creating a list of priorities, using a calendar). Elsborg et al. (2015) as well as Partington and Orlick (1991) reported that SPCs must maintain a proper work-life balance if they want to remain helpful to their clients. Furthermore, it is worth noting that Pack et al. (2014) found that SPCs had difficulty incorporating self-practice into their lives because of their busy schedule. Therefore, SPCs should be encouraged to use different time managements strategies to remain healthy and find the time to include self-practice into their schedule.

Of interest to the current study was that SPCs discussed utilizing goal setting to grow their business. Given numerous graduate students and recent graduates aspire to build their own private practice (Taylor, 2008), this finding seems logical. However, applied sport and exercise psychology programs in North America do not offer business courses to their students. Therefore, SPCs are using goal setting to enhance their business knowledge and skills. For instance, a SPC may set the goal of taking an online business class or create a social media campaign.

SPCs in the current study also mentioned employing psychological skills to better understand the skills. More specifically, this process enabled SPCs to identify the subtle processes behind the psychological skills, believe in them, and gain confidence in their ability to teach them to their clients. This supports the finding of Pack et al. (2014), where SPCs reported using self-practice to gain a deeper understanding of the 
psychological skills they teach to their clients and legitimise their interventions. As a result, SPCs should "practice what they preach" to facilitate client uptake of the psychological skills being taught.

Despite the strengths of the present study, which includes the support of previous research with SPCs and novel findings pertaining to the psychological skills used by SPCs, several limitations should be noted. First, there were only performance enhancement consultants recruited for this study, which may limit the generalizability of the findings. Future researchers should make an effort to recruit licensed psychologists working in the field of sport psychology, given their experiences may be different. Second, the study was conducted during the preparation phase of the PyeongChang 2018 Olympic Winter Games, which could have limited the number of participants in the study, due to scheduling conflicts. Future researchers should avoid recruiting SCPs prior to major international sporting events. Third, only SPCs consulting in Canada and those who obtained their highest degree from a Canadian university were interviewed. Although gaining the perspective from Canadian-based SPCs is extremely valuable, future research should be conducted with SPCs from other countries and with different educational backgrounds. For instance, interviewing SPCs trained in the United States, which may focus more on the applied side of sport psychology, could possibly result in varied or unique findings.

Despite the noted limitations, the current study provides an understanding of what psychological skills SPCs use as well as when, how, and why they use them. Given no empirical study has been conducted specifically to examine the psychological skills employed by SPCs, findings from the present study provide an interesting avenue for 
future research. Knowing what psychological skills are used as well as when, how, and why, a psychological skills training program could be developed to help SPCs improve their consulting. Moreover, the current study includes practical implications that can be utilized by SPCs. SPCs can review the findings from this study to identify which psychological skills they can use to improve their consulting. For example, if SPCs want to refine their service delivery, they can use self-reflection after a session and write down in their case notes what were their strengths, weaknesses, and areas that need to be improved. Finally, the results from this study could serve as a strong argument for the incorporation of self-practice into the curriculum of sport and exercise psychology programs, given the range of benefits that SPCs can potentially experience from the practice of psychological skills (e.g., foster the consultant-client relationship, refine their service delivery, understand the psychological skill, enhance psychological constructs). 


\section{References}

Agnew, M. (1922). The auditory imagery of great composers. Psychological Monographs, 31, 279-287. doi: 10.1037/h0093171

Andersen, M. B. (2000). Introduction. In M. B. Andersen (Ed.), Doing sport psychology (pp. xiii-xvii). Champaign, IL: Human Kinetics.

Andersen, M. B. (2012). Supervision and mindfulness in sport and performance psychology. In S. M. Murphy (Ed.), The Oxford handbook of sport and performance psychology. New York, NY: Oxford University Press.

Anderson, A., Miles, A., Robinson, P., \& Mahoney, C. (2004). Evaluating the athlete's perception of the sport psychologist's effectiveness: What should we be assessing? Psychology of Sport \& Exercise, 5, 255-277. doi: 10.1016/s14690292(03)00005-0

Anton, N. E., Montero, P. N., Howley, L. D., Brown, C., \& Stefanidis, D. (2015). What stress coping strategies are surgeons relying upon during surgery? The American Journal of Surgery, 210, 846-851. doi: 10.1016/j.amjsurg.2015.04.002

Arnold, R., \& Sarkar, M. (2015). Preparing athletes and teams for the Olympic Games: Experiences and lessons learned from the world's best sport psychologists. International Journal of Sport \& Exercise Psychology, 13, 4-20. doi: $10.1080 / 1612197 x .2014 .932827$

Arthur, R. A., Fitzwater, J., Roberts, R., Hardy, J., \& Arthur, C. A. (2017). Psychological skills and "the paras": The indirect effects of psychological skills on endurance. Journal of Applied Sport Psychology, 29, 449-465. doi: 10.1080/10413200.2017.1306728 
Association for Applied Sport Psychology (n.d.). About AASP. Retrieved from http://www.appliedsportpsych.org/about/

Barbour, S., \& Orlick, T. (1999). Mental skills of National Hockey League players. Journal of Excellence, 2, 16-36. Retrieved from http://www.zoneofexcellence.ca/Journal.html

Bennett-Levy, J. (2006). Therapist skills: A cognitive model of their acquisition and refinement. Behavioural and Cognitive Psychotherapy, 34, 57-78. doi: $10.1017 / \mathrm{s} 1352465805002420$

Bennett-Levy, J., Turner, F., Beaty, T., Smith, M., Paterson, B., \& Farmer, S. (2001). The value of self-practice of cognitive therapy techniques and self-reflection in the training of cognitive therapists. Behavioural and Cognitive Psychotherapy, 29, 203-220. doi: 10.1017/s1352465801002077

Boyatzis, R. E. (1998). Transforming qualitative information: Thematic analysis and code development. Thousand Oaks, CA: Sage.

Braun, V., \& Clarke, V. (2006). Using thematic analysis in psychology. Qualitative Research in Psychology, 3, 77-101. doi: 10.1191/1478088706qp063oa

Burke, S., \& Orlick, T. (2003). Mental strategies of elite mount Everest climbers. Journal of Excellence, 8, 42-58. Retrieved from http://www.zoneofexcellence.ca/Journal.html

Canadian Sport Psychology Association (n.d.). CSPA Professional Membership Requirements. Retrieved from https://www.cspa-acps.com/membershiprequirements 
Cecil, S. (2015). A week in the life of an applied sport psychologist. Sport \& Exercise Psychology Review, 11(2), 77-81. Retrieved from http://www.bps.org.uk/publications/member-network-publications/memberpublications/sport-and-exercise-psychology-review

Cotterill, S. (2011). Routes to practising as a sport and exercise psychologist. The Sport and Exercise Scientist, 29(1), 18-19. Retrieved from http://www.bases.org.uk/The-Sport-and-Exercise-Scientist

Cotterill, S. (2012). Experience of working in an elite sports academy: A case study in professional cricket. Sport \& Exercise Psychology Review, 8(1), 45-53. Retrieved from http://www.bps.org.uk/publications/member-network-publications/memberpublications/sport-and-exercise-psychology-review

Cotterill, S. T., \& Symes, R. (2014). Integrating social media and new technologies into your practice as a sport psychology consultant. Sport and Exercise Psychology Review, 10(1), 55-64. Retrieved from http://www.bps.org.uk/publications/member-network-publications/memberpublications/sport-and-exercise-psychology-review

Crewswell, J. W. (2007). Qualitative inquiry and research design: Choosing among five approaches (2nd ed.). Thousand Oaks, CA: Sage.

Cropley, B., Baldock, L., Mellalieu, S. D., Neil, R., Wagstaff, C. D., \& Wadey, R. (2016). Coping with the demands of professional practice: Sport psychology consultants' perspectives. The Sport Psychologist, 30, 290-302. doi: $10.1123 /$ tsp.2015-0125 
Denzin, N. K. (1978). Sociological methods: A sourcebook (2nd ed.). New York: McGraw Hill.

Elsborg, P., Diment, G. M., \& Elbe, A. (2015). Sport psychology consultants' perceptions of their challenges at the London 2012 Olympic Games. The Sport Psychologist, 29, 183-195. doi: 10.1123/tsp.2013-0105

Etherington, K. (2004). Becoming a reflexive researcher: Using our selves in research. London: Jessica Kingsley Publishers.

Fagéus, K. (1999). Love and fear: Personal and artistic development for musicians. Journal of Excellence, 2, 6-10. Retrieved from http://www.zoneofexcellence.ca/Journal.html

Faull, A., \& Cropley, B. (2009). Reflective learning in sport: A case study of a senior level triathlete. Reflective Practice, 10, 325-339. doi:

$10.1080 / 14623940903034655$

Fletcher, D., Rumbold, J. L., Tester, R., \& Coombes, M. S. (2011). Sport psychologists’ experiences of organizational stressors. The Sport Psychologist, 25, 363-381. doi: 10.1123/tsp.25.3.363

Fortin-Guichard, D., Boudreault, V., Gagnon, S., \& Trottier, C. (2017). Experience, effectiveness, and perceptions toward sport psychology consultants: A critical review of peer-reviewed articles. Journal of Applied Sport Psychology. Advance online publication. doi: 10.1080/10413200.2017.1318416

Freitas, S. P., Dias, C. S., \& Fonseca, A. M. (2013a). Elite Portuguese soccer players' use of psychological techniques: Where, when and why. Journal of Human Sport and Exercise, 8, 847-860. doi: 10.4100/jhse.2013.83.10 
Freitas, S., Dias, C., \& Fonseca, A. (2013b). Elite soccer coaches' use of psychological techniques. International Journal of Psychological Studies, 5, 56-70. doi: 10.5539/ijps.v5n3p56

Giges, B., \& Petitpas, A. (2000). Brief contact interventions in sport psychology. The Sport Psychologist, 14, 176-187. doi: 10.1123/tsp.14.2.176

Gould, D., Finch, L. M., \& Jackson, S. A. (1993). Coping strategies used by national champion figure skaters. Research Quarterly for Exercise and Sport, 64, 453-68. doi: 10.1080/02701367.1993.10607599

Hanna, P. (2012). Using internet technologies (such as Skype) as a research medium: A research note. Qualitative Research, 12, 239-242. doi:

$10.1177 / 1468794111426607$

Hatzigeorgiadis, A., Zourbanos, N., Galanis, E., \& Theodorakis, Y. (2011). Self-talk and sports performance: A meta-analysis. Perspectives on Psychological Science, 6, 348-356. doi: 10.1177/1745691611413136

Hohmann, M., \& Orlick, T. (2014). Examining the psychological skills used by elite Canadian military pilots. Journal of Excellence, 16, 4-19. Retrieved from http://www.zoneofexcellence.ca/Journal.html

Holt, A. (2010). Using the telephone for narrative interviewing: A research note. Qualitative Research, 10, 113-121. doi: 10.1177/1468794109348686

Ibrahim, E. F., Richardson, M. D., \& Nestel, D. (2015). Mental imagery and learning: A qualitative study in orthopaedic trauma surgery. Medical Education, 49, 888-900. doi: 10.1111/medu.12759 
Lindsay, P., Breckon, J. D., Thomas, O., \& Maynard, I. W. (2007). In pursuit of congruence: A personal reflection on methods and philosophy in applied practice. The Sport Psychologist, 21, 335-352. doi: 10.1123/tsp.21.3.335

McCann, S. (2008). At the Olympics, everything is a performance issue. International Journal of Sport \& Exercise Psychology, 6, 267-276. doi: $10.1080 / 1612197 x .2008 .9671871$

McCormick, A., \& Meijen, C. (2015). A lesson learned in time: Advice shared by experienced sport psychologists. Sport \& Exercise Psychology Review, 11(1), 4354. Retrieved from http://www.bps.org.uk/publications/member-networkpublications/member-publications/sport-and-exercise-psychology-review

McDougall, M., Nesti, M., \& Richardson, D. (2015). The challenges of sport psychology delivery in elite and professional sport: Reflections from experienced sport psychologists. The Sport Psychologist, 29, 265-277. doi: 10.1123/tsp.2014-0081

Miles, M. B., \& Huberman, A. M. (1990). Animadversions and reflection on the uses of qualitative inquiry. In E. W. Eisner \& A. Peshkin (Eds.), Qualitative inquiry in education: The continuing debate (pp. 339-357). New York: Teachers College Press.

Moyle, G. M. (2015). Skating on Olympic ice: Working with winter Olympians. International Journal of Sport \& Exercise Psychology, 13, 56-73. doi: $10.1080 / 1612197 x .2014 .995203$

Munroe, K. J., Giacobbi, P. R., Hall, C., \& Weinberg, R. (2000). The four Ws of imagery use: Where, when, why, and what. The Sport Psychologist, 14, 119-137. doi: 10.1123/tsp.14.2.119 
Murphy, T., \& Orlick, T. (2006). Mental strategies of professional actors. Journal of Excellence, 11, 103-125. Retrieved from http://www.zoneofexcellence.ca/Journal.html

Neff, F. (1990). Delivering sport psychology services to a professional sport organization. The Sport Psychologist, 4, 378-385. doi: 10.1123/tsp.4.4.378

Nordin, S. M., \& Cumming, J. (2005). Professional dancers describe their imagery: Where, when, what, why, and how. The Sport Psychologist, 19, 395-416. doi: 10.1123/tsp.19.4.395

Pack, S., Hemmings, B., \& Arvinen-Barrow, M. (2014). The self-practice of sport psychologists: Do they practice what they preach? The Sport Psychologist, 28, 198-210. doi: 10.1123/ijsnem.2012-0085

Park, J.-K. (2000). Coping strategies used by Korean national athletes. The Sport Psychologist, 14, 63-80. doi: 10.1123/tsp.14.1.63

Partington, J., \& Orlick, T. (1991). An analysis of Olympic sport psychology consultants' best-ever consulting experiences. The Sport Psychologist, 5, 183-193. doi: $10.1123 /$ tsp.5.2.183

Petitpas, A. J., Giges, B., \& Danish, S. J. (1999). The sport psychologist-athlete relationship: Implications for training. The Sport Psychologist, 13, 344-357. doi: 10.1123/tsp.13.3.344

Pirie, J. G. (1998). A TV show host's performance: An exploratory study. Journal of Excellence, 1, 50-60. Retrieved from http://www.zoneofexcellence.ca/Journal.html 
Poczwardowski, A., \& Sherman, C. P. (2011). Revisions to the sport psychology service delivery (SPSD) heuristic: Explorations with experienced consultants. The Sport Psychologist, 25, 511-531. doi: 10.1123/tsp.25.4.511

Poczwardowski, A., Sherman, C. P., \& Henschen, K. P. (1998). A sport psychology service delivery heuristic: Building on theory and practice. The Sport Psychologist, 12, 191-207. doi: 10.1123/tsp.12.2.191

Portenga, S. T., Aoyagi, M. W., \& Cohen, A. B. (2017). Helping to build a profession: A working definition of sport and performance psychology. Journal of Sport Psychology in Action, 8, 47-59. doi: 10.1080/21520704.2016.1227413

Pusenjak, N., Grad, A., Tusak, M., Leskovsek, M., \& Schwarzlin, R. (2015). Can biofeedback training of psychophysiological responses enhance athletes' sport performance? A practitioner's perspective. The Physician and Sportsmedicine, 43, 287-99. doi: 10.1080/00913847.2015.1069169

Rubin, H. J., \& Rubin, I. S. (2012). Qualitative interviewing: The art of hearing data (3rd ed.). Thousand Oaks, CA: Sage.

Sharp, L., \& Hodge, K. (2013). Effective sport psychology consulting relationships: Two coach case studies. The Sport Psychologist, 27, 313-324. doi: $10.1123 /$ tsp.27.4.313

Sheard, M., \& Golby, J. (2006). Effect of a psychological skills training program on swimming performance and positive psychological development. International Journal of Sport \& Exercise Psychology, 4, 149-169. doi:

$10.1080 / 1612197 x .2006 .9671790$ 
Simons, J. P., \& Andersen, M. B. (1995). The development of consulting practice in applied sport psychology: Some personal perspectives. The Sport Psychologist, 9, 449-468. doi: 10.1123/tsp.9.4.449

Smith, B., \& Sparkes, A. C. (2016). Interviews: Qualitative interviewing in the sport and exercise sciences. In B. Smith \& A. C. Sparkes (Eds.), Routledge handbook of qualitative research in sport and exercise (pp. 103-123). New York: Routledge.

Sparkes, A. C., \& Smith, B. (2014). Qualitative research methods in sport, exercise and health: From process to product. New York: Routledge.

Sprung, H. (1995). An exploration of mental strategies of astronauts (Master's thesis). Retrieved from https://www.ruor.uottawa.ca

Stambulova, N., \& Johnson, U. (2010). Novice consultants' experiences: Lessons learned by applied sport psychology students. Psychology of Sport \& Exercise, 11, 295303. doi: 10.1016/j.psychsport.2010.02.009

Steptoe, A. (1989). Stress, coping and stage fright in professional musicians. Psychology of Music, 17, 3-11. doi: 10.1177/0305735689171001

Straub, W. F., \& Hinman, D. A. (1992). Profiles and professional perspectives of 10 leading sport psychologists. The Sport Psychologist, 6, 297-312. doi: $10.1123 /$ tsp.6.3.297

Symes, R. (2014). From cricket to cage fighting: A week in the life of a sport psychologist. Sport \& Exercise Psychology Review, 10(1), 78-90. Retrieved from http://www.bps.org.uk/publications/member-network-publications/memberpublications/sport-and-exercise-psychology-review 
Taylor, J. (2008). Prepare to succeed: Private consulting in applied sport psychology. Journal of Clinical Sport Psychology, 2, 160-177. doi: 10.1123/jcsp.2.2.160

Thelwell, R. C., \& Greenlees, I. A. (2001). The effects of a mental skills training package on gymnasium triathlon performance. The Sport Psychologist, 15, 127-141. doi: $10.1123 /$ tsp.15.2.127

Thelwell, R. C., Weston, N. J. V., Greenlees, I. A., \& Hutchings, N. V. (2008). A qualitative exploration of psychological-skills use in coaches. The Sport Psychologist, 22, 38-53. doi: 10.1123/tsp.22.1.38

Tod, D., Andersen, M. B., \& Marchant, D. B. (2011). Six years up: Applied sport psychologists surviving (and thriving) after graduation. Journal of Applied Sport Psychology, 23, 93-109. doi: 10.1080/10413200.2010.534543

Tod, D., Marchant, D., \& Andersen, M. B. (2007). Learning experiences contributing to service-delivery competence. The Sport Psychologist, 21, 317-334. doi: 10.1123/tsp.21.3.317

Tracy, S. (2010). Qualitative quality: Eight "big-tent" criteria for excellent qualitative research. Qualitative Inquiry, 16, 837-851. doi: 10.1177/1077800410383121

Weinberg, R. S., \& Gould, D. (2015). Foundations of sport and exercise psychology (6th ed.). Champaign, IL: Human Kinetics.

Weinberg, R., \& McDermott, M. (2002). A comparative analysis of sport and business organizations: Factors perceived critical for organizational success. Journal of Applied Sport Psychology, 14, 282-298. doi: 10.1080/10413200290103563 
Woodcock, C., Richards, H., \& Mugford, A. (2008). Quality counts: Critical features for neophyte professional development. The Sport Psychologist, 22, 491-506. doi: $10.1123 /$ tsp. 22.4 .491

Zizzi, S. J., \& Andersen, M. B. (2010). An Eastern philosophical approach. In S. J. Hanrahan \& M. B. Andersen (Eds.), Routledge handbook of applied sport psychology: A comprehensive guide for students and practitioners (pp. 194-202). London, UK: Routledge. 


\section{TABLE}

Table 1

Participant Characteristics and Consulting Details

\begin{tabular}{ccccccccc}
\hline $\begin{array}{c}\text { Participant } \\
\text { Number }\end{array}$ & Age & Gender & Education & Title & $\begin{array}{c}\text { Years of } \\
\text { Experience }\end{array}$ & Status & Fee & Sports \\
\hline SPC1 & 47 & Female & PhD & PEC & 23 & Full-time & Paid & Variety \\
SPC2 & 47 & Female & PhD & PEC & 9 & Part-time & Paid & Variety \\
SPC3 & 35 & Male & PhD & PEC & 10 & Part-time & Paid & Variety \\
SPC4 & 30 & Male & Masters & PEC & 5 & Part-time & Paid & Variety \\
SPC5 & 38 & Female & Masters & PEC & 5 & Part-time & Paid & Variety \\
SPC6 & 34 & Female & PhD & PEC & 10 & Part-time & Paid & Variety \\
SPC7 & 39 & Male & PhD & PEC & 18 & Part-time & Paid & Variety \\
SPC8 & 29 & Female & Masters & PEC & 4 & Part-time & Paid & Variety \\
\hline
\end{tabular}




\section{FIGURES}

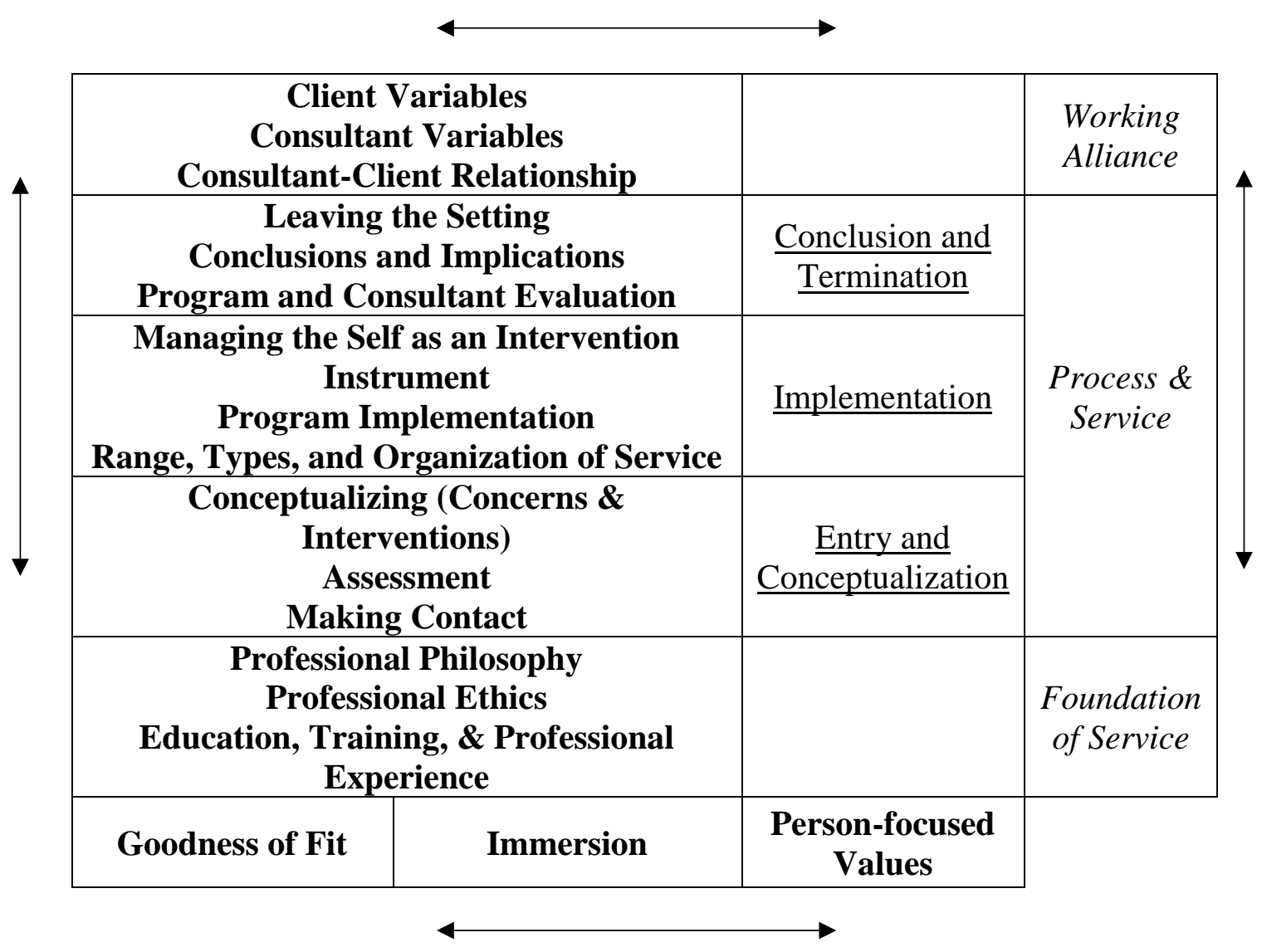

Figure 1. Revised sport psychology service delivery heuristic. Adapted from "Revisions to the Sport Psychology Service Delivery (SPSD) Heuristic: Explorations with Experienced Consultants," by A. Poczwardowski and C. P. Sherman, 2011, The Sport Psychologist, 25, p. 528. 


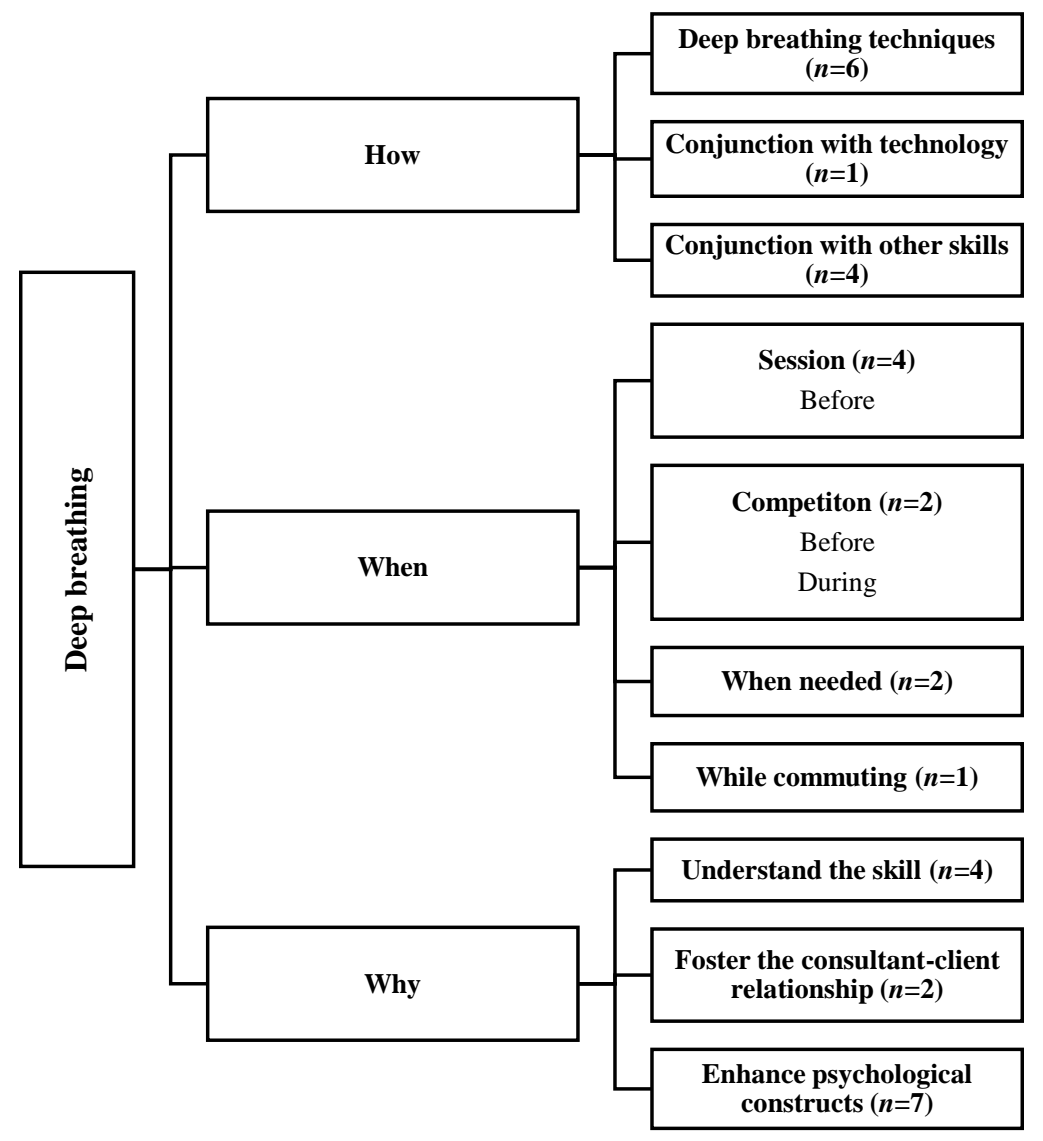

Figure 2. Framework of SPCs' Use of Deep Breathing.

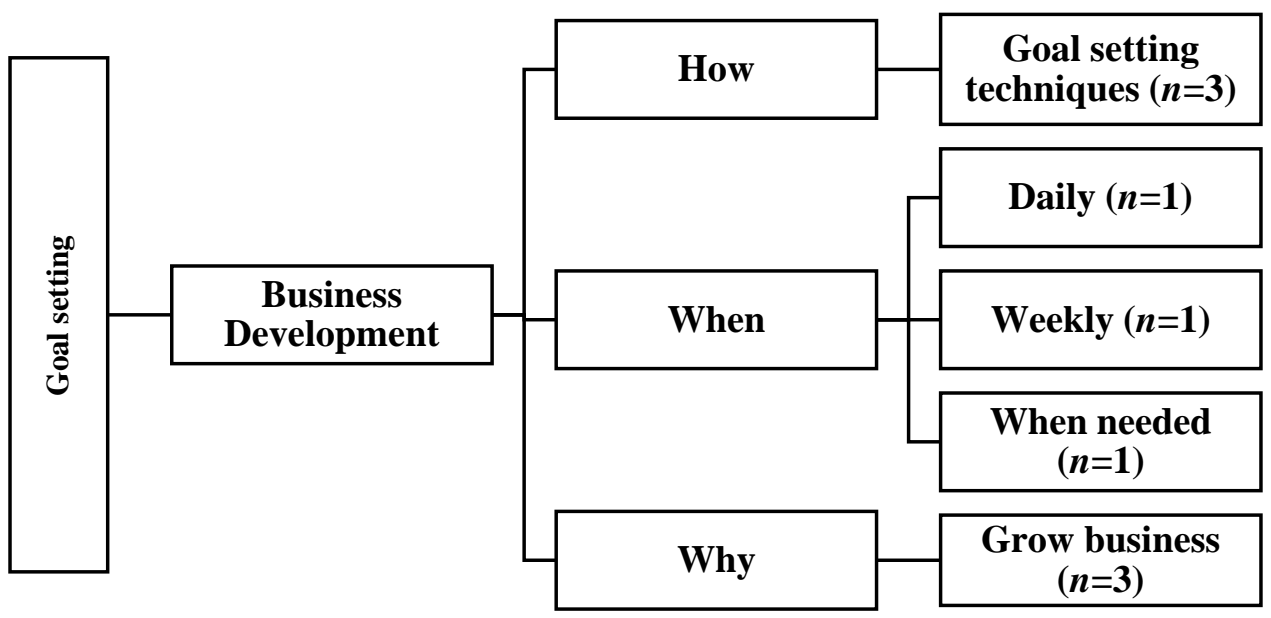

Figure 3a. Framework of SPCs' Use of Goal Setting for Business Development. 


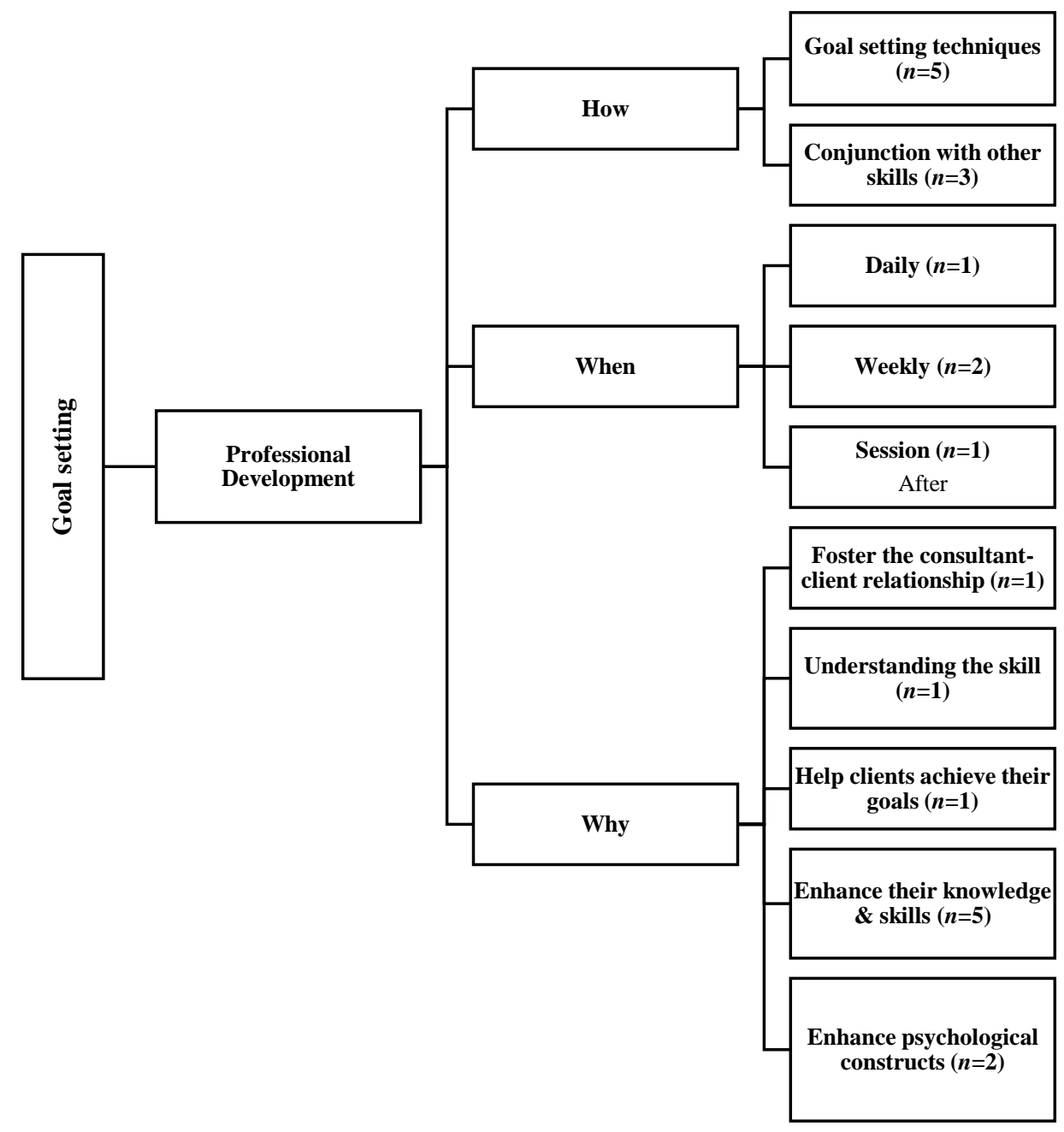

Figure 3b. Framework of SPCs' Use of Goal Setting for Professional Development. 


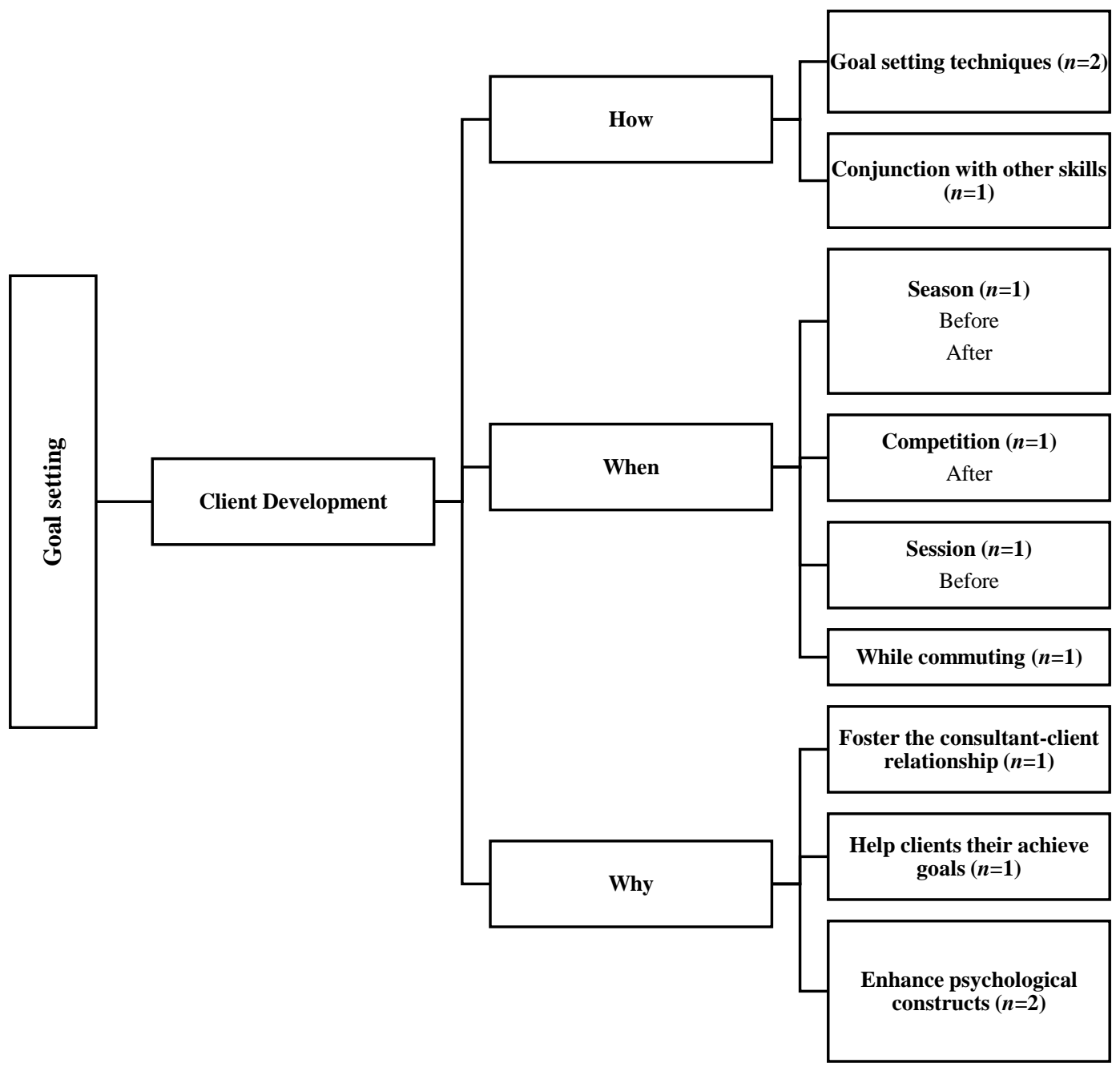

Figure 3c. Framework of SPCs' Use of Goal Setting for Client Development. 


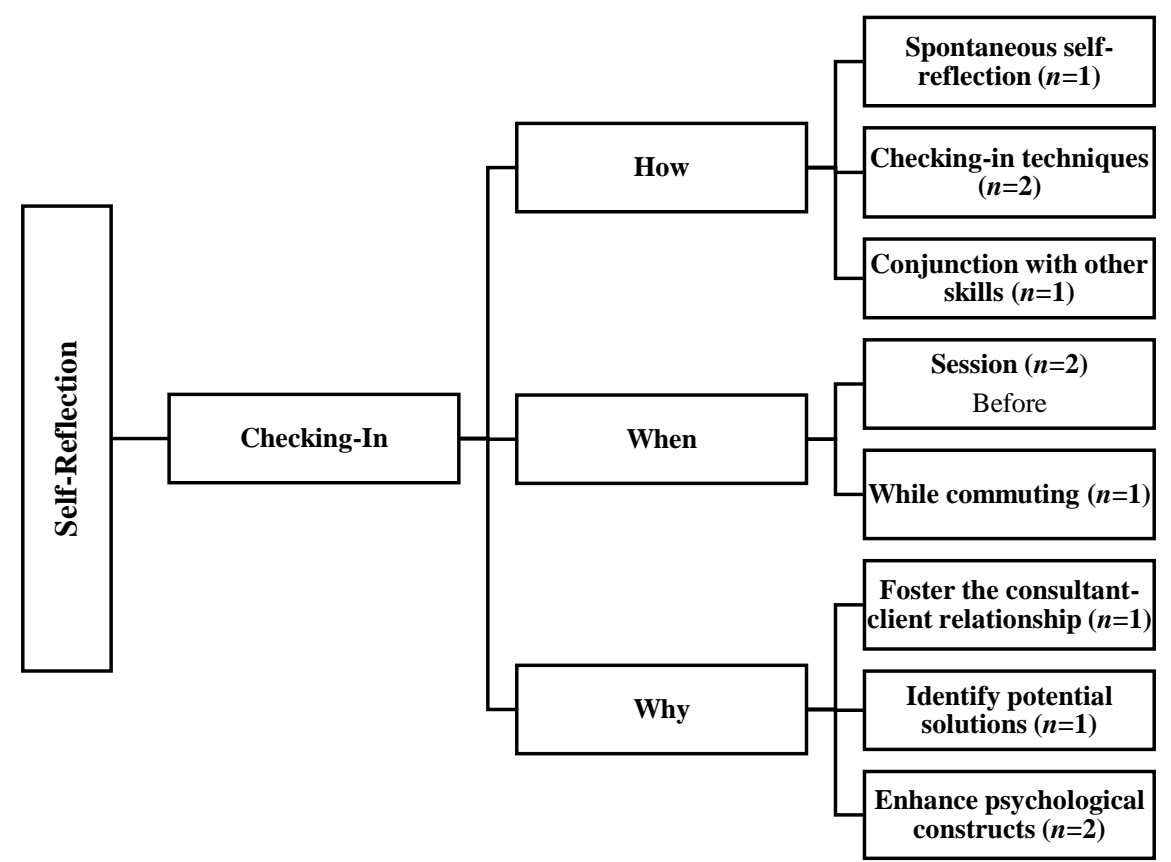

Figure 4a. Framework of SPCs' Use of Self-Reflection for Checking-In.

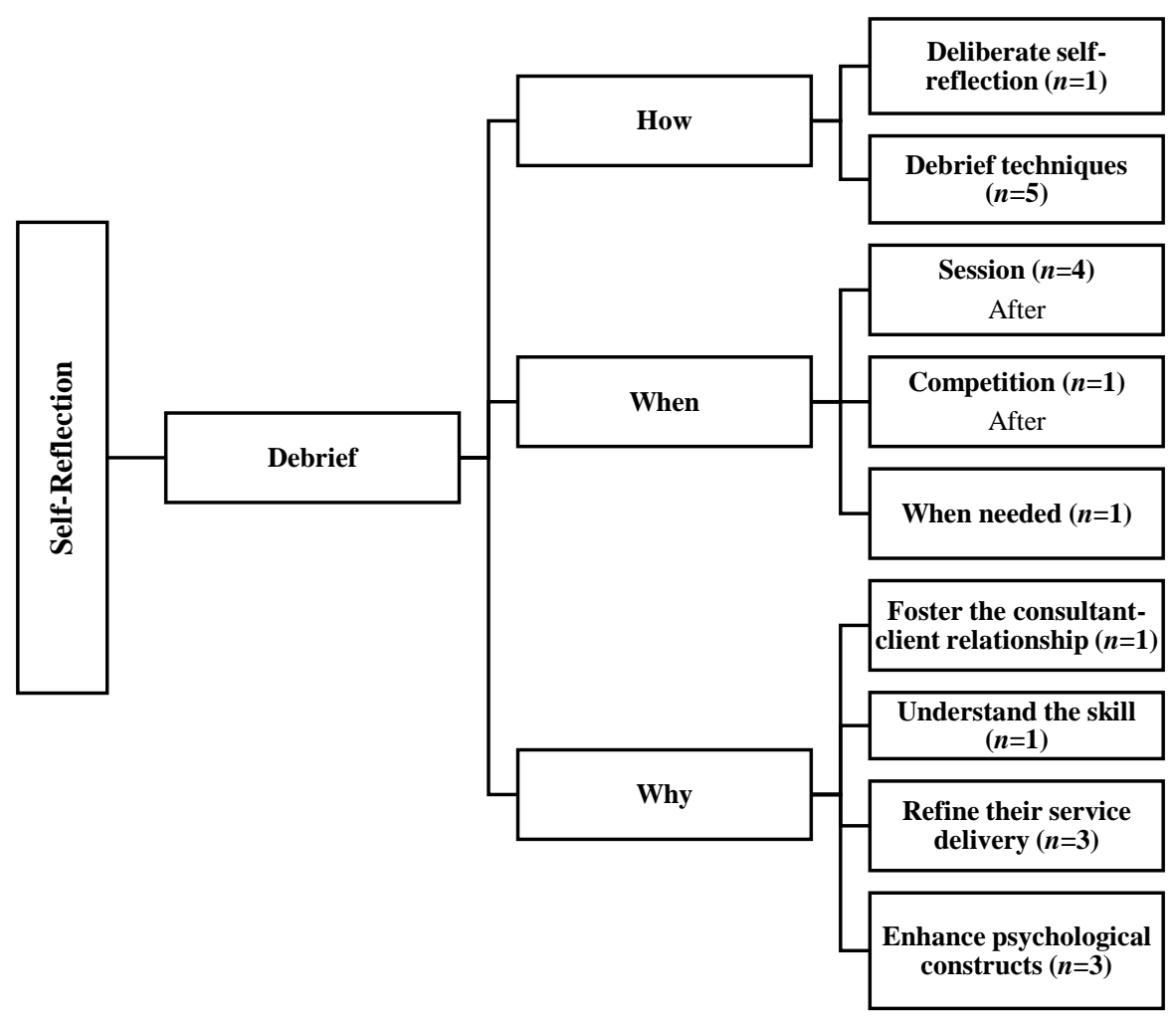

Figure 4b. Framework of SPCs' Use of Self-Reflection for Debriefing. 


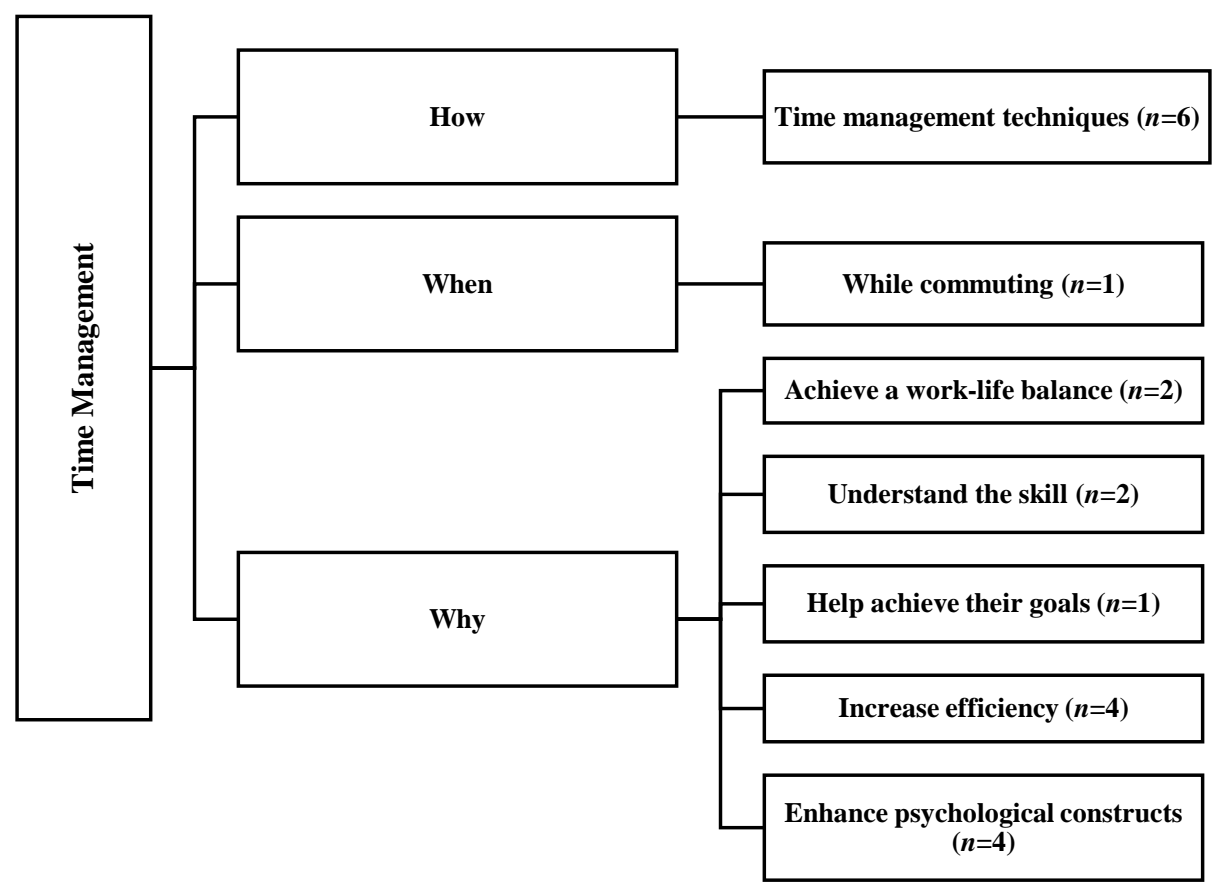

Figure 5. Framework of SPCs' Use of Time Management.

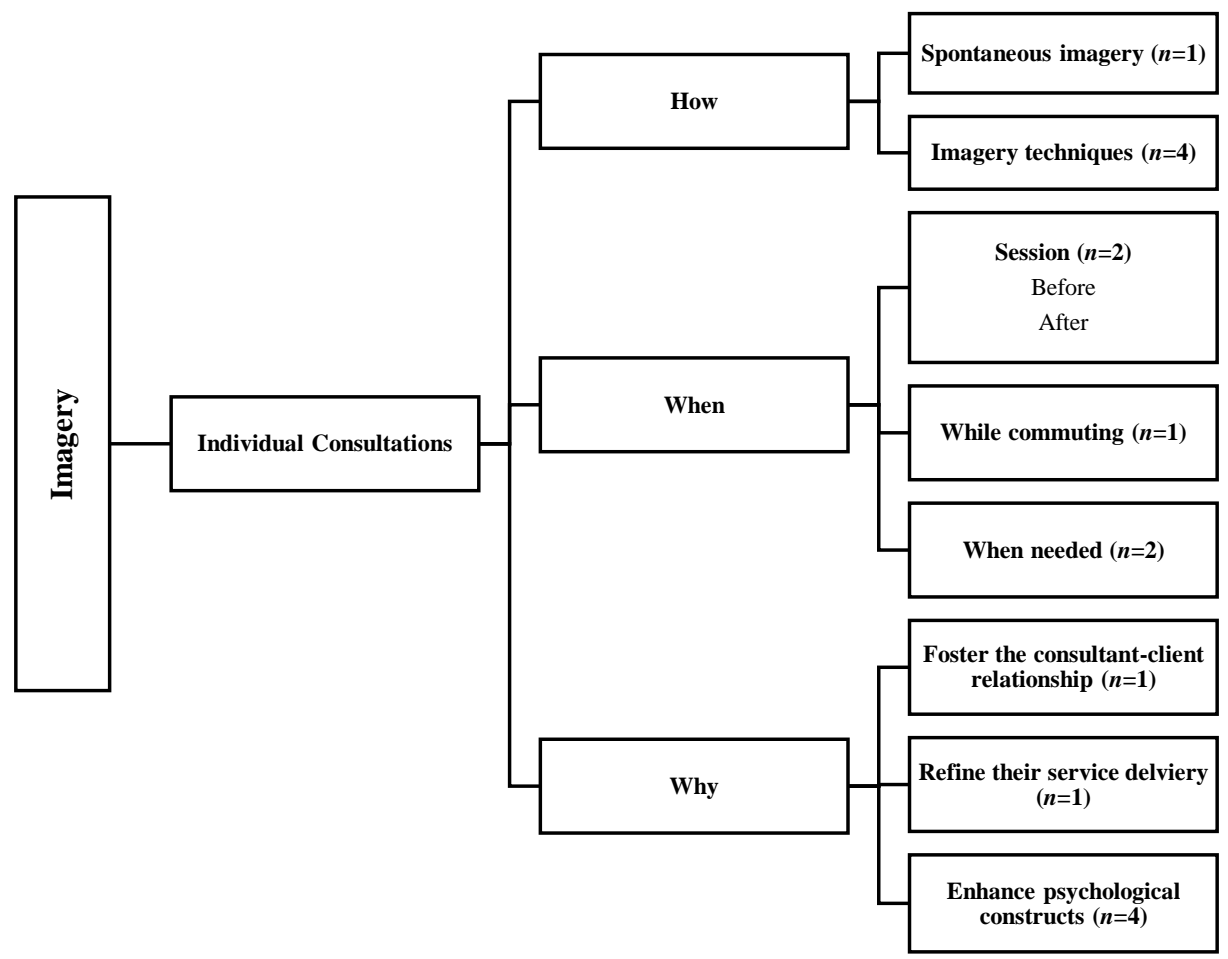

Figure 6a. Framework of SPCs' Use of Imagery for Individual Consultations. 


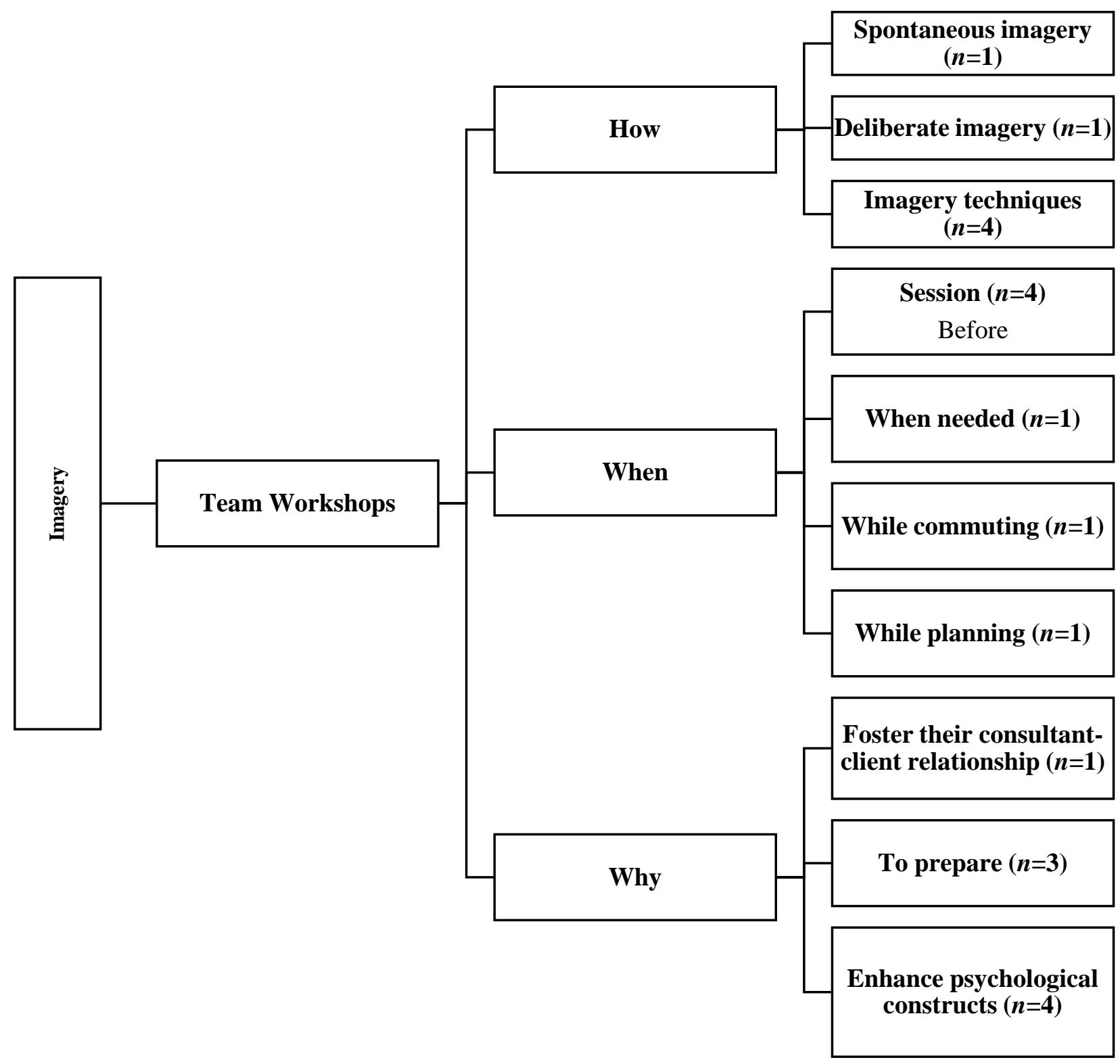

Figure $6 b$. Framework of SPCs' Use of Imagery for Team Workshops. 


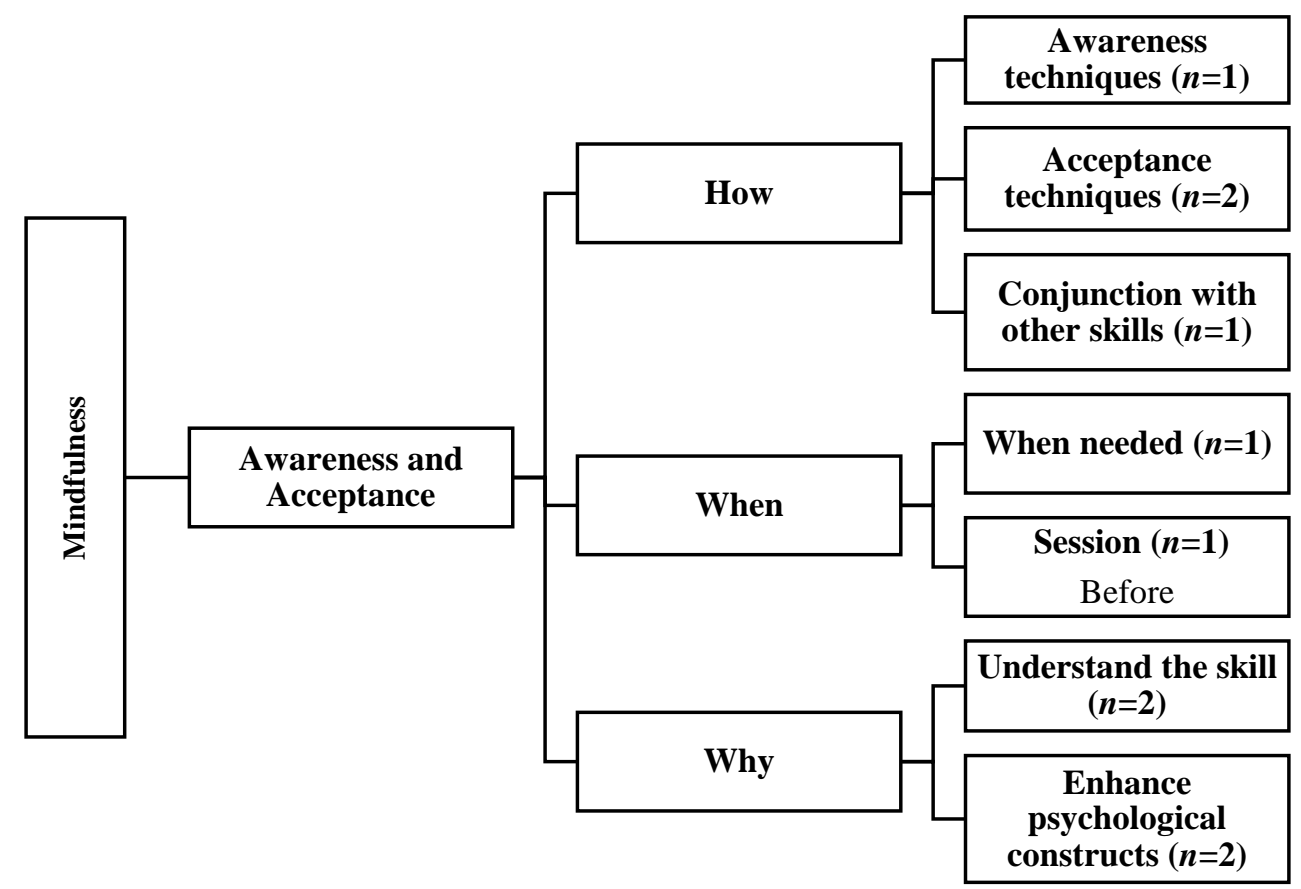

Figure 7a. Framework of SPCs' Use of Mindful Awareness and Acceptance.

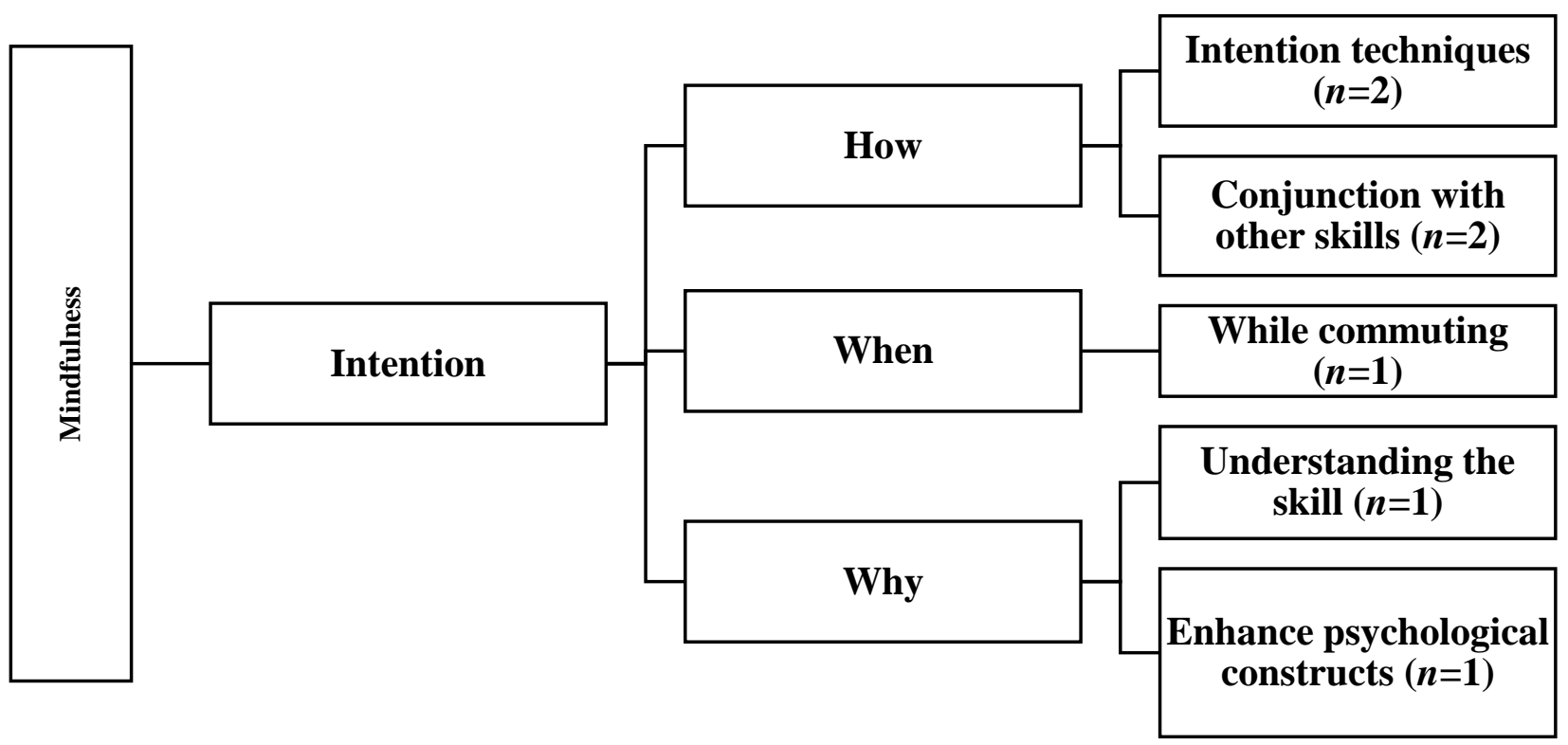

Figure 7b. Framework of SPCs' Use of Mindful Intention. 


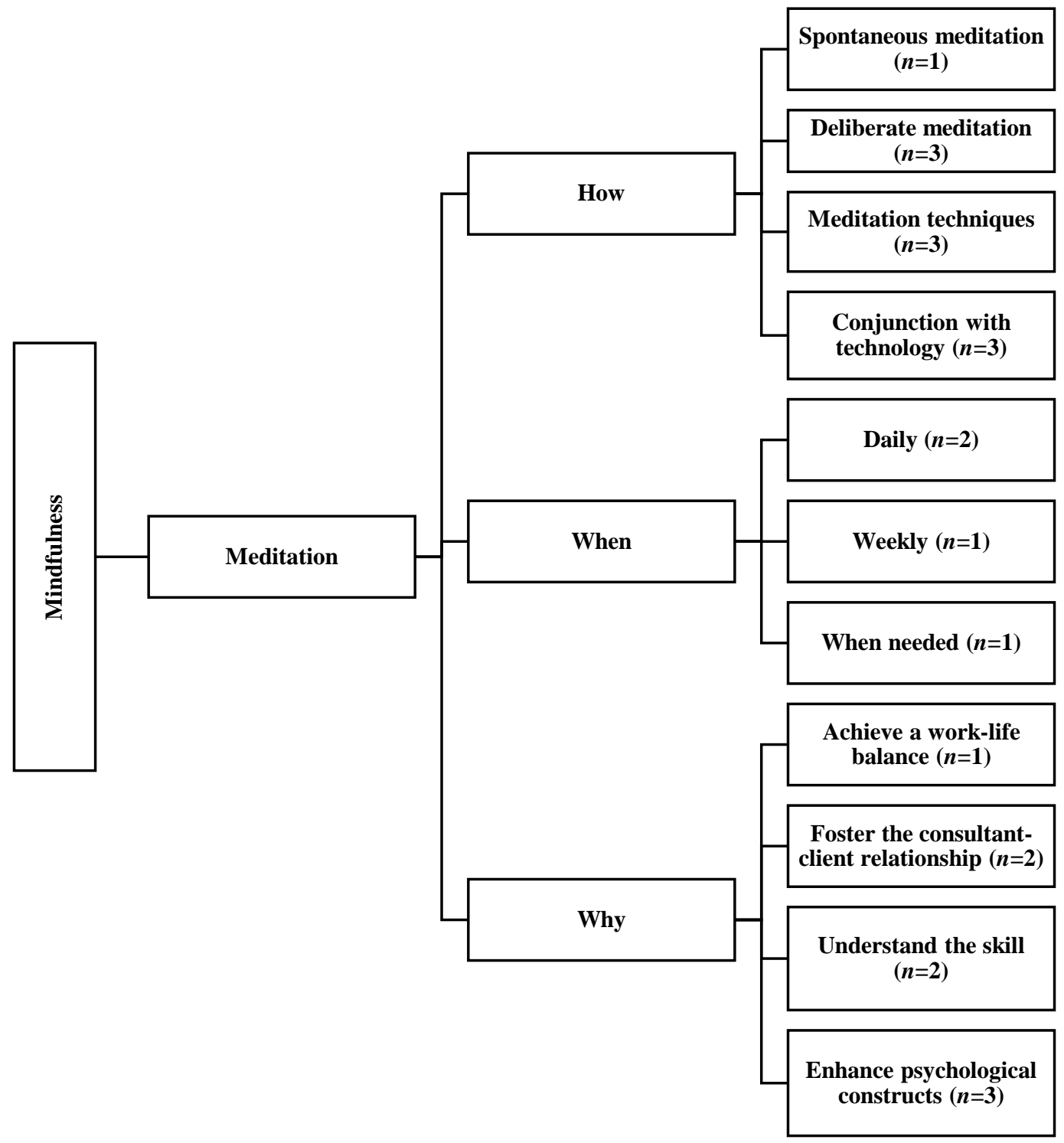

Figure 7c. Framework of SPCs' Use of Mindful Meditation. 


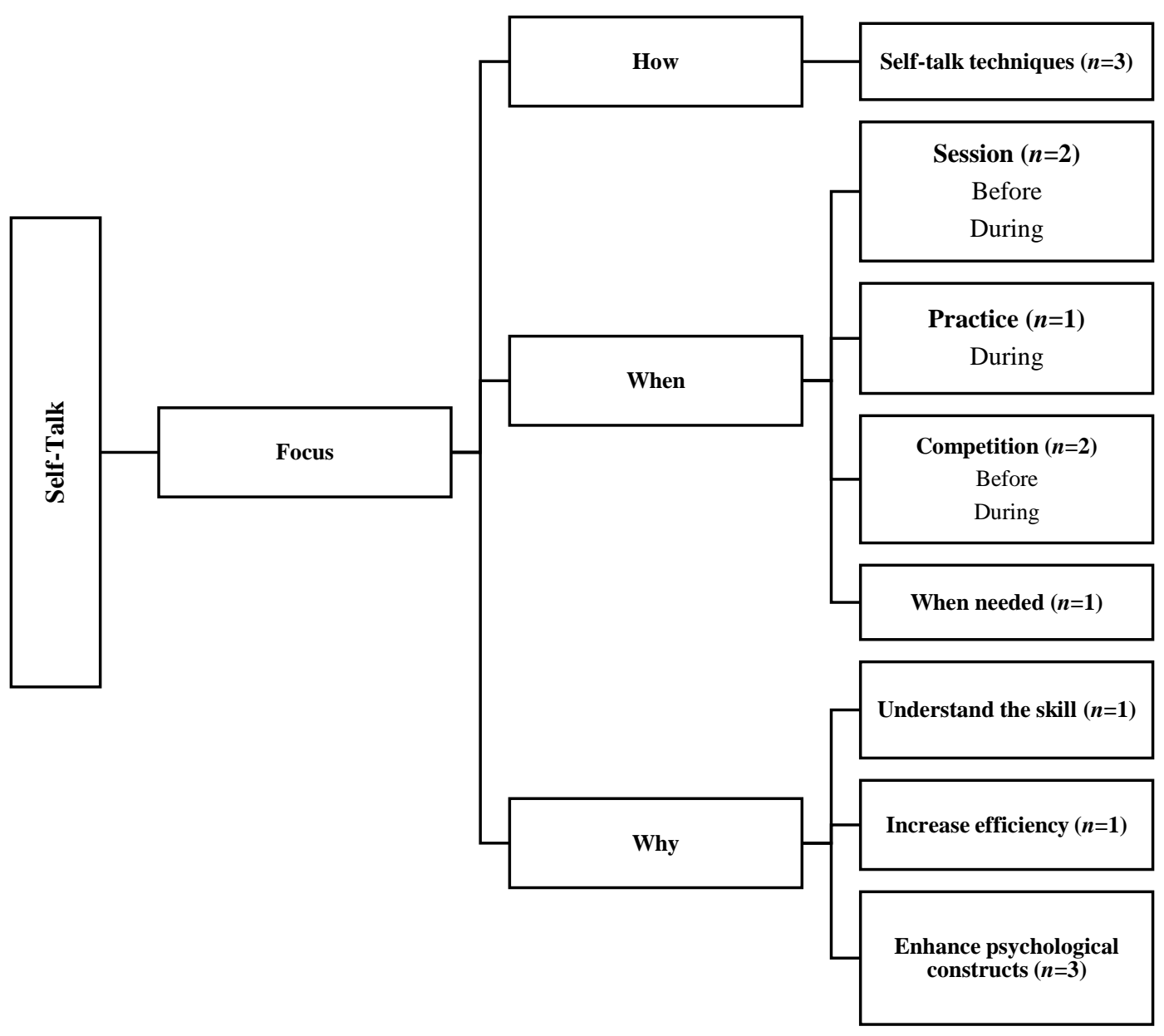

Figure 8a. Framework of SPCs' Use of Self-Talk for Focus.

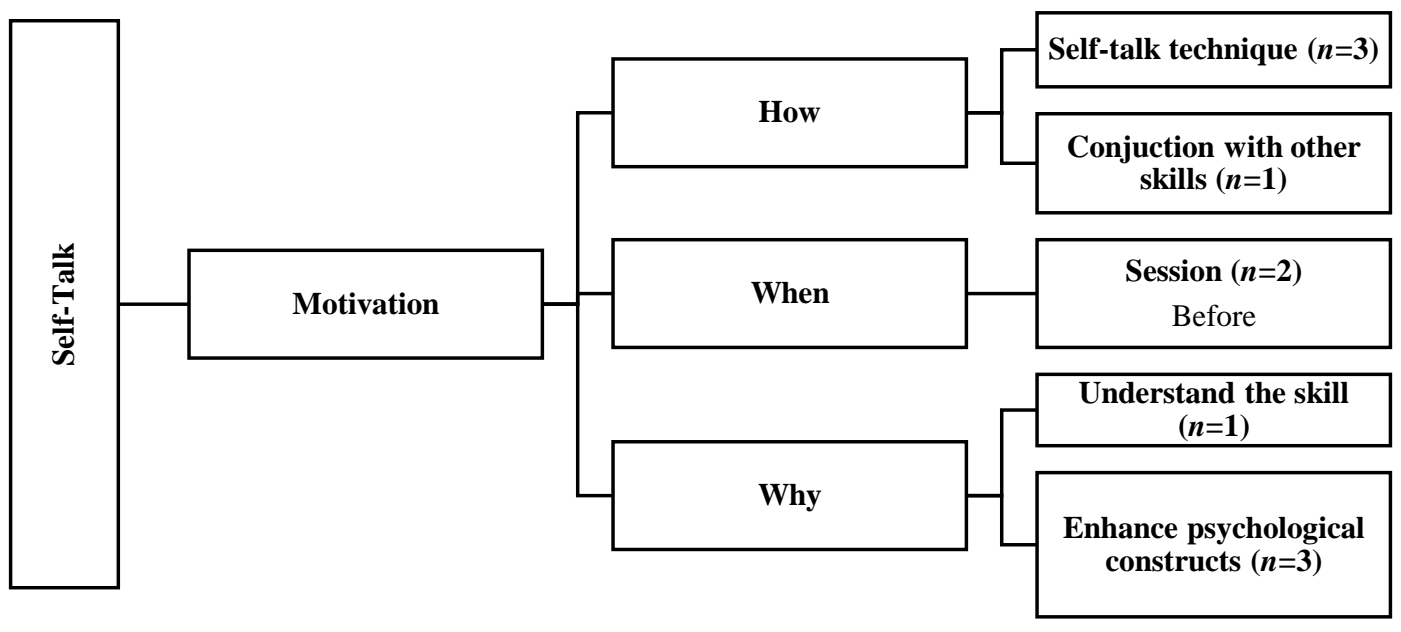

Figure $8 b$. Framework of SPCs' Use of Self-Talk for Motivation. 


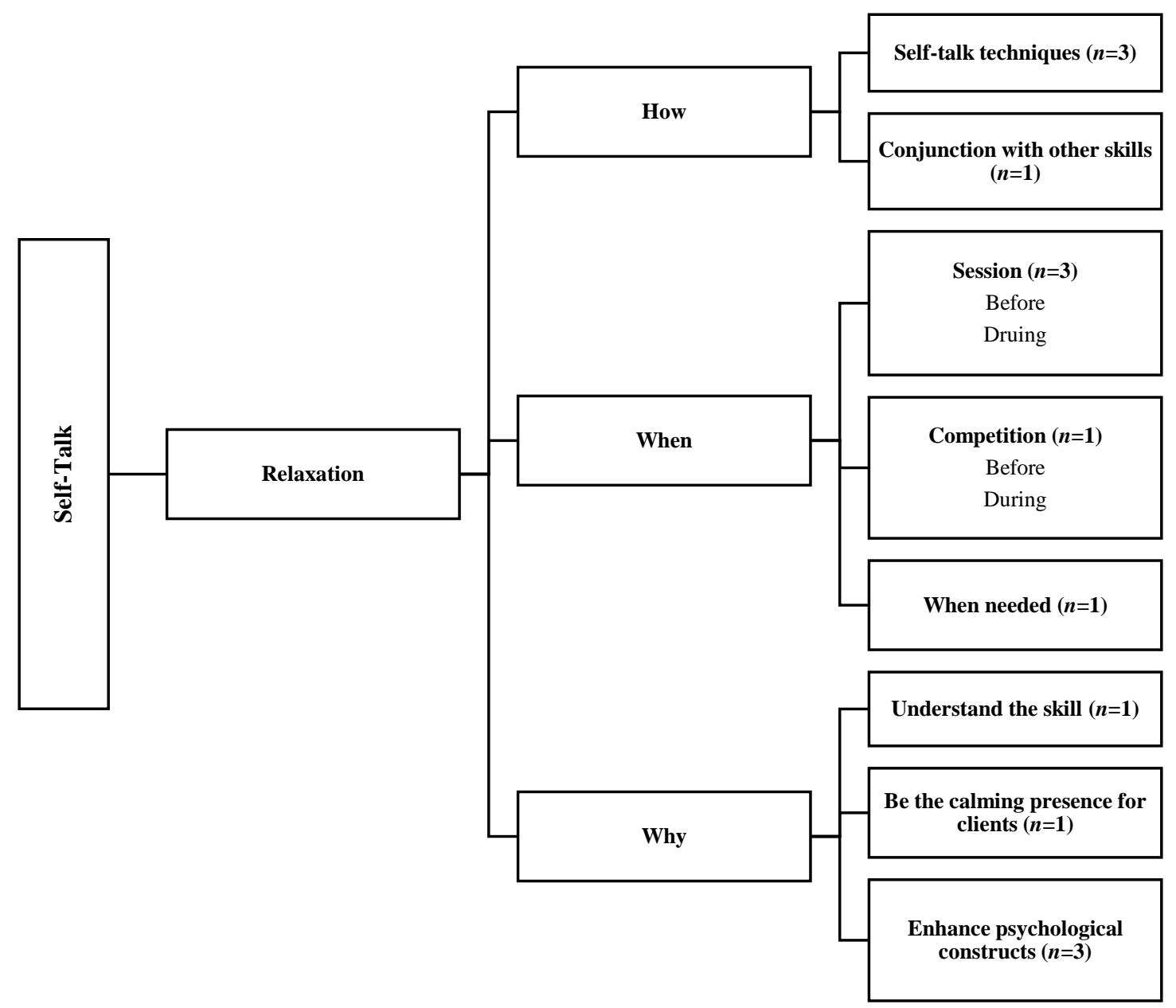

Figure $8 c$. Framework of SPCs' Use of Self-Talk for Relaxation.

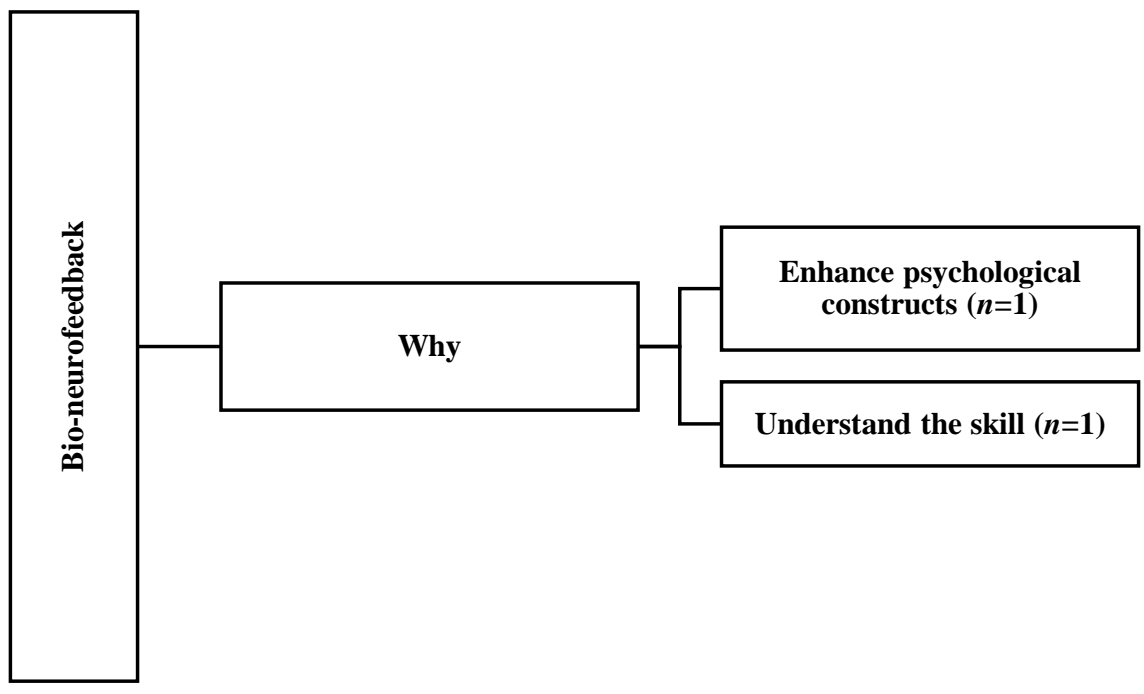

Figure 9. Framework of SPCs' Use of Bio-Neurofeedback. 


\section{REVIEW OF LITERATURE}

\section{Introduction}

The overall purpose of this study is to examine the psychological skills used by sport psychology consultants to improve their consulting. The review of literature is divided into six sections (a) applied sport psychology, (b) services provided by sport psychology consultants, (c) sport psychology service delivery heuristic, (d) managing the self as an intervention instrument, (e) psychological skills used by other performers, and (f) research with sport psychology consultants.

\section{Applied Sport Psychology}

Applied sport psychology can be defined as "the application of psychological principles of human performance in helping athletes consistently perform in the upper range of their capabilities and more thoroughly enjoy the sport performance process" (Portenga, Aoyagi, \& Cohen, 2017, p. 52). According to the Association for Applied Sport Psychology (AASP), applied sport psychology can be delivered by both psychologists and performance enhancement consultants. Although each can provide individual and group consultations, psychologists are trained in clinical and counseling psychology and licensed by their respective regulatory body, whereas performance enhancement consultants are only trained in sport and exercise sciences (AASP, n.d.). The title sport psychology consultant (SPC) will be used throughout this review of literature to encompass psychologists and performance enhancement consultants.

In Canada, the organization devoted to applied sport psychology is the Canadian Sport Psychology Association. Professional members must abide by a code of ethics and meet the following criteria: (a) at a minimum, a Master's degree in sport psychology or 
related field, (b) a demonstrated understanding of foundational disciplines such as human kinetics or kinesiology, psychology, and counselling, (c) extensive consulting experience, (d) hands on experience in sport, and (e) favourable supervisor and client evaluations (CSPA, n.d.). In the United States, the AASP, which is the largest organization dedicated to the promotion of applied sport psychology in the country, offers certification to qualified members with a graduate degree that have completed the required sport psychology courses, a certification exam, and a supervised field experience (AASP, n.d.). In the United Kingdom, individuals with training in mainstream psychology are advised to get certified by the British Psychological Society, whereas individuals with training in sport and exercise sciences are encouraged to fulfill the requirements of the British Association of Sport and Exercise Sciences (BASES, n.d.). In Australia, an individual interested in providing psychological services to athletes and coaches under the Australian Institute of Sport must first become a licensed psychologist and then complete a graduate degree in sport and exercise psychology accredited by the Australian Psychological Association (AIS, n.d.).

Most consultations done by SPCs with clients are short, practical (Giges \& Petitpas, 2000), and occur in a variety of settings (Andersen, 2000). Apart from the SPC's office, they can occur in the bus, cafeteria, locker room, training and competition venues, (McCann, 2008), parking lot, or hotel lobby (McCann, 2000). Furthermore, SPCs consult with athletes and coaches during training sessions and competitions (Dorfman, 1990; Halliwell, 1990; Sharp \& Hodge, 2011). Their main objective is to help athletes get better at what they do (Andersen, 2000). Empirical studies have consistently demonstrated that teaching psychological skills to athletes can significantly increase their sport performance 
(Driskell, Copper, \& Moran, 1994; Hatzigeorgiadis, Zourbanos, Galanis, \& Theodorakis, 2011; Meyers, Whelan, \& Murphy, 1996; Sheard \& Golby, 2006).

\section{Psychological Skills Provided by Sport Psychology Consultants}

Recently, some researchers have argued that a psychological skill, which does not have an agreed upon definition in the sport and exercise psychology literature, should refer to a technique that can be practiced (e.g., goal setting, imagery) or an indicator of the level of ability (e.g., arousal regulation, attentional control), as opposed to a psychological quality (e.g., confidence, commitment; Arthur, Fitzwater, Roberts, Hardy, $\&$ Arthur, 2017). The goal of any psychological skills training program is to help athletes systematically and consistently practice mental or psychological skills for the purpose of enhancing performance, increasing enjoyment, or achieving greater sport and physical activity self-satisfaction (Weinberg \& Gould, 2015). The following subsections will provide a very brief description of the most common psychological skills used in applied sport psychology (AASP, n.d.). A psychological skills training program will often include a combination of these psychological skills.

Arousal regulation. Arousal is defined as the body's physiological and psychological energy levels that range from deep sleep to frenzy (Gould, Greenleaf, \& Krane, 2002). Because the optimal level of arousal is different for everyone, an athlete will need to find ways to increase or decrease it prior to competition. Several strategies proven to reduce arousal include: (a) deep breathing, (b) progressive relaxation (systematic tensing and relaxing of muscles), (c) meditation (focusing on the breath), (d) autogenic training (focusing on feelings of warmth, heaviness, and relaxation in the limbs and muscles of the body), and (e) biofeedback (using information from body signals to 
understand how your body responds to different situations). Moreover, there are many strategies to increase arousal which include: (a) pep talks, (b) bulletin boards, (c) precompetitive workouts, (d) verbal cues, (e) rapid breathing, (f) imagery, and (g) music (Munroe-Chandler \& Hall, 2016). Researchers have suggested that arousal regulation may be as important to athletes as technical or tactical skills (Jensen, Roman, Shaft, \& Wrisberg, 2013).

Attentional control. Attention is defined as the process of concentrating on specific thoughts, activities, or cues in the environment (Goldstein, 2008). Attention can vary in terms of its width and direction. On the one hand, attentional width can either be broad or narrow, such as golfers focusing only on the hole in front of them (narrow) or on the entire green and cheering crowd behind it (broad). On the other hand, attentional direction can either be internal, such as golfers focusing on the tension in their shoulders before a putt, or external, such as focusing on the golf ball (Nideffer, 1976). A variety of strategies are available for controlling attention, including: (a) attention simulation training (replicating relevant attention-demanding situations in your practice sessions), (b) performance routines (developing a sequence of thoughts and actions that will be implemented before the performance of a specific skill), (c) attentional cues (using words or statements to direct one's attention to a specific component of the task), and (d) imagery (Munroe-Chandler \& Hall, 2016). Abernethy (2001) noted that attention is an essential component of optimal motor performance.

Communication. Communication is the process whereby people try to understand others and be understood by them (Anderson, 1959). Interactions in a team can occur between coach-team, coach-athlete, athlete-coach, and athlete-athlete (Harris \& 
Harris, 1984). Common strategies to improve communication include: (a) assertiveness training (expressing yourself honestly), (b) active listening (being concerned about the content discussed), and (c) showing empathy (putting yourself in the other person's shoes; Yukelson, 2006). Effective communication occurs when group members listen attentively to one another and use each other's strengths (Sullivan, 1993).

Goal setting. Goal setting involves identifying specific and desirable objectives that are designed to guide one's actions. Athletes can set three types of goals. Outcome goals focus on the results of a competition such as winning a gold medal at the next Olympic Games. Performance goals focus on surpassing a personal performance standard such as running the first 50 meters of the race in less than six seconds. Process goals focus on the execution of specific actions during a performance such as bringing the knees high up during a sprint (Munroe-Chandler \& Hall, 2016). Researchers have suggested that athletes should set all three types of goals to enhance performance (Filby, Maynard, \& Graydon, 1999).

Imagery. Imagery is defined as the creation or re-creation of an image in your mind that represents a real experience (White \& Hardy, 1998). Athletes use five types of imagery. Cognitive specific imagery refers to imaging the execution of specific skills such as a free-throw in basketball. Cognitive general imagery involves imaging strategies or sequences of movements such as a "fast break". Motivational specific imagery pertains to imaging the achievement of a goal such as winning the game's most valuable player. Motivational general-arousal refers to using imagery to decrease anxiety or increase energy levels. Motivational general-mastery involves imaging oneself being confident 
and in control (Hall, Mack, Paivio, \& Hausenblas, 1998). Imagery can impact an athlete's behavioural, cognitive, and affective outcomes (Munroe-Chandler \& Morris, 2011).

Self-talk. Self-talk refers to the overt or covert dialogue that athletes have with themselves, which is multidimensional and dynamic in nature, includes an element of personal interpretation, and serves instructional and/or motivational functions (Hardy, 2006). Instructional self-talk involves statements that athletes use to improve their skill execution (Hardy, Gammage, \& Hall, 2001). For example, when performing a squat, athletes can tell themselves, "straight back". Motivational self-talk refers to statements that athletes use for mastery, arousal regulation, and increasing their drive (Hardy, Hall, \& Alexander, 2001). For instance, at the end of a race, an athlete can yell out, "I can do it". In terms of dimensions, self-talk can be positive or negative, overt or covert, assigned or freely chosen, motivating or demotivating, not intense or very intense, and occur often or never (Hardy, 2006). Compared to unsuccessful athletes, successful athletes use more instructional self-talk, during competition, and engage in more positive self-talk, prior to competition (Highlen \& Bennett, 1983).

Team building. Team building is a strategy designed to improve the functioning of a team by developing and implementing specific action plans that use group dynamics principles to increase cohesion (Spink, 2016). Cohesion refers to the tendency for a group to remain unified in the pursuit of its goals and/or to satisfy the needs of its members (Carron, Brawley, \& Widmeyer, 1998). Cohesion can be increased by implementing action plans that target one or multiple group factors present in the team environment (e.g., distinctiveness, togetherness), team structure (e.g., role clarity, leadership, group norms), or team processes (e.g. sacrifices, goals and objectives, cooperation; Carron \& 
Spink, 1993). For example, a SPC can get basketball players to wear all the same colored laces to make the team more distinct and increase their levels of cohesion. Team building programs targeting one group factor at a time can have a positive impact on cohesion (e.g., Pain \& Hardwood, 2009; Senécal, Loughead, \& Bloom, 2008).

Time management/organization. Time management refers to an individual's ability to plan their schedule in a way that will help them achieve their goals and avoid potential obstacles such as conflicts and confusion (AASP, n.d.). Time management training involves setting goals and priorities, making lists and schedules, and developing a preference for organization (Macan, 1994). Time management skills are especially important for student-athletes if they want to succeed both inside and outside of the classroom (Carodine, Almond, \& Gratto, 2001).

\section{Sport Psychology Service Delivery Heuristic}

Although a great deal of information on the different services provided by SPCs is available, there is little research conducted on how to best deliver those services (Andersen, 2000). A notable exception is the sport psychology service delivery (SPSD) heuristic, developed by Poczwardowski, Sherman, and Henschen (1998) and designed to help SPCs effectively plan, implement, and evaluate their psychological services (i.e., services that address performance issues if the SPC is a performance enhancement consultant or services that address performance and non-performance issues if the SPC is a licensed psychologist). Their general framework is composed of 11 factors, which include: (a) professional boundaries, (b) professional philosophy, (c) making contact, (d) assessment, (e) conceptualizing athletes' concerns and potential interventions, (f) range, types, and organization of service, (g) program implementation, (h) managing the self as 
an intervention instrument, (i) program and consultant evaluation, (j) conclusions and implications, and (k) leaving the setting (Poczwardowski et al., 1998).

Based on the assumption that a SPC's professional philosophy can affect different aspects of the consulting process (Poczwardowski et al., 1998), a new conceptualization for this specific factor of the SPSD heuristic was developed (Poczwardowski, Sherman, \& Ravizza, 2004). The researchers' investigation resulted in the creation of five components that SPCs should consider when reflecting on their professional philosophy, namely personal core beliefs and values, theoretical paradigm concerning behaviour change, models of practice and the consultant's role, intervention goals, and intervention techniques and methods (Poczwardowski et al., 2004).

Like many other professionals, SPCs are constantly faced with challenges. For instance, experienced SPCs operating in elite and professional environments often struggle with finding congruence, managing multiple relationships, dealing with the influence of elite sport cultures, and surviving and thriving (McDougall, Nesti, \& Richardson, 2015). Therefore, to provide a better representation of the challenges associated with sport psychology consulting, Poczwardowski and Sherman (2011) proposed a revised sport psychology service delivery (SPSD-R) heuristic (see Figure 10). Based on semi-structured interviews with 10 experienced SPCs, the factors in the original heuristic were modified and five new factors were added. A brief description of each factor included in the SPSD-R (bolded in Figure 1) is provided in the subsequent paragraphs. Given that Arnold and Sarkar (2015) stated that neophyte SPCs can learn a lot from experienced SPCs, each description herein will contain lessons from experienced SPCs on how to effectively deliver psychological services. Furthermore, the information 
in the parenthesis will indicate whether the respective factor was added or revised from the original heuristic.

Education, training, and professional experience (factor modified from the original heuristic) refers to the benefits or limitations associated with a SPC's educational background and range of professional experiences (Poczwardowski et al., 1998). Experienced SPCs are trained in both psychology and sport sciences (Partington \& Orlick, 1991; Sharp \& Hodge, 2011; Simons \& Andersen, 1995; Straub \& Hinman, 1992) and gain valuable experience by working with a variety of athletes and teams early in their career (Fifer, Henschen, Gould, \& Ravizza, 2008; Statler, 2002).

Professional ethics (factor modified from the original heuristic) pertains to the ethical obligations and legal aspects associated with sport psychology practice (Poczwardowski et al., 1998). Researchers have reported that experienced SPCs keep their consultations confidential and only share information with coaches if the athlete gives them permission (Sharp \& Hodge, 2011; Statler, 2002). Furthermore, experienced SPCs make agreements with athletes, coaches, and sport directors about the ethical boundaries that need to be respected (Elsborg, Diment, \& Elbe, 2015). Several experienced SPCs have shared, in their reflections, other strategies used to clarify ethical boundaries. For example, Neff (1990) constantly questions the appropriateness of his actions, while Moyle (2015) studies the professional codes of practice.

Professional philosophy (factor from the original heuristic) is a SPC's personal beliefs about the nature of human behaviour change (Poczwardowski et al., 1998). Many experienced SPCs use athlete-centred (Partington \& Orlick, 1991; Sharp \& Hodge, 2011; Simons \& Andersen, 1995; Statler, 2002) and eclectic approaches (Cotterill, 2012; 
Poczwardowski et al. 2004; Symes, 2014). An independent consultant noted that reflective practice, which involves thinking about and learning from "tacit knowledge in action" (Knowles, Gilbourne, Tomlinson, \& Anderson, 2007), helps her become more athlete-centred (McCormick \& Meijen, 2015). In addition, experienced SPCs reported using a service delivery method congruent with their personal philosophy (McDougall et al., 2015; Statler, 2002). In his reflection piece, Cotterill (2012), who has a philosophy based on the cognitive-behavioural approach, acknowledged his use of Rationale Emotive Behaviour therapy with some of his athletes.

Making contact (factor from the original heuristic) refers to a SPC's ability to gain entry and acceptance into the athletes', coaches', or organization's environment (Ravizza, 1988). Experienced SPCs gain entry by building a strong reputation, networking with coaches, and learning self-promotion skills (Fifer et al., 2008). In commentaries mentioning self-promotion skills, Loehr (1990) discussed using athlete testimonials to prove that his services were helpful, while Symes (2014) created a website to enable future clients to find her. Ogilvie, the Father of Applied Sport Psychology in North America, stated that sport psychology should be sold to coaches and sport administrators through an educational process (Straub \& Hinman, 1992). In support of this finding, researchers suggested that the first presentation to the coaching staff and athletes should be interactive, practical, and include an overview of sport psychology (Earle \& Earle, 2013; Ravizza, 1988).

Assessment (factor from the original heuristic) involves identifying the athlete's, coach's, or organization's strengths, limitations, and goals that are essential for individual and/or collective growth (Poczwardowski et al., 1998). Fifer et al. (2008) noted that 
experienced SPCs use psychometric testing (e.g., personality tests, learning styles inventories), interviews, observations, or some combination. However, Partington and Orlick (1991) found that experienced SPCs only use psychometric tests if they are directly related to the sport or the athlete's needs. Some experienced SPCs view psychometric tests as impersonal, time-consuming, costly (Dorfman, 1990), impractical (Orlick, 1989), and uncomfortable for the athletes (Halliwell, 1990).

Conceptualizing (concerns and interventions) (factor from the original heuristic) can be defined as the way a SPC thinks about a client's problem (Cormier \& Cormier, 1998). Several experienced SPCs in McCormick and Meijen's (2015) commentary said that SPCs need to be patient and avoid the urge of providing quick fixes if they want to get at the "real issue". In addition, Dorfman (1990) indicated that having an athlete's trust and confidence would help uncover the "real issues" hindering performance.

Range, types, and organization of services (factor from the original heuristic) pertains to the different psychological services provided by a SPC (Poczwardowski et al., 1998). Experienced SPCs offer a variety of psychological services that typically address performance or non-performance issues (Loehr, 1990; Neff, 1990; Orlick, 1989). For example, Loehr (1990) pointed out that $90 \%$ of his work involves dealing with sport specific concerns by teaching athletes psychological skills such as goal setting as well as arousal, attitude, motivation, and confidence control. However, $10 \%$ of his work consists of addressing personal issues such as martial or family problems, eating disorders, drug addiction, and anxiety.

Program implementation (factor from the original heuristic) is defined as the way SPCs teach or deliver their psychological services to their client (Poczwardowski et al., 
1998). Researchers have consistently indicated that experienced SPCs prefer delivering their psychological services through individual meetings rather than team meetings (Cotterill, 2012; Dorfman, 1990; Fifer et al., 2008; Halliwell, 1990; Loehr, 1990; Orlick, 1989; Partington \& Orlick, 1991). Moreover, many experienced SPCs noted that psychological skills training should be part of individual or team practices (Ravizza, 1988; Simons \& Andersen, 1995) and that coaches should be involved in the process (Arnold \& Sarkar, 2015; Cotterill, 2012; Sharp \& Hodge, 2011).

Managing the self as an intervention instrument (factor from the original heuristic) is related to how SPCs handle some of their physical and psychological limitations (e.g., being tired, overworked, angry, making mistakes) (Poczwardowski et al., 1998). This factor, which will be expanded upon in the subsequent section, generally involves coping tools and intra- and inter-personal self-management strategies used by SPCs (Poczwardowski \& Sherman, 2011).

Program and consultant evaluation (factor from the original heuristic) refers to how SPCs evaluate themselves and the effectiveness of their interventions (Poczwardowski et al., 1998). Researchers have noted that experienced SPCs constantly ask themselves how they can be more successful (Arnold \& Sarkar, 2015), observe how well their athletes progress (Statler, 2002), and do not use competitions results to evaluate their performance (Fifer et al., 2008). In his personal reflection, Halliwell (1990) noted that there are several good measures of effectiveness, which include direct feedback from athletes and coaches, being in demand, and being invited back to a team.

Conclusion and implications (factor from the original heuristic) pertains to what a SPC does after each consulting experience (Poczwardowski et al., 1998). For maximal 
professional growth, Poczwardowski et al. (1998) noted the importance for SPCs to reflect on each consulting experience by keeping summary notes in a journal and/or debriefing with a supervisor.

Leaving the setting (factor from the original heuristic) refers to what a SPC does when a contract is completed or terminated by a client or when an appropriate referral is made (Poczwardowski et al., 1998). On the one hand, McDougall et al. (2015) discovered that, in elite sport, a contract can be terminated for many reasons (e.g., failure to reach performance standards, an organization's financial status, inability to maintain positive relationships with athletes, coaches, and management, change in leadership). On the other hand, Poczwardowski et al. (1998) noted that, after the completion of a contract, SPCs should practice follow-up strategies such as phone calls, homework, reminder cards, and additional consultations if need be. Moreover, experienced SPCs should have a referral plan, use their network to facilitate the referral process, and refer athletes when they feel that they do not have the tools to help them (Statler, 2002).

Consultant-client relationship (factor added to the original heuristic) refers to the working alliance between the SPC and the client (Poczwardowski \& Sherman, 2011). Several experienced SPCs have cited in their commentaries that the consultant-client relationship plays an important role in consulting effectiveness (Cotterill, 2012;

Halliwell, 1990; Neff, 1990). Furthermore, researchers have concluded that trust is one of the most essential component to building a strong working alliance (Arnold \& Sarkar, 2015; Sharp \& Hodge, 2013; Statler, 2002). In terms of building trust, experienced SPCs should follow through on what they say, lead by example, and preserve the confidentiality they guaranteed at the beginning of the relationship (Fifer et al., 2008). In 
addition, many experienced SPCs mentioned the importance of building relationships with everyone in the organization (e.g., athletes, coaches, support staff, management; Arnold \& Sarkar, 2015; Fifer et al., 2008; McDougall et al., 2015; Moyle, 2015; Symes, 2014).

Consultant variables (factor added to the original heuristic) pertain to the style, personal qualities, attitudes, and skills that a SPC possesses (Poczwardowski \& Sherman, 2011). Statler (2002) reported that experienced SPCs are calm, honest, hard-working, open, patient, flexible, approachable, reflective, and professional. Furthermore, experienced SPCs have strong counseling skills and are proficient in observing, focusing, checking in for understanding, being receptive, and listening. The importance of this latter counselling skill has been recognized by many other experienced SPCs (Dorfman, 1990; McCormick \& Meijen, 2015; Partington \& Orlick, 1991).

Client variables (factor added to the original heuristic) refers to the personal characteristics of the client that impact consulting effectiveness (Poczwardowski \& Sherman, 2011). Research that stems from qualitative studies and personal reflections reported that sport psychology interventions are most effective when clients are both receptive and committed (Cecil, 2015; Neff, 1990; Partington \& Orlick, 1991; Sharp \& Hodge, 2011).

Person-focused values (underlying factor that emerged as a meta-theme in the revised heuristic) deals with how a SPC actualizes values such as freedom, autonomy, privacy, and dignity (Poczwardowski \& Sherman, 2011). Several experienced SPCs have noted that they look at their clients as normal people instead of just athletes (Lindsay, 2014; Ravizza, 2002). 
Immersion (underlying factor added to the original heuristic) refers to how engaged a SPC is in terms of learning about the sport and dealing with athlete or team issues (Poczwardowski \& Sherman, 2011). Partington and Orlick (1991) discovered that best-ever consultations occurred when the SPC had the opportunity to spend a significant amount of time with athletes and coaches. Many experienced SPCs noted that they are present during training, competition (Fifer et al., 2008; Neff, 1990; Partington \& Orlick, 1991), and social functions (Elsborg et al., 2015; Partington \& Orlick, 1991). In addition, they often help with practical matters that are not technically part of their responsibilities (e.g., loading the bus for away games; Elsborg et al., 2015; Fifer et al., 2008).

Finally, goodness of fit (underlying factor added to the original heuristic) relates to how well SPCs fit in with the organization for which they are working (Poczwardowski \& Sherman, 2011). Statler (2002) found that experienced SPCs fit in by learning about the sport they are working in as well as the sport's politics and subculture. In support of this finding, Symes (2014) cited that SPCs do not need to know everything about a sport, but they must be ready to do their own research and ask many questions. Furthermore, experienced SPCs have mentioned that they make sure that their personality fits with the organization's (Neff, 1990) and that their philosophy is congruent with the coach's (Ravizza, 1988).

Taken together, the SPSD-R outlines a multitude of different factors that SPCs need to consider if they want to effectively plan, implement, and evaluate their psychological services. Delivering psychological services is challenging and often viewed by experienced SPCs as a "performance" (Poczwardowski \& Sherman, 2011). Expanding on these findings, Moyle (2015) noted that just like Olympic athletes, SPCs 
need to take care of themselves if they want to perform to the best of their abilities. According to her, SPCs need to carefully monitor their nutrition, rest, physical fitness, mental health, relationships, work-life balance, self-care, and life skills. Therefore, one could argue that managing the self as an intervention instrument is one of the most important factors in the SPSD-R because it can have a major impact on every aspect of the consulting process. For instance, a SPC that is constantly stressed due to not finding the time to exercise and eat well, will not have the ability to focus and show empathy during a consultation.

\section{Managing the Self as an Intervention Instrument}

Poczwardowski and Sherman (2011) found multiple categories of coping tools and intra- and inter-personal self-management strategies used by experienced SPCs. These include dealing with fatigue and managing life balance issues, using social support, self-awareness, peer support and consultation, and knowing and improving the self. Moreover, the authors noted in their discussion that neophyte SPCs may have the ability to provide rich perspectives on the different factors of effective practice. Therefore, to expand on their findings, the following subsections will outline specific examples of coping tools and intra- and inter-personal self-management strategies used by experienced and neophyte SPCs.

Coping tools. Fletcher, Rumbold, Tester, and Coombes (2011) identified stressors in five general areas: (a) factors intrinsic to sport psychology (e.g., workload and hours, travel arrangements), (b) roles in the organization (e.g., role ambiguity, role overload), (c) sport relationships and interpersonal demands (e.g., lack of social support), (d) career and performance development issues (e.g., job insecurities), (e) and 
organizational structure and climate of the profession (e.g., inadequate communication channels, no sense of belonging). In support of these findings, Symes (2014) noted a variety of potential stressors. She mentioned feeling very tired at the end of the day, spending a lot of time travelling in her car, consistently working six days per week, worrying about the possibility of an unstable financial situation, and not having the time to relax with friends and family. In addition, qualitative studies and personal reflections have consistently reported that neophyte SPCs experience a great deal of anxiety (Lindsay, Breckon, Thomas, \& Maynard, 2007; Mărgărit, 2013; Tod, Andersen, \& Marchant, 2011; Tonn \& Harmison, 2004) and self-doubt (Collins, Evans-Jones, \& O'Connor, 2013; Tod, Andersen, \& Marchant, 2009; Tod \& Bond, 2010; Williams \& Andersen, 2012) when delivering their services. Some neophyte SPCs have also mentioned feeling lonely at times (Owton, Bond, \& Tod, 2014; Tod \& Bond, 2010). However, to maintain their general well-being, it is crucial for SPCs to find different ways to successfully cope with these types of stressors (Cropley et al., 2016).

SPCs must cultivate self-confidence to successfully help their clients (Stambulova \& Johnson, 2010). Using strategies to increase self-confidence can be one way for SPCs to cope with their anxiety (Tod, 2007). Researchers have discovered that SPCs can enhance their self-confidence by using positive self-talk, receiving positive verbal and non-verbal feedback from clients and supervisors (Tod et al, 2011), and identifying clients that have exhibited positive changes in their attitudes, behaviours, or performance (Tod \& Bond, 2010).

SPCs must live a healthy and active lifestyle to remain helpful to their clients (Arnold \& Sarkar, 2015; Partington \& Orlick, 1991). Researchers have found that 
experienced SPCs manage themselves by getting enough sleep, exercising regularly, and eating a balanced diet (Arnold \& Sarkar, 2015; Elsborg et al., 2015; Partington \& Orlick, 1991). In support of these findings, Cogan, Flowers, Haberl, McCann, and Borlabi (2012) advised SPCs to never skip meals, sleep, or exercise. In addition, Halliwell (1990) acknowledged, in his reflection piece, that staying fit helps him be an effective SPC.

SPCs must maintain a proper balance between work, play, and relationships to remain effective (Partington \& Orlick, 1991). In their commentaries, Halliwell (1990) and Symes (2014) described how planning their consulting schedule enables them to be more efficient. Furthermore, Elsborg et al. (2015) discovered that experienced SPCs spend time with friends and family whenever they have the opportunity and use them as a source of support. This finding has also been noted in the personal reflection of several experienced SPCs (Cecil, 2015; Halliwell, 1990; Lindsay, 2014). For example, Lindsay (2014) mentioned that family days are very important to him and can include activities such as going to the local playground, visiting relatives, preparing Sunday dinner, and giving baths to his children. Moreover, during their free time, experienced SPCs relax by listening to classical music, writing notes in their journal (Elsborg et al., 2015), watching television (Symes, 2014), hiking (Lindsay, 2014), and having a few drinks (Cecil, 2015; Symes, 2014). Researchers have also proposed a model that SPCs can use to achieve work-life balance. This model includes organization, supervision and reflective practice, and leisure time. In terms of organization, SPCs should update their skills, say "no" when they are too busy, plan for potential issues, build a comprehensive support network, and have open discussions with the various professionals in their network. In terms of supervision and reflective practice, SPCs should engage in it to receive the necessary 
moral, ethical, emotional, and informational support. In terms of leisure time, SPCs should define, guard, and plan their leisure time, keep it separate from work, and make sure that physical activity is part of it (Waumsley, Hemmings, \& Payne, 2010). Apart from using coping tools, SPCs should also manage themselves by using strategies that broaden their professional knowledge base and enhance their counseling skills (Poczwardowski et al., 1998).

Intra- and inter-personal self-management strategies. Developing selfawareness is a way for SPCs to improve their practice (Cotterill, 2012) and bring about change at the personal or professional level (Knowles, Katz, \& Gilbourne, 2012). Experienced SPCs have a deep understanding of themselves and their own strengths and limitations (Simons \& Andersen, 1995; Statler, 2002). They gain this insight by engaging in reflective practice and asking self-directed questions (McDougall et al., 2015) such as who am I, why am I involved in the field of applied sport psychology, what are my needs and motivations, what are my strengths and weaknesses, and what do I bring to the consultant-client relationship (Simons \& Andersen, 1995). Similarly, neophyte SPCs engage in reflective practice (Holt \& Strean, 2001; Tod, Marchant, \& Andersen, 2007; Tonn \& Harmison, 2004), but also personal therapy (e.g., undertaking personal psychotherapy as a clinical psychology trainee; Tod et al., 2009; Tod \& Bond, 2010) to develop their self-awareness.

Mentor supervision, which is a career-long process whereby a mentor helps develop a mentee's counseling skills (Van Raalte \& Andersen, 2000), can enhance a SPC's level of expertise (Hutter, Oldenhof-Veldman, \& Oudejans, 2015). Researchers have discovered that mentor supervision can help SPCs cope with stressors (Stambulova 
\& Johnson, 2010; Tod et al., 2009; Tod et al., 2011). More specifically, mentors can share their experiences to normalize the anxiety or self-doubt experienced by their mentees (Christensen \& Aoyagi, 2014; Woodcock, Richards, \& Mugford, 2008) and teach them stress-management (Tod et al., 2009) and assertiveness-training techniques (Tod, 2007). Moreover, mentors can contribute to their mentees' professional development by providing them with new perspectives on their clients' issues and helping them critically reflect on their practice (Jones, Evans, \& Mullen, 2007; Tod et al., 2011).

Peer supervision, which is a process whereby two SPCs regularly meet to exchange ideas and discuss the issues present in their practice, can have a tremendous impact on the continuing development of a SPC (McCormick \& Meijen, 2015). Experienced SPCs have a network of colleagues and peers that can support them (Arnold \& Sarkar, 2015; Elsborg et al., 2015; Sharp \& Hodge, 2011; Simons \& Andersen, 1995; Statler, 2002). More specifically, Sharp and Hodge (2011) concluded that experienced SPCs use different formats for peer supervision. Some experienced SPCs regularly organize individual or group meetings where the goal is to help SPCs reflect on their practice, whereas other experienced SPCs do not have any formal arrangements in place and only contact their colleagues if an issue arises. In his commentary, Cotterill (2012) noted that sharing ideas and concerns with other SPCs in the same sport environments enables him to stay informed on the new research being published and incorporate creative approaches to his practice. Furthermore, Cogan et al. (2012) indicated that, during the Olympic Games, being able to talk to a colleague about a stressful situation can help SPCs effectively deal with negative emotions and get back to work. 
It is vital for SPCs to keep learning and developing their counseling skills (Simons \& Andersen, 1995). Experienced SPCs take courses and read a lot of books to learn new approaches and refine their practice (Arnold \& Sarkar, 2015). Similarly, McCormick and Meijen (2015) noted that neophyte SPCs should develop their listening skills by attending workshops or courses on counselling skills and read literature on psychology, counseling, psychotherapy, philosophy, and the arts.

SPCs can potentially improve their performance and serve as a role model to their clients, if they "practice what they preach" and use psychological skills on themselves (Poczwardowski et al., 1998). SPCs should model the refocusing and self-control skills they teach to their athletes (Partington \& Orlick, 1991) and personally experiment with all types of psychological skills (Straub \& Hinman, 1992). Ravizza, a world-renowned SPC that has worked with many professional baseball teams, mentioned that SPCs should spend time working on themselves and master an activity, exercise, or technique before teaching it to an individual or a group (Simons \& Andersen, 1995). In the section on cautions and suggestions for the future, he stated, "I see people picking up relaxation in three months, and then they feel they're ready to go out and teach it or whatever, and I think there needs to be more work on oneself before you run and share these activities with others" (p. 465). More specifically, an experienced SPC mentioned using psychological skills in his own training and competition (Statler, 2002). Moreover, Cogan et al. (2012) noted that the United States Olympic Committee sport psychology consulting team sets team goals, while Elsborg et al. (2015) found that experienced SPCs stay mentally fresh by practicing psychological skills such as relaxation techniques, cognitive behavioural therapy techniques, and mindfulness. Practicing this latter 
psychological skill could help SPCs have a better connection with themselves and their clients, remain non-judgmental, and develop empathy (Andersen, 2012; Andersen \& Mannion, 2011; Zizzi \& Andersen, 2010). In support of this suggestion, Williams and Andersen (2012) noted that the neophyte SPC in their commentary used mindfulness to ground himself when he experienced identity confusion while working with a track cycling team.

Practicing psychological skills can help SPCs manage their personal and professional challenges (Pack, Hemmings, \& Arvinen-Barrow, 2014). For example, a SPC can use imagery to cope with life stressors or rehearse the key talking points of a presentation on goal setting. Therefore, one could argue that practicing psychological skills is one of the most effective ways of managing the self as an intervention instrument. Although few researchers have examined the psychological skills used by SPCs, SPCs can learn valuable lessons from other types of performers (Straub \& Hinman, 1992).

\section{Psychological Skills Used by Other Performers}

Sport. Qualitative studies and interviews have consistently reported that elite athletes use imagery, self-talk, and relaxation techniques to maximize their performance during competitions (Gould, Finch, \& Jackson, 1993; Kabush \& Orlick, 2001; Law, Coleman, \& Orlick, 2008; Park, 2000). For example, there are personal accounts of an elite ironman triathlete visualizing himself in an environment where he had positive results in the past during his race (Grand'Maison \& Orlick, 2006), an Olympic gold medalist in rowing telling herself that her race is going to be fun (Gentner et al., 2009), and a former double Olympic gold medalist in bobsled using self-hypnosis to recover 
from training (Weder, 2000). In addition, elite athletes prioritize tasks and take time for themselves (Gould et al., 1993), set goals (Burke \& Orlick, 2003; Freitas, Dias, \& Fonseca, 2013a), and regularly evaluate their performance to determine what needs to be improved (Barbour \& Orlick, 1999). In terms of focus, an Olympic bronze medalist in canoeing noted that he focuses his thoughts and emotions on things that he can control (e.g., focusing on the execution of the race strategy instead of specific issues like the weather; Giles \& Werthner, 2002).

Similar to elite athletes, research has found that elite-level coaches use self-talk, imagery, relaxation, and goal-setting strategies in training and competition, during different time frames (before, during, and after), and for various purposes (Freitas, Dias, \& Fonseca, 2013b; Thelwell, Weston, Greenlees, \& Hutchings, 2008). Coaches note using self-talk before training and competition to control their emotions, imagery after training and competition to benefit evaluation, relaxation techniques during competition to "not let their athlete see them tense", and goal setting before training and competition to benefit communication (Thelwell et al., 2008). To cope with stress, Olusoga, Butt, Maynard, and Hays (2010) discovered that world-class coaches use time management skills, self-talk, and imagery.

Medicine. The use of imagery to improve performance has also been noted by surgeons (Anton, Montero, Howley, Brown, \& Stefanidis, 2015; Arora et al., 2009; Edwards, Sadoski, \& Burdenski, 2004; McDonald, Orlick, \& Letts, 1995). More specifically, orthopedic surgeons $(n=9)$ reported using imagery to rehearse the whole surgery or a part of it and create operative strategies (e.g., different surgical steps, contingency plan; Ibrahim, Richardson, \& Nestel, 2015). Their images were moderately 
vivid, seen from an external perspective, and based on visual or a combination of visual and tactile sensory modalities. In addition, they practiced imagery in a quiet place and utilized tools such as bone models and CT scans to improve the vividness of their images.

Surgeons also use attention control strategies to cope with stressful situations (Anton et al., 2015). A world leader in thoracic and cardiovascular surgery outlined various strategies that he uses to remain focused in the operating room. These include cutting off the lights and using his headlight to illuminate a specific area on the patient's body, putting a game face on, and using all his senses (Tribble \& Orlick, 2001). The same surgeon also mentioned the importance of creating a rhythm between having a narrow and broad focus since it is impossible to be fully focused all the time (Tribble \& Newburg, 1998). Like swimming the breaststroke, "you come up for air, transiently becoming aware of more of your surroundings, and then you regain your focus during the next stroke with your face in the water" (p.12).

Surgeons who do not receive any training on how to deal with stress, still manage to develop their own coping strategies (Arora et al., 2009). To remain calm, surgeons use humour (Lee, Brown, \& Stewart, 2009), engage in idle chatter as they prepare to enter the operating room (Tribble \& Orlick, 2001), listen to music (Anton et al., 2015; Tribble \& Orlick, 2001), use a technique where they stop, step back, and take a deep breath, and engage in self-talk (Arora et al., 2009; Wetzel et al., 2006). Furthermore, residents are taught to view their body's physiological reaction to a challenging situation as feelings of arousal instead of anxiety (Tribble \& Newburg, 1998).

Performing arts. Professional musicians (Agnew, 1922), dancers (Nordin \& Cumming, 2005), and actors (Murphy \& Orlick, 2006) also use imagery to improve their 
performance. A great example of the complexity of the imagery used by performing artists is outlined in Gertz's (1998) reflection piece. He states that opera singers are instructed to "mentally see the vowel, feel the vowel, and hear the vowel. Every vowel sound must be mentally shaped and mentally given the requisite colour before being physically produced" (p. 22).

Performing artists also use a variety of psychological skills during their preperformance routine. They relax by engaging in self-talk (Steptoe, 1989), isolating themselves, practicing breathing exercises (Murphy \& Orlick, 2006; Pirie, 1998), finding their own "inner mental room”, and listening to relaxation recordings (Fagéus, 1999). During their performance, top classical musicians maintain their concentration by not forcing anything (Talbot-Honeck \& Orlick, 1998), while professional actors focus on different aspects of the acting process such as what the other actors say or the specific circumstances of the scene (Murphy \& Orlick, 2006). Outside of their performance environment, performing artists either set concrete goals (Fagéus, 1999) or idealistic goals (Talbot-Honeck \& Orlick, 1998).

Business. In Loehr and Schwartz's (2001) commentary, a female business consultant described how she uses imagery to relax and boost her confidence before a presentation or meeting. Her ritual involves finding a quiet place to sit down, thinking about what she wants to get out of her meeting, and then imaging herself achieving her desired outcome. In support of this finding, Maddox, Anthony, and Wheatley (1987) suggested that strategic managers use imagery when developing plans for their organizations. 
Further, business executives use listening techniques such as reflective listening, focusing on the message, and paraphrasing the message, to improve the communication they have with their employees (Weinberg \& McDermott, 2002). In addition, Towaij and Orlick (2000) discovered that high achieving employees set work goals and stay organized by delegating tasks and planning their workday the night before.

Military. Through qualitative studies and personal reflections, military pilots and astronauts report using imagery to improve the consistency and quality of their performance (Garneau, 1998; Hadfield \& Orlick, 1999; Hohmann \& Orlick, 2014; Sprung, 1995). More specifically, elite Canadian military pilots use first-person and multisensory (e.g., visual, kinesthetic, auditory) imagery to prepare themselves before a flight and manage their stress (Hohmann \& Orlick, 2014), while astronauts use imagery in a variety of situations such as parachuting, flying, checklists, relationships, stress management, sport, and academics (Sprung, 1995).

Apart from imagery, military pilots use other psychological skills. They engage in self-talk to enhance their personal confidence and refocus when they get distracted, control distractions by compartmentalizing them, and partake in personal debriefs, after every flight, to learn from their mistakes (Hohmann \& Orlick, 2014). In an interview, Canadian astronaut Chris Hadfield also mentioned that he compartmentalizes distractions and engages in personal debriefs. Moreover, he discussed how important it is to set goals and have a vision and suggested that individuals could improve their concentration by focusing on progressively harder tasks (Hadfield \& Orlick, 1999).

Taken together, a considerable amount of qualitative studies and personal reflections have examined the psychological skills used by different performers (e.g., 
athletes, surgeons, actors, musicians, astronauts). However, one must not forget that SPCs are also performers (Woodcock et al., 2008). To date, only one study has been conducted to discover the psychological skills used by SPCs.

\section{Research with Sport Psychology Consultants}

Pack et al. (2014) conducted semi-structured interviews with 12 UK-based SPCs to determine if SPCs use self-practice, how they use it, and for what reasons. Selfpractice refers to practicing psychological skills (e.g., goal setting, cognitive behavioural techniques) on oneself (Bennett-Levy et al., 2001). The participants reported using selfpractice as a way of managing the self, legitimising their interventions, and gaining a deeper understanding of the psychological strategies they teach. More specifically, some of them adapted different psychological skills to suit their needs (e.g., setting goals in different parts of their lives), used psychological skills to cope with personal and professional demands (e.g., engaging in self-talk to reduce the anxiety, doing something to relax to remain empathic) as well as improve their sport performance (e.g., using selftalk and imagery when running). However, several participants noted that it can be hard to incorporate self-practice into their lives because of their busy schedule.

Although this study has confirmed that SPCs engage in self-practice, there is not enough information on which psychological skills they use as well as where, when, why, and how they use them to be more effective in their consulting. This information is crucial if we want to advance the field of sport psychology and help SPCs excel at what they do. 


\section{References}

Abernethy, B. (2001). Attention. In R. N. Singer, H. A. Hausenblas, \& C. M. Janelle (Eds.), Handbook of Sport Psychology (2nd ed., pp. 53-85). New York: John Wiley \& Sons, Inc.

Agnew, M. (1922). The auditory imagery of great composers. Psychological Monographs, 31, 279-287. doi: 10.1037/h0093171

Andersen, M. B. (2000). Introduction. In M. B. Andersen (Ed.), Doing sport psychology (pp. xiii-xvii). Champaign, IL: Human Kinetics.

Andersen, M. B. (2012). Supervision and mindfulness in sport and performance psychology. In S. M. Murphy (Ed.), The Oxford handbook of sport and performance psychology. New York, NY: Oxford University Press.

Andersen, M. B., \& Mannion, J. (2011). If you see the Buddha on the football field Tackle him. In D. Gilbourne \& M. B. Andersen (Eds.), Critical essays in applied sport psychology (pp. 173-192). Champaign, IL: Human Kinetics.

Anderson, M. P. (1959). What is communication? The Journal of Communication, 9, 5. Retrieved from http://onlinelibrary.wiley.com/journal/10.1111/(ISSN)1460-2466

Anton, N. E., Montero, P. N., Howley, L. D., Brown, C., \& Stefanidis, D. (2015). What stress coping strategies are surgeons relying upon during surgery? The American Journal of Surgery, 210, 846-851. doi: 10.1016/j.amjsurg.2015.04.002

Arnold, R., \& Sarkar, M. (2015). Preparing athletes and teams for the Olympic Games: Experiences and lessons learned from the world's best sport psychologists. International Journal of Sport \& Exercise Psychology, 13, 4-20. doi: 10.1080/1612197x.2014.932827 
Arora, S., Sevdalis, N., Nestel, D., Tierney, T., Woloshynowych, M., \& Kneebone, R. (2009). Managing intraoperative stress: What do surgeons want from a crisis training program? The American Journal of Surgery, 197, 537-543. doi: 10.1016/j.amjsurg.2008.02.009

Arthur, R. A., Fitzwater, J., Roberts, R., Hardy, J., \& Arthur, C. A. (2017). Psychological skills and "the paras": The indirect effects of psychological skills on endurance. Journal of Applied Sport Psychology, 29, 449-465. doi: $10.1080 / 10413200.2017 .1306728$

Association for Applied Sport Psychology (n.d.). About AASP. Retrieved from http://www.appliedsportpsych.org/about/

Australian Institute of Sport (n.d.). Performance psychology. Retrieved from https://www.ausport.gov.au/ais/performance_support/careers/performance_psych ology

Barbour, S., \& Orlick, T. (1999). Mental skills of national hockey league players. Journal of Excellence, 2, 16-36. Retrieved from http://www.zoneofexcellence.ca/Journal.html

Bennett-Levy, J., Turner, F., Beaty, T., Smith, M., Paterson, B., \& Farmer, S. (2001). The value of self-practice of cognitive therapy techniques and self-reflection in the training of cognitive therapists. Behavioural and Cognitive Psychotherapy, 29, 203-220. doi: 10.1017/s1352465801002077

British Association of Sport and Exercise Sciences (n.d.). Sport and exercise psychology. Retrieved from http://www.bases.org.uk/sports-psychologist 
Burke, S., \& Orlick, T. (2003). Mental strategies of elite mount Everest climbers. Journal of Excellence, 8, 42-58. Retrieved from http://www.zoneofexcellence.ca/Journal.html

Canadian Sport Psychology Association (n.d.). About. Retrieved from https://www.cspaacps.com/about

Carodine, K., Almond, K. F., \& Gratto, K. K. (2001). College student athlete success both in and out of the classroom. New Directions for Student Services, 2001, 1933. doi: $10.1002 / \mathrm{ss} .2$

Carron, A. V., Brawley, L. R., \& Widmeyer, W. N. (1998). The measurement of cohesiveness in sport groups. In J. L. Duda (Ed.), Advances in sport and exercise psychology measurement (pp. 213-226). Morgantown, WV: Fitness Information Technology.

Carron, A. V., \& Spink, K. S. (1993). Team building in an exercise setting. The Sport Psychologist, 7, 8-18. doi: 10.1123/tsp.7.1.8

Cecil, S. (2015). A week in the life of an applied sport psychologist. Sport \& Exercise Psychology Review, 11(2), 77-81. Retrieved from http://www.bps.org.uk/publications/member-network-publications/memberpublications/sport-and-exercise-psychology-review

Christensen, D. A., \& Aoyagi, M. W. (2014). Lessons learned consulting at Olympic trials: Swimming through growing pains. The Sport Psychologist, 28, 281-289. doi: $10.1123 /$ tsp.2013-0092

Cogan, K. D., Flowers, R., Haberl, P., McCann, S., \& Borlabi, W. (2012). Putting the team in sport psychology consulting: Five sport psychology consultants 
collaborating service for athletes at the USOC. Journal of Sport Psychology in Action, 3, 77-87. doi: 10.1080/21520704.2012.683089

Collins, R., Evans-Jones, K., \& O'Connor, H. L. (2013). Reflections on three neophyte sport and exercise psychologists' developing philosophies for practice. The Sport Psychologist, 27, 399-409. doi: 10.1123/tsp.27.4.399

Cormier, L. S., \& Cormier, W. H. (1998). Interviewing strategies for helpers: Fundamental skills and cognitive behavioral interventions (4th ed.). Pacific Grove, CA: Brooks/Cole.

Cotterill, S. (2012). Experience of working in an elite sports academy: A case study in professional cricket. Sport \& Exercise Psychology Review, 8(1), 45-53. Retrieved from http://www.bps.org.uk/publications/member-network-publications/memberpublications/sport-and-exercise-psychology-review

Cropley, B., Baldock, L., Mellalieu, S. D., Neil, R., Wagstaff, C. D., \& Wadey, R. (2016). Coping with the demands of professional practice: Sport psychology consultants' perspectives. The Sport Psychologist, 30, 290-302. doi:

10.1123/tsp.2015-0125

Dorfman, H. A. (1990). Reflections on providing personal and performance enhancement consulting services in professional baseball. The Sport Psychologist, 4, 341-346. doi: $10.1123 /$ tsp.4.4.341

Driskell, J. E., Copper, C., \& Moran, A. (1994). Does mental practice enhance performance? Journal of Applied Psychology, 79, 481-491. doi: 10.1037//00219010.79 .4 .481 
Earle, K., \& Earle, F. (2013). Dodging the bullets: Personal reflections on common issues in sport psychology consultancy. Sport \& Exercise Psychology Review, 9(2), 6973. Retrieved from http://www.bps.org.uk/publications/member-networkpublications/member-publications/sport-and-exercise-psychology-review

Edwards, J. C., Sadoski, M., \& Burdenski, T. K. (2004). Physicians' reported use of mental images and language in clinical reasoning. Imagination, Cognition, and Personality, 24, 41-50. doi: 10.2190/hvp5-qqxd-6pjc-lfdx

Elsborg, P., Diment, G. M., \& Elbe, A. (2015). Sport psychology consultants' perceptions of their challenges at the London 2012 Olympic Games. The Sport Psychologist, 29, 183-195. doi: 10.1123/tsp.2013-0105

Fagéus, K. (1999). Love and fear: Personal and artistic development for musicians. Journal of Excellence, 2, 6-10. Retrieved from http://www.zoneofexcellence.ca/Journal.html

Fifer, A., Henschen, K., Gould, D., \& Ravizza, K. (2008). What works when working with athletes. The Sport Psychologist, 22, 356-377. doi: 10.1123/tsp.22.3.356

Filby, W., Maynard, I., \& Graydon, J. (1999). The effect of multiple-goal strategies on performance outcomes in training and competition. Journal of Applied Sport Psychology, 11, 230-246. doi: 10.1080/10413209908404202

Fletcher, D., Rumbold, J. L., Tester, R., \& Coombes, M. S. (2011). Sport psychologists’ experiences of organizational stressors. The Sport Psychologist, 25, 363-381. doi: 10.1123/tsp.25.3.363 
Freitas, S. P., Dias, C. S., \& Fonseca, A. M. (2013a). Elite Portuguese soccer players' use of psychological techniques: Where, when and why. Journal of Human Sport and Exercise, 8, 847-860. doi: 10.4100/jhse.2013.83.10

Freitas, S., Dias, C., \& Fonseca, A. (2013b). Elite soccer coaches' use of psychological techniques. International Journal of Psychological Studies, 5, 56-70. doi: 10.5539/ijps.v5n3p56

Garneau, M. (1998). Excellence in space. Journal of Excellence, 1, 24-31. Retrieved from http://www.zoneofexcellence.ca/Journal.html

Gentner, N. B., Sager, C., Pope, S., Leonard, J., Delgado, E., McAlarnen, M., Czapla, R., Efland, A., Schulefand, A., Vanaman, J., Atkins, B., \& Spak, J. (2009). Lase focused: Insight into the mental preparation of an Olympic gold medalist rower. Journal of Excellence, 13, 33-39. Retrieved from http://www.zoneofexcellence.ca/Journal.html

Gertz, H. (1998). Thinking sound: Reflections on the application of mental training to opera. Journal of Excellence, 1, 20-23. Retrieved from http://www.zoneofexcellence.ca/Journal.html

Giges, B., \& Petitpas, A. (2000). Brief contact interventions in sport psychology. The Sport Psychologist, 14, 176-187. doi: 10.1123/tsp.14.2.176

Giles, S., \& Werthner, P. (2002). Interview with Steve Giles, 2000 Olympic medalist. Journal of Excellence, 6, 86-103. Retrieved from http://www.zoneofexcellence.ca/Journal.html

Goldstein, E. B. (2008). Cognitive psychology: Connecting mind, research, and everyday experience (2nd ed.). Belmont, CA: Thompson/Wadsworth. 
Gould, D., Finch, L. M., \& Jackson, S. A. (1993). Coping strategies used by national champion figure skaters. Research Quarterly for Exercise and Sport, 64, 453-68. doi: 10.1080/02701367.1993.10607599

Gould, D., Greenleaf, C., \& Krane, V. (2002). Arousal-anxiety and sport behavior. In T. Horn (Ed.), Advances in sport psychology (2nd ed., pp. 207-241). Champaign, IL: Human Kinetics.

Grand'Maison, K., \& Orlick, T. (2006). Focusing lessons from an elite ironman triathlete: Chris McCormack. Journal of Excellence, 11, 69-87. Retrieved from http://www.zoneofexcellence.ca/Journal.html

Hadfield, C., \& Orlick, T. (1999). Interview with Chris Hadfield, Canadian astronaut. Journal of Excellence, 2, 84-91. Retrieved from http://www.zoneofexcellence.ca/Journal.html

Hall, C., Mack, D., Paivio, A., \& Hausenblas, H. (1998). Imagery use by athletes: Development of the sport imagery questionnaire. International Journal of Sport Psychology, 29(1), 73-89. Retrieved from http://www.ijsp-online.com/

Halliwell, W. (1990). Providing sport psychology consulting services in professional hockey. The Sport Psychologist, 4, 369-377. doi: 10.1123/tsp.4.4.369

Hardy, J. (2006). Speaking clearly: A critical review of the self-talk literature. Psychology of Sport \& Exercise, 7, 81-97. doi: 10.1016/j.psychsport.2005.04.002

Hardy, J., Gammage, K., \& Hall, C. R. (2001). A descriptive study of athlete self-talk. The Sport Psychologist, 15, 306-318. doi: 10.1123/tsp.15.3.306 
Hardy, J., Hall, C. R., \& Alexander, M. R. (2001). Exploring self-talk and affective states in sport. Journal of Sports Sciences, 19, 469-475. doi: $10.1080 / 026404101750238926$

Harris, D. V., \& Harris, B. L. (1984). Sports psychology: Mental skills for physical people. Champaign, IL: Leisure Press.

Hatzigeorgiadis, A., Zourbanos, N., Galanis, E., \& Theodorakis, Y. (2011). Self-talk and sports performance: A meta-analysis. Perspectives on Psychological Science, 6, 348-356. doi: 10.1177/1745691611413136

Highlen, P. S., \& Bennett, B. B. (1983). Elite divers and wrestlers: A comparison between open- and closed-skill athletes. Journal of Sport Psychology, 5, 390-409. doi: $10.1123 /$ jsp.5.4.390

Hohmann, M., \& Orlick, T. (2014). Examining the psychological skills used by elite Canadian military pilots. Journal of Excellence, 16, 4-19. Retrieved from http://www.zoneofexcellence.ca/Journal.html

Holt, N. L., \& Strean, W. B. (2001). Reflecting on initiating sport psychology consultation: A self-narrative of neophyte practice. The Sport Psychologist, 15, 188-204. doi: 10.1123/tsp.15.2.188

Hutter, R. I., Oldenhof-Veldman, T., \& Oudejans, R. R. (2015). What trainee sport psychologists want to learn in supervision. Psychology of Sport \& Exercise, 16, 101-109. doi: 10.1016/j.psychsport.2014.08.003

Ibrahim, E. F., Richardson, M. D., \& Nestel, D. (2015). Mental imagery and learning: A qualitative study in orthopaedic trauma surgery. Medical Education, 49, 888-900. doi: 10.1111/medu.12759 
Jensen, P., Roman, J., Shaft, B., \& Wrisberg, C. (2013). In the cage: MMA fighters' experience of competition. The Sport Psychologist, 27, 1-12. doi: $10.1123 /$ tsp. 27.1 .1

Jones, L., Evans, L., \& Mullen, R. (2007). Multiple roles in an applied setting: Trainee sport psychologist, coach, and researcher. The Sport Psychologist, 21, 210-226. doi: 10.1123/tsp.21.2.210

Kabush, D., \& Orlick, T. (2001). Focusing for excellence: Lessons from elite mountain bike racers. Journal of Excellence, 5, 39-62. Retrieved from http://www.zoneofexcellence.ca/Journal.html

Knowles, Z., Gilbourne, D., Tomlinson, V., \& Anderson, A. G. (2007). Reflections on the application of reflective practice for supervision in applied sport psychology. The Sport Psychologist, 21, 109-122. doi: 10.1123/tsp.21.1.109

Knowles, Z., Katz, J., \& Gilbourne, D. (2012). Reflective practice within elite consultancy: Diary extracts and further discussion on a personal and elusive process. The Sport Psychologist, 26, 454-469. doi: 10.1123/tsp.26.3.454

Law, J., Coleman, J., \& Orlick, T. (2008). Embracing the challenges and gifts of big mountain free skiing: An interview with Jonny Law - world tour champion. Journal of Excellence, 12, 78-94. Retrieved from http://www.zoneofexcellence.ca/Journal.html

Lee, F. J., Brown, J. B., \& Stewart, M. (2009). Exploring family physician stress: Helpful strategies. Canadian Family Physician, 55(3), 288-289. Retrieved from http://www.cfp.ca/ 
Lindsay, P. (2014). A week in the life of an applied sport psychologist. Sport \& Exercise Psychology Review, 10(3), 80-86. Retrieved from http://www.bps.org.uk/publications/member-network-publications/memberpublications/sport-and-exercise-psychology-review

Lindsay, P., Breckon, J. D., Thomas, O., \& Maynard, I. W. (2007). In pursuit of congruence: A personal reflection on methods and philosophy in applied practice. The Sport Psychologist, 21, 335-352. doi: 10.1123/tsp.21.3.335

Loehr, J. E. (1990). Providing sport psychology consulting services to professional tennis players. The Sport Psychologist, 4, 400-408. doi: 10.1123/tsp.4.4.400

Loehr, J., \& Schwartz, T. (2001). The making of a corporate athlete. Harvard Business Review, 79(1), 120-8. Retrieved from https://hbr.org/

Macan, T. H. (1994). Time management: Test of a process model. Journal of Applied Psychology, 79, 381-391. doi: 10.1037//0021-9010.79.3.381

Maddox, N., Anthony, W. P., \& Wheatley, W. (1987). Creative strategic planning using imagery. Long Range Planning, 20, 118-124. doi: 10.1016/0024-6301(87)900999

Mărgărit, E. (2013). Becoming a sport psychologist: Experiences of a volunteer. Sport Science Review, 22, 77-107. doi: 10.2478/ssr-2013-0005

McCann, S. (2000). Doing sport psychology at the really big show. In M. B. Andersen (Ed.), Doing sport psychology (pp. 209-222). Champaign, IL: Human Kinetics. McCann, S. (2008). At the Olympics, everything is a performance issue. International Journal of Sport \& Exercise Psychology, 6, 267-276. doi: 10.1080/1612197x.2008.9671871 
McCormick, A., \& Meijen, C. (2015). A lesson learned in time: Advice shared by experienced sport psychologists. Sport \& Exercise Psychology Review, 11(1), 4354. Retrieved from http://www.bps.org.uk/publications/member-networkpublications/member-publications/sport-and-exercise-psychology-review

McDonald, J., Orlick, T., \& Letts, M. (1995). Mental readiness in surgeons and its links to performance excellence in surgery. Journal of Pediatric Orthopaedics, 15, 691697. doi: 10.1097/01241398-199509000-00027

McDougall, M., Nesti, M., \& Richardson, D. (2015). The challenges of sport psychology delivery in elite and professional sport: Reflections from experienced sport psychologists. The Sport Psychologist, 29, 265-277. doi: 10.1123/tsp.2014-0081

Meyers, A.W., Whelan, J.P. \& Murphy, S.M. (1996). Cognitive behavioral strategies in athletic performance enhancement. In M. Hersen, R. M. Miller, \& A. S. Belack (Eds.), Handbook of behavior modification (pp. 137-164). Pacific Grove, CA: Brooks/Cole.

Moyle, G. M. (2015). Skating on Olympic ice: Working with winter Olympians. International Journal of Sport \& Exercise Psychology, 13, 56-73. doi: 10.1080/1612197x.2014.995203

Munroe-Chandler, K., \& Hall, C. (2016). Sport psychology interventions. In P. R. E. Crocker (Ed.), Sport and exercise psychology: A Canadian perspective (3rd ed., pp. 168-198). Don Mills, ON: Pearson.

Munroe-Chandler, K., \& Morris, T. (2011). Imagery. In T. Morris \& P. Terry (Eds.), The new sport and exercise psychology companion (pp. 275-308). Morgantown, WV: Fitness Information Technology. 
Murphy, T., \& Orlick, T. (2006). Mental strategies of professional actors. Journal of Excellence, 11, 103-125. Retrieved from http://www.zoneofexcellence.ca/Journal.html

Neff, F. (1990). Delivering sport psychology services to a professional sport organization. The Sport Psychologist, 4, 378-385. doi: 10.1123/tsp.4.4.378

Nideffer, R. M. (1976). Test of attentional and interpersonal style. Journal of Personality and Social Psychology, 34, 394-404. doi: 10.1037//0022-3514.34.3.394

Nordin, S. M., \& Cumming, J. (2005). Professional dancers describe their imagery: Where, when, what, why, and how. The Sport Psychologist, 19, 395-416. doi: 10.1123/tsp.19.4.395

Olusoga, P., Butt, J., Maynard, I., \& Hays, K. (2010). Stress and coping: A study of world class coaches. Journal of Applied Sport Psychology, 22, 274-293. doi: $10.1080 / 10413201003760968$

Orlick, T. (1989). Reflections on sportpsych consulting with individual and team sport athletes at summer and winter Olympic games. The Sport Psychologist, 3, 358365. doi: 10.1123/tsp.3.4.358

Owton, H., Bond, K., \& Tod, D. (2014). "It's my dream to work with Olympic athletes": Neophyte sport psychologists' expectations and initial experiences regarding service delivery. Journal of Applied Sport Psychology, 26, 241-255. doi: $10.1080 / 10413200.2013 .847509$

Pack, S., Hemmings, B., \& Arvinen-Barrow, M. (2014). The self-practice of sport psychologists: Do they practice what they preach? The Sport Psychologist, 28, 198-210. doi: 10.1123/ijsnem.2012-0085 
Pain, M., \& Harwood, C. (2009). Team building through mutual sharing and open discussion of team functioning. The Sport Psychologist, 23, 523-542. doi: $10.1123 /$ tsp. 23.4 .523

Park, J.-K. (2000). Coping strategies used by Korean national athletes. The Sport Psychologist, 14, 63-80. doi: 10.1123/tsp.14.1.63

Partington, J., \& Orlick, T. (1991). An analysis of Olympic sport psychology consultants' best-ever consulting experiences. The Sport Psychologist, 5, 183-193. doi: 10.1123/tsp.5.2.183

Pirie, J. G. (1998). A TV show host's performance: An exploratory study. Journal of Excellence, 1, 50-60. Retrieved from http://www.zoneofexcellence.ca/Journal.html

Poczwardowski, A., \& Sherman, C. P. (2011). Revisions to the sport psychology service delivery (SPSD) heuristic: Explorations with experienced consultants. The Sport Psychologist, 25, 511-531. doi: 10.1123/tsp.25.4.511

Poczwardowski, A., Sherman, C. P., \& Henschen, K. P. (1998). A sport psychology service delivery heuristic: Building on theory and practice. The Sport Psychologist, 12, 191-207. doi: 10.1123/tsp.12.2.191

Poczwardowski, A., Sherman, C. P., \& Ravizza, K. (2004). Professional philosophy in the sport psychology service delivery: Building on theory and practice. The Sport Psychologist, 18, 445-463. doi: 10.1123/tsp.18.4.445

Portenga, S. T., Aoyagi, M. W., \& Cohen, A. B. (2017). Helping to build a profession: A working definition of sport and performance psychology. Journal of Sport Psychology in Action, 8, 47-59. doi: 10.1080/21520704.2016.1227413 
Ravizza, K. (1988). Gaining entry with athletic personnel for season-long consulting. The Sport Psychologist, 2, 243-254. doi: 10.1123/tsp.2.3.243

Ravizza, K. (2002). A philosophical construct: A framework for performance enhancement. International Journal of Sport Psychology, 33(1), 4-18. Retrieved from http://www.ijsp-online.com/

Senécal, J., Loughead, T. M., \& Bloom, G. A. (2008). A season-long team-building intervention: Examining the effect of team goal setting on cohesion. Journal of Sport \& Exercise Psychology, 30, 186-199. doi: 10.1123/jsep.30.2.186

Sharp, L.-A., \& Hodge, K. (2011). Sport psychology consulting effectiveness: The sport psychology consultant's perspective. Journal of Applied Sport Psychology, 23, 360-376. doi: 10.1080/10413200.2011.583619

Sharp, L., \& Hodge, K. (2013). Effective sport psychology consulting relationships: Two coach case studies. The Sport Psychologist, 27, 313-324. doi:

$10.1123 /$ tsp.27.4.313

Sheard, M., \& Golby, J. (2006). Effect of a psychological skills training program on swimming performance and positive psychological development. International Journal of Sport \& Exercise Psychology, 4, 149-169. doi:

10.1080/1612197x.2006.9671790

Simons, J. P., \& Andersen, M. B. (1995). The development of consulting practice in applied sport psychology: Some personal perspectives. The Sport Psychologist, 9, 449-468. doi: 10.1123/tsp.9.4.449 
Spink, K. S. (2016). Group cohesion in sport and exercise. In P. R. E. Crocker (Ed.), Sport and exercise psychology: A Canadian perspective (3rd ed., pp. 227-255). Don Mills, ON: Pearson.

Sprung, H. (1995). An exploration of mental strategies of astronauts (Master's thesis). Retrieved from https://www.ruor.uottawa.ca

Stambulova, N., \& Johnson, U. (2010). Novice consultants' experiences: Lessons learned by applied sport psychology students. Psychology of Sport \& Exercise, 11, 295303. doi: 10.1016/j.psychsport.2010.02.009

Statler, T. (2002). The art of applied sport psychology: Perceptions of outstanding consultants (Doctoral dissertation). Available from ProQuest Dissertations and Theses Global database (UMI No. 3021483)

Steptoe, A. (1989). Stress, coping and stage fright in professional musicians. Psychology of Music, 17, 3-11. doi: 10.1177/0305735689171001

Straub, W. F., \& Hinman, D. A. (1992). Profiles and professional perspectives of 10 leading sport psychologists. The Sport Psychologist, 6, 297-312. doi: 10.1123/tsp.6.3.297

Sullivan, P. A. (1993). Communication skills training for interactive sports. The Sport Psychologist, 7, 79-91. doi: 10.1123/tsp.7.1.79

Symes, R. (2014). From cricket to cage fighting: A week in the life of a sport psychologist. Sport \& Exercise Psychology Review, 10(1), 78-90. Retrieved from http://www.bps.org.uk/publications/member-network-publications/memberpublications/sport-and-exercise-psychology-review 
Talbot-Honeck, C., \& Orlick, T. (1998). The essence of excellence: Mental skills of top classical musicians. Journal of Excellence, 1, 61-75. Retrieved from http://www.zoneofexcellence.ca/Journal.html

Thelwell, R. C., Weston, N. J. V., Greenlees, I. A., \& Hutchings, N. V. (2008). A qualitative exploration of psychological-skills use in coaches. The Sport Psychologist, 22, 38-53. doi: 10.1123/tsp.22.1.38

Tod, D., Andersen, M. B., \& Marchant, D. B. (2009). A longitudinal examination of neophyte applied sport psychologists' development. Journal of Applied Sport Psychology, 21, 1-16. doi: 10.1080/10413200802593604

Tod, D., Andersen, M. B., \& Marchant, D. B. (2011). Six years up: Applied sport psychologists surviving (and thriving) after graduation. Journal of Applied Sport Psychology, 23, 93-109. doi: 10.1080/10413200.2010.534543

Tod, D., \& Bond, K. (2010). A longitudinal examination of a British neophyte sport psychologist's development. The Sport Psychologist, 24, 35-51. doi: $10.1123 /$ tsp. 24.1 .35

Tod, D., Marchant, D., \& Andersen, M. B. (2007). Learning experiences contributing to service-delivery competence. The Sport Psychologist, 21, 317-334. doi: 10.1123/tsp.21.3.317

Tonn, E., \& Harmison, R. J. (2004). Thrown to the wolves: A student's account of her practicum experience. The Sport Psychologist, 18, 324-340. doi: 10.1123/tsp.18.3.324 
Tribble, C., \& Newburg, D. (1998). Learning to fly: Teaching mental strategies to future surgeons. Journal of Excellence, 1, 6-19. Retrieved from http://www.zoneofexcellence.ca/Journal.html

Tribble, C., \& Orlick, T. (2001). Interview with Curt Tribble, elite surgeon. Journal of Excellence, 5, 117-125. Retrieved from http://www.zoneofexcellence.ca/Journal.html

Van Raalte, J. L., \& Andersen, M. B. (2000). Supervision I: From models to doing. In M. B. Andersen (Ed.), Doing sport psychology (pp. 153-165). Champaign, IL: Human Kinetics.

Waumsley, J. A., Hemmings, B., \& Payne, S. M. (2010). Work-life balance, role conflict and the UK sport psychology consultant. The Sport Psychologist, 24, 245-262. doi: $10.1123 /$ tsp. 24.2 .245

Weder, G. (2000). Excelling in speed. Journal of Excellence, 3, 19-26. Retrieved from http://www.zoneofexcellence.ca/Journal.html

Weinberg, R. S., \& Gould, D. (2015). Foundations of sport and exercise psychology (6th ed.). Champaign, IL: Human Kinetics.

Weinberg, R., \& McDermott, M. (2002). A comparative analysis of sport and business organizations: Factors perceived critical for organizational success. Journal of Applied Sport Psychology, 14, 282-298. doi: 10.1080/10413200290103563

Wetzel, C. M., Kneebone, R. L., Woloshynowych, M., Nestel, D., Moorthy, K., Kidd, J., \& Darzi, A. (2006). The effects of stress on surgical performance. The American 
Journal of Surgery, 191(1) 5-10. Retrieved from

http://www.americanjournalofsurgery.com/

White, A., \& Hardy, L. (1998). An in-depth analysis of the uses of imagery by high-level slalom canoeists and artistic gymnasts. The Sport Psychologist, 12, 387-403. doi: $10.1123 /$ tsp.12.4.387

Williams, D. E., \& Andersen, M. B. (2012). Identity, wearing many hats, and boundary blurring: The mindful psychologist on the way to the Olympic and Paralympic Games. Journal of Sport Psychology in Action, 3, 139-152. doi:

$10.1080 / 21520704.2012 .683090$

Woodcock, C., Richards, H., \& Mugford, A. (2008). Quality counts: Critical features for neophyte professional development. The Sport Psychologist, 22, 491-506. doi: $10.1123 /$ tsp.22.4.491

Yukelson, D. P. (2006). Communicating effectively. In J. M. Williams (Ed.), Applied sport psychology: Personal growth to peak performance (5th ed., pp. 1-14). Boston, MA: McGraw-Hill.

Zizzi, S. J., \& Andersen, M. B. (2010). An Eastern philosophical approach. In S. J. Hanrahan \& M. B. Andersen (Eds.), Routledge handbook of applied sport psychology: A comprehensive guide for students and practitioners (pp. 194-202). London, UK: Routledge. 


\section{FIGURE}

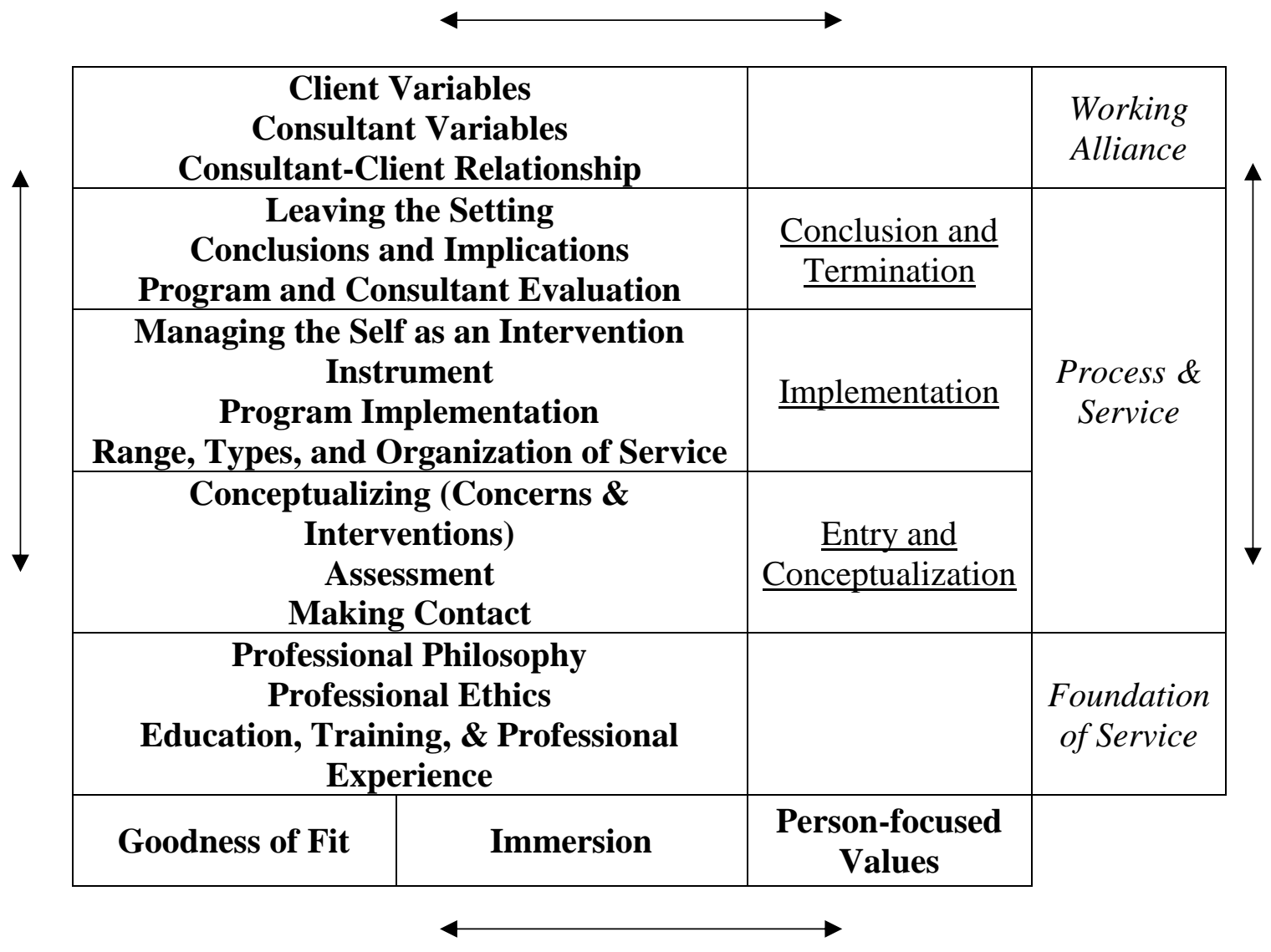

Figure 10. Revised sport psychology service delivery heuristic. Adapted from "Revisions to the Sport Psychology Service Delivery (SPSD) Heuristic: Explorations with Experienced Consultants," by A. Poczwardowski and C. P. Sherman, 2011, The Sport Psychologist, 25, p. 528. 


\title{
APPENDICES
}

\section{APPENDIX A}

\author{
Email to Participants
}

Hello Mr./Mrs./Dr./Prof.

My name is Shawn Filion and I am a Masters student from the Faculty of Human Kinetics at the University of Windsor working under the supervision of Dr. Krista Chandler.

I am sending you this email because I am looking to recruit Sport Psychology Consultants (SPCs) to participate in my study.

Inclusion Criteria:

- Male or female

- Licensed psychologist or performance enhancement consultant

- Minimum 2 years of consulting experience

- Obtained their highest degree at a Canadian university

- Professional member of the Canadian Sport Psychology Association (CSPA)

- Use or have used psychological skills to improve their consulting

Through one-on-one interviews, my aim is to examine the psychological skills used by SPCs to improve their consulting.

The interviews will be conducted in mid to late January 2018.

Given your experience as a SPC, I believe you would be able to provide valuable information in this regard.

Please find attached to this email the letter of information/consent providing more detailed information on the nature of the study.

I do hope you will consider being part of this exciting research. If you would like to participate in my study, please let me know by email as soon as possible. Your help would be greatly appreciated!

If you have any questions or concerns about the research, please feel free to contact Shawn Filion (519) 253-3000 ext. 4997, filions@ uwindsor.ca or Dr. Krista Chandler (519) 2533000 X 2446, Chandler@uwindsor.ca.

Thank you very much and have a nice day,

Shawn F. 


\section{APPENDIX B}

\section{Letter of Information and Consent}

The psychological skills used by sport psychology consultants to improve their consulting.

You are being asked to participate in a research study conducted by Shawn Filion, a secondyear Masters student from the Faculty of Human Kinetics at the University of Windsor and his advisor, Dr. Krista Chandler. This study has received University of Windsor REB clearance (REB \#34366). If you have any questions or concerns about the research, please feel free to contact Shawn Filion (519) 253-3000 ext. 4997, filions@uwindosr.ca or Dr. Krista Chandler (519) 253-3000 X 2446, chandler@uwindsor.ca

\section{PURPOSE OF THE STUDY}

The purpose of this study will be to qualitatively examine the psychological skills used by sport psychology consultants to improve their consulting.

\section{INCLUSION CRITERIA}

- Male or female

- Licensed psychologist or performance enhancement consultant

- Minimum 2 years of consulting experience

- Obtained their highest degree at a Canadian university

- Professional member of the Canadian Sport Psychology Association (CSPA)

- Use or have used psychological skills to improve their consulting

\section{PROCEDURES}

If you volunteer in this study, I will ask you to:

\section{1) Participate in an interview}

Participants will take part in a short (45-60 min) interview over the telephone. This interview will ask questions pertaining to what psychological skills you use or have used to improve your consulting as well as where, when, how, and why you use or have used them. Audio recording will be necessary because we want to capture all your comments concerning the psychological skills that you use or have used. The interview session will be structured around five main questions: what psychological skills do you use or have used to improve your consulting, why do you use or have used each psychological skill, in what setting/location do you use or have used each psychological skill, when do you use or have used each psychological skill, and how do you use or have used each psychological skill. Specific probes will be used to gain a better understanding of the ideas that you are talking about.

\section{2) Be Audio Recorded}

Audio recording is required for this study. If you do not wish to be audio recorded, you will not be part of the study. You are free to withdraw at any time by not participating in the interview or choosing not to respond to the questions. Your name will not be revealed to anyone, as the recording and listening of the audio 
files will be done in full privacy. Audio recordings are filed by number only and stored in a password-protected computer in the lead researcher's office. The audio recordings are for research use only. The recordings will be appropriately disposed of after the study is completed.

\section{POTENTIAL RISKS AND DISCOMFORTS}

There are not known or anticipated risks from discussing the psychological skills used to improve your consulting.

\section{POTENTIAL BENEFITS TO PARTICIPANTS AND/OR TO SOCIETY}

Given the limited research specifically examining the psychological skills used by sport psychology consultant, the results from the proposed study will further contribute to the scientific literature. Moreover, the results may be used to develop a psychological skills training program for sport psychology consultants.

\section{COMPENSATION FOR PARTICIPATION}

Participants will not receive compensation for participating in the study.

\section{CONFIDENTIALITY}

During the data collection phase, all participant data will be kept on a password-protected computer, to which only the listed investigators have access to. The audio-recordings will be placed in a folder which will be "password protected" and "encrypted". All audio files will be destroyed immediately after transcription and verification. Each participant has the right to review the audio recordings and may request to have their section of the recordings edited by the researcher. Once the data collection phase is complete, each participant will be assigned a participant number and participants' data, identified only by participant number, will be entered into a qualitative analysis program. The resulting data set will be password-protected to ensure that only the listed investigators are able to access the data. In release of the findings, the results will be referred to only by a participant number, and thus, it will not be possible to identify or link any results to any one specific participant. Any information that is obtained in connection with this study and that can be identified with you will remain confidential and will be disclosed only with your permission.

\section{PARTICIPATION AND WITHDRAWAL}

Participants will be informed that if they volunteer to participate in this study they can withdraw at any time without penalty, prior to March $1^{\text {st }}, 2018$. You may refuse to answer any questions and will still remain a participant in the study. The investigator may withdraw you from this research study if circumstances arise which warrant doing so.

\section{FEEDBACK OF THE RESULTS OF THIS STUDY TO THE PARTICIPANTS}

The investigator will provide a written summary of the study's findings to you upon request. If you have any additional concerns or questions you can email or call the investigators at the address or number provided above. Please keep this email in your records.

\section{SUBSEQUENT USE OF DATA}

The data may be used in publications and presentations. 


\section{RIGHTS OF RESEARCH PARTICIPANTS}

If you have questions regarding your rights as a research participant, contact: Research Ethics Coordinator, University of Windsor, Windsor, Ontario, N9B 3P4; Telephone: 519253-3000, ext. 3948; e-mail: ethics@uwindsor.ca

\section{SIGNATURE OF INVESTIGATOR}

These are the terms under which I will conduct research.

Signature of Investigator

Date

Please keep a copy of this letter for your record 


\section{APPENDIX C}

Interview Guide

\section{Psychological Skills used by Sport Psychology Consultants to Improve Their}

\section{Consulting}

\section{Interview Guide}

\section{Welcome}

a. Hello Mr./Mrs./Dr./Prof. this is , how are you doing today?

b. Thank you very much for taking the time to participate in this interview.

\section{Consent for Audio Recording}

a. Before we begin, I would like to know if you give us your consent to record this conversation over the telephone. Please listen carefully to the following statement.

b. You are free to withdraw at any time by requesting that the audio recording be stopped. Your name will not be revealed to anyone and the audio recording will be kept confidential. Audio recordings are filed by number only and stored in a password-protected computer. The destruction of the audio recording will be completed after transcription and verification. Confidentiality will be respected and the audio recording will only be used for professional reasons.

c. Do you consent to the audio recording of this interview?

d. Thank you! 


\section{Guidelines}

a. You will be audio-recorded because we don't want to miss any of your comments. Therefore, be sure to speak loudly enough because all your comments are important to us.

b. Do you have any questions?

c. Okay, let's begin the interview!

\section{Getting to Know You (approx. $10 \mathrm{~min}$ )}

a. Please tell me your full name, age, and how many years you have been working as a Sport Psychology Consultant?

b. Why have you decided to work as a Sport Psychology Consultant?

c. What is your educational background?

i. Sport and exercise sciences or clinical and counselling psychology?

ii. Masters or $\mathrm{PhD}$ ?

1. Are you a licensed psychologist?

iii. Where did you obtain your highest degree?

d. Do you work as a full-time or part-time Sport Psychology Consultant?

e. For your services, do you get paid or do some pro bono?

i. What is the \% between paid services and pro bono services?

f. What sports do you typically work with?

i. Individual or team sports?

ii. What is the $\%$ of time that you allocate to individual vs. team sports? 
g. Can you describe what your typical week looks like during your "peak season"?

h. Can you describe the typical psychological services that you provide to your clients?

i. Psychological skills training

ii. Counseling approach

\section{Overview of the topic:}

a. We want to hear what psychological skills you use or have used to improve your consulting. Therefore, I will provide you with a definition of a psychological skill.

b. Definition of a psychological skill

i. The set of trainable psychological abilities and methods that are held to underpin successful learning and performance. The basic psychological skills may include goal-setting, self-talk, and imagery, amongst many others (Dictionary of Sport and Exercise Science and Medicine, 2008).

c. Today we will be discussing what psychological skills you use or have used to improve your consulting as well as where, when, how, and why you use or have used them.

\section{Key Questions:}

a. Psychological skills used: So please tell me ... What psychological skills do you use or have used to improve your consulting?

i. Probes 
1. Tell me more about ...

2. Can you describe in more details ...

3. Can you expand upon ...

b. Why the psychological skill is used: You use

(psychological skill) to improve which aspect of your consulting?

i. Implement sport psychology-specific knowledge (e.g., gain a deeper understanding of the psychological skill being taught)

ii. Gather important information on your clients (e.g., focusing, listening, observing)

iii. Create a positive connection with your clients (e.g., empathy, caring, positive regard, non-judgmental attitude)

iv. Perform better in general (e.g., confidence, calmness, creativity, patience, preparation, self-awareness)

c. How the psychological skill is used: How do you practice (psychological skill)?

i. Can you describe what a typical session looks like?

1. What type of do you use/set? (e.g., what type of imagery do you use, what type of goals do you set)

2. What do you focus on?

3. What do you tell yourself?

ii. How long are each session?

iii. How often do you practice this psychological skill?

iv. What tools do you use? 
v. Can you give me an example?

d. When and where the psychological skills are used: You mentioned using (psychological skills). Can you describe when and where you use these psychological skills?

\section{e. Final Thoughts}

i. Is there anything that we have discussed today that you would like to expand on or talk more about?

ii. Do you have any questions about the interview or the study in general?

\section{f. Summary}

i. Summarize the most important findings

1. Did we miss anything?

\section{Snowball Sampling}

a. Could you suggest another Sport Psychology Consultant that would be interested in being interviewed?

i. Male or female

ii. Licensed psychologists or Performance Enhancement Consultant

iii. Minimum 2 years of consulting experience

iv. Obtained their highest degree at a Canadian university

v. Professional member of the Canadian Sport Psychology Association

vi. Use or have used psychological skills to improve their consulting 


\section{Goodbye}

a. Thank you very much for participating in this interview and sharing your experience with me today. Have a great day! 
VITA AUCTORIS

NAME:

PLACE OF BIRTH:

YEAR OF BIRTH:

EDUCATION:
Shawn Filion

Pointe-Claire, Quebec, Canada

École Secondaire Félix-Leclerc, Pointe-Claire, QC, 2008

McGill University, B.Ed. Physical and Health Education, Montreal, QC, 2016

University of Windsor, M.H.K., Windsor, ON, 2018 